Prepared in cooperation with the Bureau of Reclamation

\title{
Dynamics of Endangered Sucker Populations in Clear Lake Reservoir, California
}

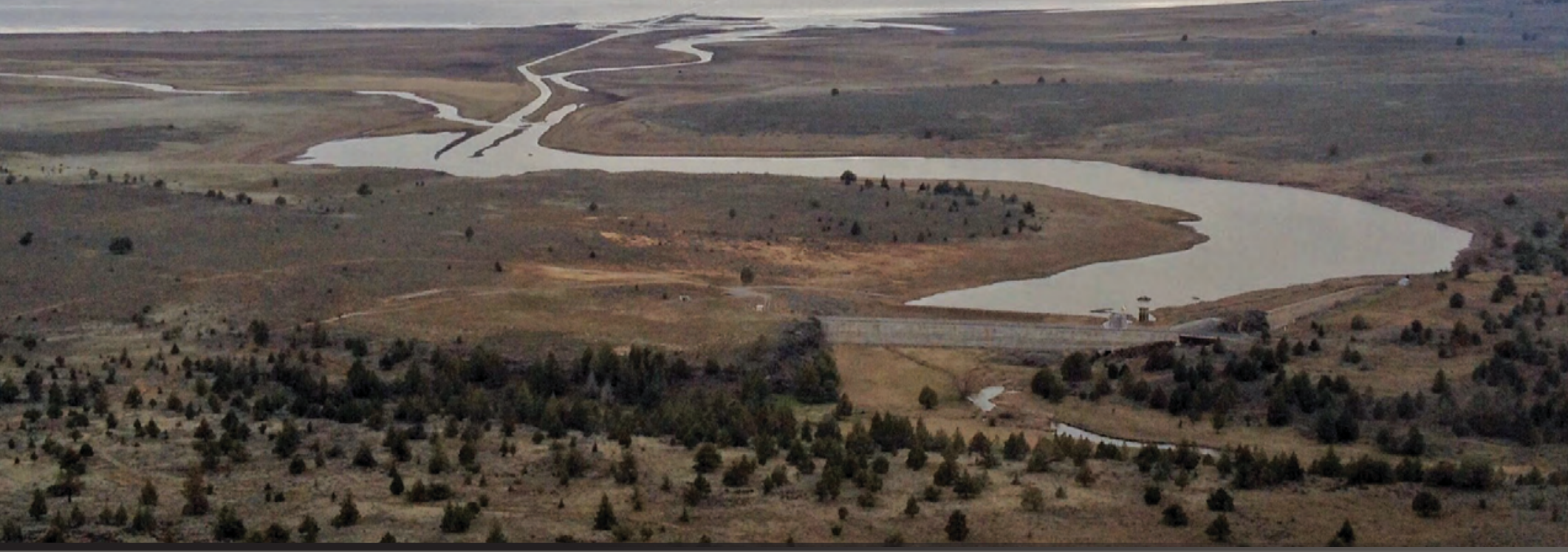

Open-File Report 2021-1043 
Cover: Clear Lake Dam, dam channel, Willow Creek, and east lobe of Clear Lake

Reservoir, California. Photograph by Uwe Britsch, Skinner Aviation, used with permission. 


\section{Dynamics of Endangered Sucker Populations in Clear Lake Reservoir, California}

By David A. Hewitt, Brian S. Hayes, Alta C. Harris, Eric C. Janney, Caylen M.

Kelsey, Russell W. Perry, and Summer M. Burdick

Prepared in cooperation with the Bureau of Reclamation

Open-File Report 2021-1043 


\section{U.S. Geological Survey, Reston, Virginia: 2021}

For more information on the USGS - the Federal source for science about the Earth, its natural and living resources, natural hazards, and the environment—visit https://www.usgs.gov or call 1-888-ASK-USGS.

For an overview of USGS information products, including maps, imagery, and publications, visit https://store.usgs.gov/.

Any use of trade, firm, or product names is for descriptive purposes only and does not imply endorsement by the U.S. Government.

Although this information product, for the most part, is in the public domain, it also may contain copyrighted materials as noted in the text. Permission to reproduce copyrighted items must be secured from the copyright owner.

Suggested citation:

Hewitt, D.A., Hayes, B.S., Harris, A.C., Janney, E.C., Kelsey, C.M., Perry, R.W., and Burdick, S.M., 2021, Dynamics of endangered sucker populations in Clear Lake Reservoir, California: U.S. Geological Survey Open-File Report 2021-1043, 59 p., https://doi.org/10.3133/ofr20211043.

ISSN 2331-1258 (online) 


\section{Contents}

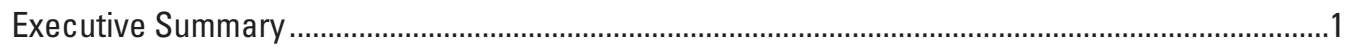

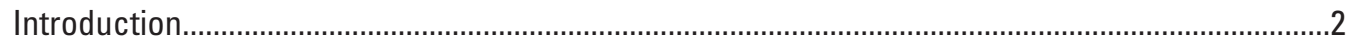

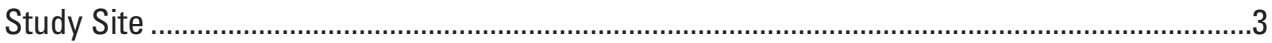

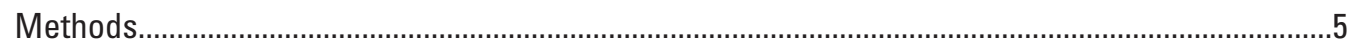

Fall Trammel Net Sampling.....................................................................................................

Spring Passive Integrated Transponder Tag Detections on Remote Antennas........................7

Willow Creek Water Temperature and Instream Flow ..........................................................

Capture-Recapture Analysis of Annual Survival ...................................................................

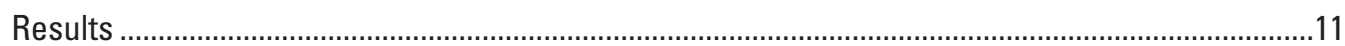

Sucker Catches in Fall Trammel Net Sampling ....................................................................11

Spring Sucker Detections on Remote Passive Integrated Transponder Tag Antennas .........11

Historical Reservoir Inflows in Context of Sucker Spawning Migrations (1919-2016) ...........16

Size Composition in Fall Trammel Net Catches........................................................................17

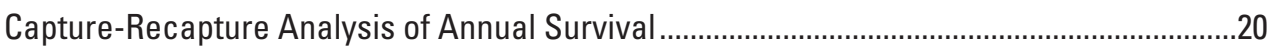

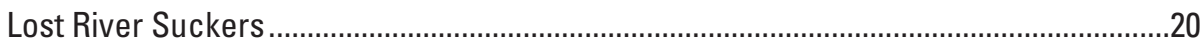

Shortnose/Klamath Largescale Suckers ...................................................................20

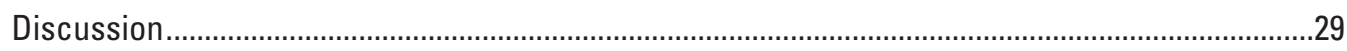

Inference about Recruitment from Changes in Size Composition.........................................30

Spawning Migrations, Survival, and Population Dynamics....................................................31

Implications for Water Management ...................................................................................

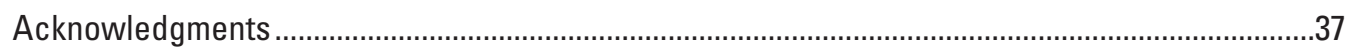

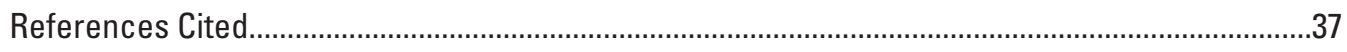

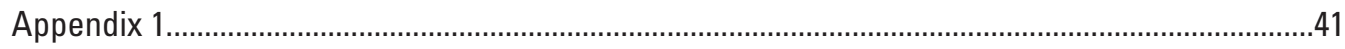

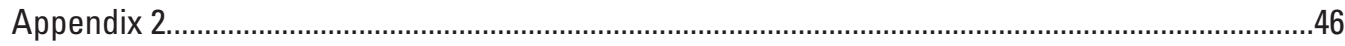

\section{Figures}

1. Map of Clear Lake Reservoir, California, and its primary tributaries within the Upper Klamath River Basin

2. Aerial imagery showing the the northeastern corner of the east lobe of Clear Lake Reservoir, California, at two different water levels-A high water year, July 2017, and a low water year, July 2014.

3. Graph showing the percentage of fall trammel net catches made up of recaptured individuals for Lost River suckers and shortnose suckers in Clear Lake Reservoir, California, 2005-19

4. Frequency histograms of fork lengths of male and female Lost River suckers captured in trammel nets in Clear Lake Reservoir, California, during fall sampling, 2004-19.

5. Frequency histograms of fork lengths of male and female shortnose and Klamath largescale suckers combined captured in trammel nets in Clear Lake Reservoir, California, during fall sampling, 2004-19.

6. Graph showing the estimates of annual survival probability with 95 percent confidence intervals for Lost River suckers and shortnose suckers and Klamath largescale suckers combined in Clear Lake Reservoir, California, 2006-18 
7. Graphs showing end-of-month water surface elevations, Clear Lake Reservoir, California, 1910-2019.

8. Graph showing end-of-month water levels for water years 2004-19 as measured at the Clear Lake Dam, California.

\section{Tables}

1. Timing and summary information for trammel net sampling in Clear Lake Reservoir, California, 2004-19.

2. Summary information for remote passive integrated transponder tag antenna sampling in Willow Creek and the strait between the lobes of Clear Lake Reservoir, California, during the spawning seasons of 2006-19...

3. Summary of sucker catches in fall trammel net sampling in Clear Lake Reservoir, California, 2004-19.

4. Suckers classified as shortnose sucker and Klamath largescale sucker that were captured in fall trammel net sampling in Clear Lake Reservoir, California, 2004-19

5. Detections of Lost River suckers and shortnose and Klamath largescale suckers combined on the remote passive integrated transponder tag antennas in Willow Creek and the strait channel at Clear Lake Reservoir, California, 2006-19.....17

6. Summary of encounters for Lost River suckers in Clear Lake Reservoir, California, fall 2005 through spring 2019

7. Model selection results for the Barker capture-recapture models fitted to the data for Lost River Suckers in Clear Lake Reservoir, California, 2005-19.

8. Demographic parameter estimates for Lost River suckers in Clear Lake Reservoir, California

9. Summary of encounters for shortnose or Klamath largescale suckers in Clear Lake Reservoir, California, fall 2005 through spring 2019

10. Model selection results for the Barker capture-recapture models fitted to the data for shortnose sucker and Klamath largescale sucker combined in Clear Lake Reservoir, California, 2005-19

11. Demographic parameter estimates for shortnose and Klamath largescale suckers combined in Clear Lake Reservoir, California

12. End-of-month minimum water levels expected for Clear Lake Reservoir under the 2002/2008 proposed action across different water year types 


\section{Conversion Factors}

International System of Units to U.S. customary units

\begin{tabular}{|c|c|c|}
\hline Multiply & By & To obtain \\
\hline \multicolumn{3}{|c|}{ Length } \\
\hline centimeter $(\mathrm{cm})$ & 0.3937 & inch (in.) \\
\hline millimeter (mm) & 0.03937 & inch (in.) \\
\hline meter $(\mathrm{m})$ & 3.281 & foot $(\mathrm{ft})$ \\
\hline kilometer $(\mathrm{km})$ & 0.6214 & mile (mi) \\
\hline \multicolumn{3}{|c|}{ Volume } \\
\hline acre-foot (acre-ft) & 1,233 & cubic meter $\left(\mathrm{m}^{3}\right)$ \\
\hline acre-foot (acre-ft) & 0.001233 & cubic hectometer $\left(\mathrm{hm}^{3}\right)$ \\
\hline \multicolumn{3}{|c|}{ Flow Rate } \\
\hline cubic foot per second $\left(\mathrm{ft}^{3} / \mathrm{s}\right)$ & 0.02832 & cubic meter per second $\left(\mathrm{m}^{3} / \mathrm{s}\right)$ \\
\hline
\end{tabular}

U.S. customary units to International System of Units

\begin{tabular}{llll}
\hline & Multiply & By & To obtain \\
\hline \multicolumn{4}{c}{ Length } \\
\hline foot $(\mathrm{ft})$ & 0.3048 & meter $(\mathrm{m})$ & \\
\hline
\end{tabular}

Temperature in degrees Celsius $\left({ }^{\circ} \mathrm{C}\right)$ may be converted to degrees Fahrenheit $\left({ }^{\circ} \mathrm{F}\right)$ as:

$$
{ }^{\circ} \mathrm{F}=\left(1.8 \times{ }^{\circ} \mathrm{C}\right)+32 .
$$

\section{Acronyms}

AWPE American white pelican

BA Biological assessment

B0 Biological opinion

DCCO double-crested cormorant

EOM end-of-month

$\mathrm{FL} \quad$ fork length

$\mathrm{kHz} \quad$ kilohertz

KLS Klamath largescale sucker

LRS Lost River sucker

PIT passive integrated transponder

SNS shortnose sucker

SNS-KLS shortnose sucker and Klamath largescale sucker combined

TAF thousand acre-feet

USFWS U.S. Fish and Wildlife Service 



\title{
Dynamics of Endangered Sucker Populations in Clear Lake Reservoir, California
}

\author{
By David A. Hewitt, Brian S. Hayes, Alta C. Harris, Eric C. Janney, Caylen M. Kelsey, Russell W. Perry, and \\ Summer M. Burdick
}

\section{Executive Summary}

In collaboration with the Bureau of Reclamation, the U.S. Geological Survey began a consistent monitoring program for endangered Lost River suckers (Deltistes luxatus) and shortnose suckers (Chasmistes brevirostris) in Clear Lake Reservoir, California, in fall 2004. The program was intended to improve understanding of the Clear Lake Reservoir populations because they are important to recovery efforts for these species. We report results from the ongoing program and include sampling efforts through fall 2019. We summarize catches and passive integrated transponder (PIT) tagging efforts from trammel net sampling in the fall seasons (September-October each year) and detections of PITtagged suckers on remote antennas in the spring in each year from 2006 to 2019. We also combine the data from physical captures and remote detections in capture-recapture models to provide estimates of annual survival for suckers in the reservoir.

A lack of genetic distinctiveness between shortnose suckers and Klamath largescale suckers (Catostomus snyderi) in the Lost River subbasin, including Clear Lake Reservoir, is a likely cause of past difficulty in identification of these species. Field identification can be subjective for many captured individuals, and very few individuals were identified as Klamath largescale suckers in the most recent years of our monitoring program. For this report, we combine individuals that were identified as either shortnose sucker (SNS) or Klamath largescale sucker (KLS) into a single "SNS-KLS" group for most analyses. Identification of Lost River suckers (LRS) is based on external morphological characteristics.

Sucker catches were typically higher in years when reservoir water levels were lower, presumably because lower water concentrates fish and increases trammel net capture efficiency. We captured between 115 and 650 LRS and between 393 and 2,298 SNS-KLS during fall sampling each year. The sex ratio of captured LRS has consistently been close to 1:1 or somewhat female-biased, whereas the sex ratio of SNS-KLS has been strongly biased towards females. The percentage of the catch made up of individuals that had been captured and tagged in previous years was low for LRS in all years, whereas for SNS-KLS the percentage increased rather steadily throughout the study. Catches of LRS in the most recent years exceeded the long-term average, and size composition of the catch for both taxa indicated substantial recruitment of new cohorts in 2018-19. In 2019, catches indicated that populations of both taxa were dominated by fish less than 350 millimeters (mm) FL. Size composition data indicated intermittent recruitment for both taxa in other years as well, but inferring the year(s) in which new recruits were spawned was unclear. Ongoing monitoring of juvenile suckers in the reservoir will provide valuable information about the recruitment process.

The remote PIT tag antennas in Willow Creek, the only substantial tributary to the reservoir, detected between 7 and 5,071 PIT-tagged suckers in a given spawning season. The number of individuals detected was lower in years when flows were low in Willow Creek and in years when access to Willow Creek through the east lobe was limited by low reservoir water levels (surface elevation below 4,524 feet [ft]). Detections were particularly low in 4 years impacted by both factors $(2009,2010,2014,2015)$. In years when water level or instream flows affected spawning migrations, LRS tended to migrate in relatively larger numbers than SNS-KLS. In years with sufficient access and instream flows, spawning migrations into Willow Creek began soon after ice was out of the creek and off of the reservoir, as early as late January or early February when water temperature was as low as 2-3 degrees Celsius $\left({ }^{\circ} \mathrm{C}\right)$. Spawning migrations were typically complete by the end of April or early May. Similar to results from sucker populations in Upper Klamath Lake, Oregon, migrations appeared to be controlled by water temperature rather than stream discharge. Upstream movements within a season increased when water temperature was increasing and slowed or stopped completely when water temperature decreased; movements appeared to be unrelated to changes in discharge. For LRS, more males than females were detected on the Willow Creek antennas, in contrast to the sex ratio in fall trammel net captures. In contrast, the sex ratio for SNSKLS was similar between the fall trammel net captures and the individuals detected on the Willow Creek antennas. 
To provide historical context for the conditions observed during our study relative to the timing and magnitude of spawning migrations, we developed an approach based on reservoir water levels to estimate inflows to the reservoir from Willow Creek for the long-term period of record (1919-2019). We compared estimated inflows to the migrations we observed in 2006-19 and then evaluated inflows in past years to consider the effects of inflows on spawning migrations over a longer time period. Ignoring the effect of low reservoir water levels on access to spawning tributaries, inflows during our study would have limited spawning to some extent in about half of the years, more frequently than occurred in the past.

To estimate annual survival of PIT-tagged suckers, we used Barker capture-recapture models that incorporated both physical captures during fall sampling and re-encounters of tagged suckers through detection on the remote PIT tag antennas in the spring (included as "resightings"). Because relatively few PIT-tagged fish were subsequently recaptured in trammel net sampling, encounters on the antennas between fall sampling periods were essential to parameter estimation. Remote antennas installed in the strait between the east and west lobes of the reservoir in 2014-17 were critical in this regard by providing detections of individuals that did not migrate into Willow Creek, especially in the drought years of 2014 and 2015. Encounter histories for over 3,600 LRS and over 17,500 SNS-KLS were used in capture-recapture models. Recapture and resighting probabilities for LRS tended to be higher for males than females. For SNS-KLS, females had slightly higher recapture probabilities than males, but resighting probabilities were similar between the sexes.

Survival estimates varied considerably among years and were often lower than has been observed for populations in Upper Klamath Lake. Females of both taxa had higher survival than males. Survival for LRS ranged from 0.74 to 0.96 in all years except 2009, 2013, and 2015. In those years, survival was much lower at 0.57-0.67. Survival for SNS-KLS was lower on average than for LRS, as expected based on life span, but both sexes of SNS-KLS had higher survival than LRS in 2009, 2014, and 2015. Survival for SNS-KLS was low for both sexes in 2006, 2011, and 2013, and male SNS-KLS had relatively low survival in 2016 and 2017 as well. Low survival for SNSKLS in high inflow years may have been partly attributable to the tendency of that taxa to make more extensive migrations into the tributaries when conditions permitted. Both LRS and SNS-KLS had low estimated survival in 2013.

Predation by colonial nesting waterbirds, especially American white pelicans (Pelecanus erythrorhynchos) and double-crested cormorants (Phalacrocorax auritus), is one factor contributing to low survival in some years. Years with high estimated rates of avian predation corresponded with low survival estimates from capture-recapture models. In 2013, reservoir water levels were low, and Willow Creek flows were just sufficient to allow suckers to make small to moderate spawning migrations in a constrained time window. Avian predation rates were relatively high in that year, suggesting that birds were able to prey on fish migrating through shallow water. Regarding low survival of LRS in the drought year of 2015, telemetry data showed that LRS made a migration to the east lobe but could not access Willow Creek. Predation during residence in the shallow east lobe is a potential explanation for mortality observed in that year. The low reservoir water level in 2015 appears to have discouraged a spawning migration by SNS-KLS, and survival was contrastingly high for that taxa. Survival of all suckers was relatively high in 2010 and 2014, years in which low reservoir water level and low inflows appear to have prevented or discouraged any substantial spawning migrations.

The spawning migrations, changes in size composition, and annual survival of endangered sucker populations in Clear Lake Reservoir are dynamic. Our monitoring of the populations, which began in 2004 with a focus on re-encountering PIT-tagged individuals, has now yielded substantial insight into these dynamics. Our findings should be useful to management agencies as they seek to balance the needs for water for irrigation and the needs of endangered suckers, particularly during drought conditions. The long-term sustainability of Clear Lake suckers is challenged by variable and sometimes low survival, naturally variable spawning success that is limited in some years by low instream flows, and low reservoir water levels that can impede access to tributaries for spawning and increase the risk of avian predation. Continued research and monitoring are warranted to resolve remaining key uncertainties and to monitor the status of the populations.

\section{Introduction}

Lost River suckers (Deltistes luxatus) and shortnose suckers (Chasmistes brevirostris) are federally endangered catostomids endemic to the Upper Klamath River Basin of southern Oregon and northern California (fig. 1). Both species are long-lived; Terwilliger and others (2010) reported a Lost River sucker (LRS) aged at more than 50 years old, and Scoppettone and Vinyard (1991) reported shortnose suckers (SNS) aged at more than 30 years old. Historical accounts indicate that both species were once extremely abundant throughout the Upper Klamath Basin and were harvested in both a Native American subsistence fishery and a recreational snag fishery (Cope, 1884; Gilbert, 1898; Golden, 1969; Rasmussen, 2011). Both species were listed as endangered in 1988 by the U.S. Fish and Wildlife Service under the Endangered Species Act, primarily because of evidence for overall range reductions, habitat alterations, and decreasing population sizes in Upper Klamath Lake, Oregon (USFWS, 1988). 
Although populations of LRS and SNS in Upper Klamath Lake have received the most research attention, Clear Lake Reservoir in Modoc County, California, supports self-sustaining populations of each species that have been identified as critical to recovery efforts (USFWS, 2012). The life history, spawning biology, and status of LRS and SNS populations in Upper Klamath Lake are reasonably well studied (Buettner and Scoppettone, 1990; Scoppettone and Vinyard, 1991; Perkins and others, 2000; Cooperman and Markle, 2003; Janney and others, 2008; Burdick and others, 2015; Hewitt and others, 2018). In contrast, populations in Clear Lake Reservoir have received less research attention. Data collected by Andreasen (1975) and Koch and others (1975) indicated that the populations were in decline, but later sampling showed that both species were abundant and that the populations were characterized as having diverse age structures (Buettner and Scoppettone, 1991; Scoppettone and others, 1995; Perkins and Scoppettone, 1996; USFWS, 2002).

In collaboration with the Bureau of Reclamation

(Reclamation), the U.S. Geological Survey began a long-term study at Clear Lake Reservoir in fall 2004 to monitor sucker spawning migrations and to characterize the status and dynamics of the populations (Hewitt and Hayes, 2013). The study consists of two types of sampling: (1) trammel net sampling in the fall to capture and tag suckers with passive integrated transponder (PIT) tags; and (2) sampling with remote underwater PIT tag antennas to monitor the spawning migrations of tagged fish. Hewitt and Hayes (2013) reported that through 2009 SNS were substantially more abundant in the reservoir than LRS and that recaptures of previously tagged suckers in fall sampling were relatively uncommon. They also noted that the magnitude of spring spawning migrations, as evidenced by detections of fish on the remote antennas, appeared to be limited in years when flows in the spawning tributary were low, such as 2007 and 2010. Previous information indicated that spawning migrations would also be limited by impeded access to spawning tributaries when lake surface elevations were particularly low, as during drought periods. Despite these limitations on spawning migrations, the size compositions of fish captured in the fall showed that successful spawning led to the addition of new individuals to the populations of both species in some years (Hewitt and Hayes, 2013).

In this report, we describe ongoing research efforts for endangered suckers in Clear Lake Reservoir and summarize data from sampling that occurred from fall 2004 to fall 2019 in order to address three objectives: (1) describe the species and size composition of suckers captured in fall trammel net sampling; (2) describe the timing and magnitude of the spawning migrations for each species based on detections of PIT-tagged fish during the spring, and examine factors that affect the spawning migrations; and (3) characterize the status and dynamics of the populations based on catch and detection data as well as estimates of annual survival from capturerecapture models. We consider new information from genetic analyses and change how we report results for suckers other than LRS. Finally, Hewitt and Hayes (2013) concluded that stronger inferences about population dynamics would depend on the collection of remote detections of PIT-tagged fish outside of the spawning tributary during the spring of years with low flows, and in spring 2014 we added an array of remote antennas in the strait between the two lobes of the reservoir to provide such detections.

\section{Study Site}

Clear Lake Reservoir is part of the Lost River subbasin that spans the Oregon-California border (fig. 1). Clear Lake Reservoir was a natural lake at the start of the Lost River that was enlarged by Reclamation with a dam completed in 1910. The dam was built to control water flows in the Lost River and reduce downstream flows into reclaimed portions of Tule Lake. The reservoir also provides irrigation water for agricultural operations in the Lost River subbasin, primarily the lands west of the Lost River in the Langell Valley.

Clear Lake Reservoir has distinct east and west lobes that are connected in the north through a shallow strait. Water is deeper in the west lobe than in the east lobe, and in low water years the east lobe is shallow enough in the late summer and fall to make boat travel difficult. Historical reports and maps of the area show that the east lobe was a complex of marshes and meadows prior to construction of the dam (Klamath County Historical Society, 1971; http://digitallib.oit.edu/ digital/collection/kwl/id/240). During severe droughts such as those that occurred in 1992, 2014, and 2015, the east lobe can dry up almost completely, with water remaining only in the channel leading to Clear Lake Dam and in spring pools just west of the entrance to the dam channel. Willow Creek, the spawning tributary for suckers and the only substantial tributary to the reservoir, enters the reservoir in the northeastern corner of the east lobe near Clear Lake Dam (fig. 2). 


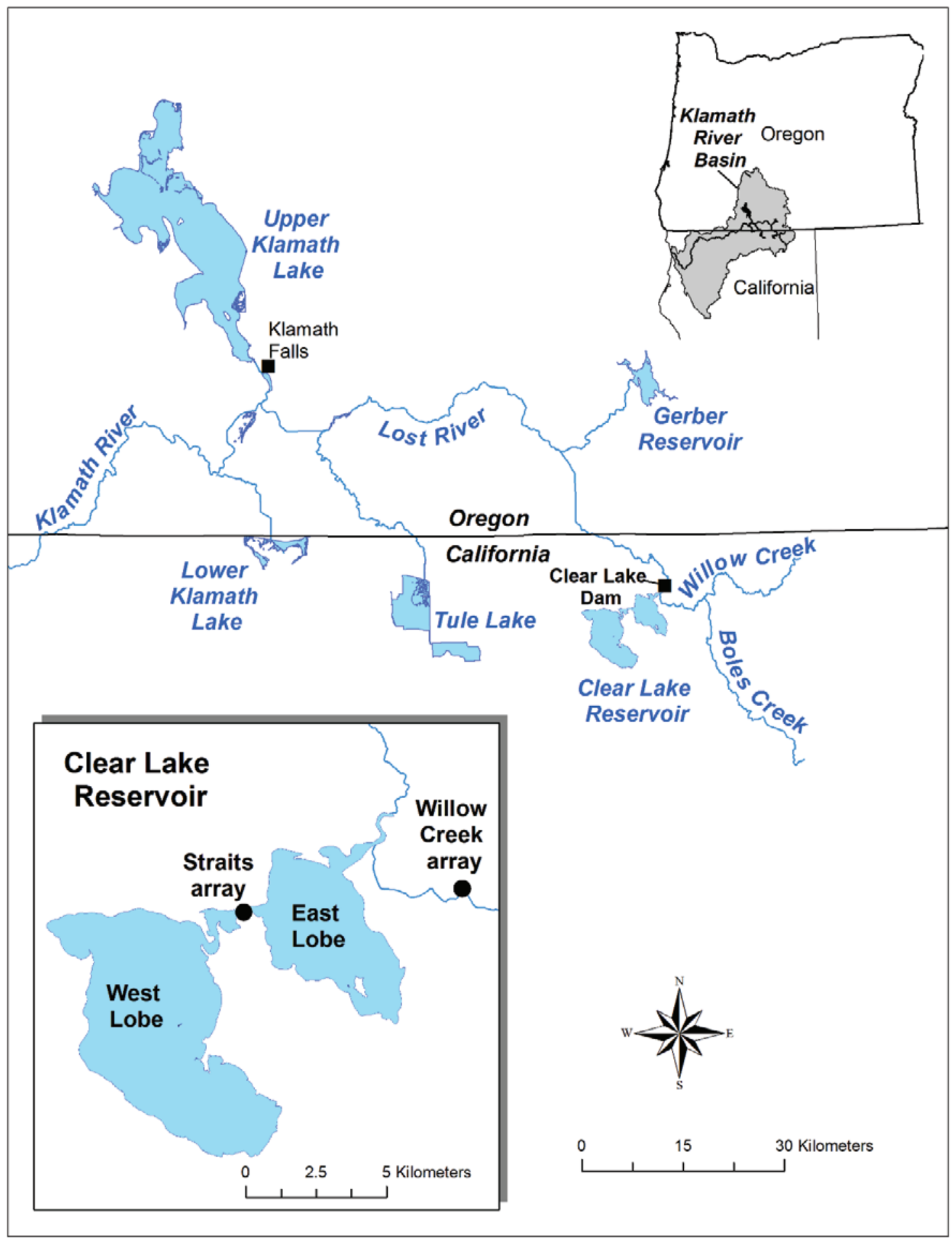

Figure 1. Clear Lake Reservoir, California, and its primary tributaries within the Upper Klamath River Basin. The inset at lower left shows Clear Lake Reservoir in more detail during low water (see fig. 2), with locations of remote Passive Integrated Transponder tag antenna arrays (filled black circles) in Willow Creek and the strait between the west and east lobes of the reservoir. 


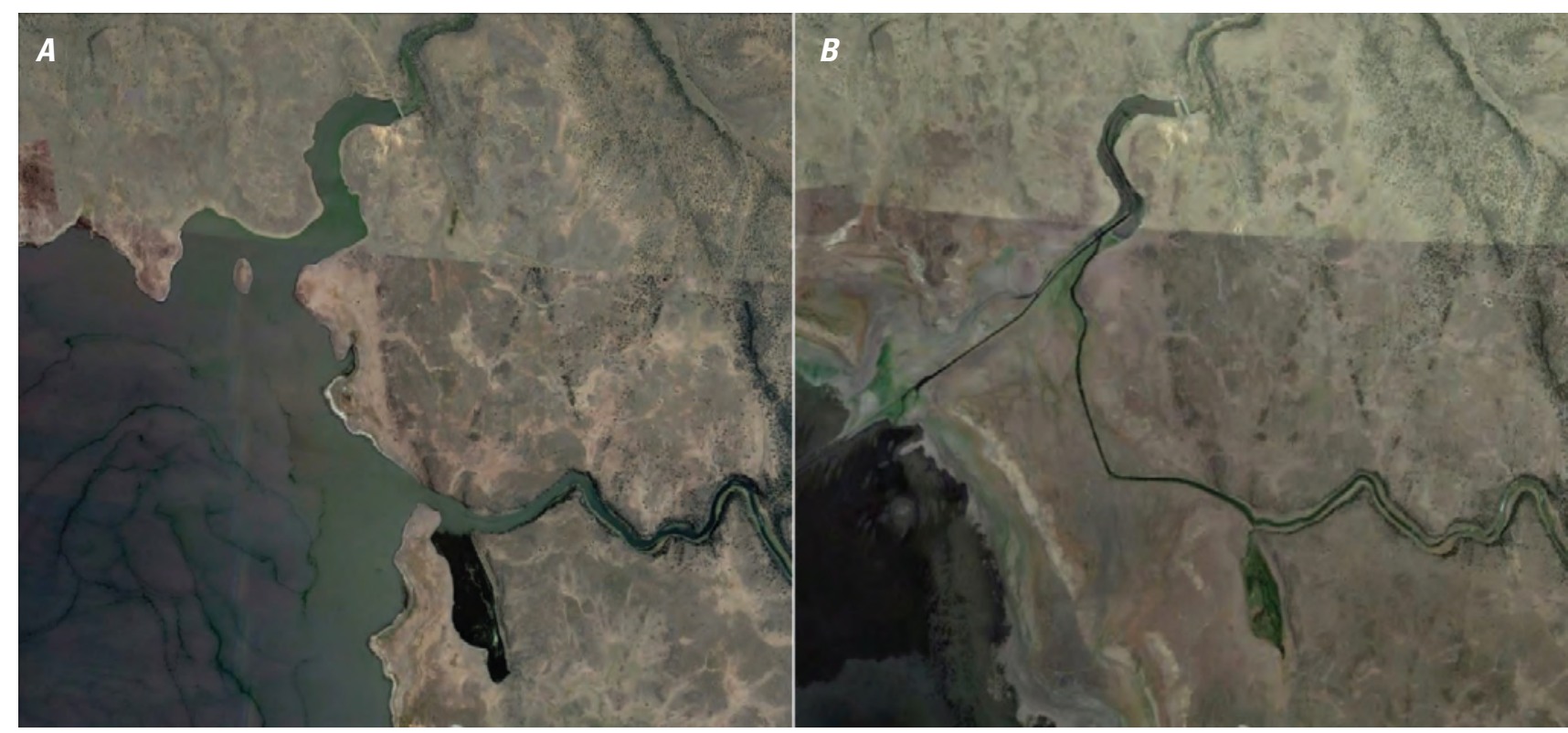

Figure 2. Northeastern corner of the east lobe of Clear Lake Reservoir, California, at two different water levels-A high water year, July 2017 (4,532.3 feet; A), and a low water year, July 2014 (4,522 feet; B). Clear Lake Dam is at the top center of each image, and the Lost River begins at the dam and flows north (toward top of images). Willow Creek, the spawning tributary for suckers, flows into the reservoir from the east at the lower right of each image. In high water years like 2017, the creek empties directly into the east lobe of the lake just downstream from where it exits its canyon. In low water years, the creek turns north across an alluvial flat after exiting its canyon and empties into the channel between the east lobe and Clear Lake Dam. Within the study period, water levels only approached those shown in the image on the left in spring of 2006, 2017, and 2019. However, in 2007-08, 2011-12, and 2016-19, water levels were high enough in the spring to allow fish to access Willow Creek without having to navigate through the narrow channel between the east lobe and the dam. Each spring beginning in 2006, a remote passive integrated transponder tag antenna array has been located in the Willow Creek canyon in the creek bend at the right edge of the images. Source: Google Earth ${ }^{\mathrm{TM}}$, copyright 2021.

\section{Methods}

\section{Fall Trammel Net Sampling}

Suckers were captured with trammel nets in Clear Lake Reservoir during the months of September and October each year, except for 2004 (table 1). In 2004, sampling began in October and extended into the early part of November. Locations for net sets were initially chosen at random in 2004, but later in 2004 and continuing through 2015, effort was concentrated more along the shoreline where sucker catches were higher. Particularly in more recent years, locations for net sets were chosen non-randomly and adaptively throughout a season to focus sampling effort where sucker catches were highest. The objective of fall trammel net sampling was to capture as many suckers as possible for tagging.

At the start of a typical sampling day, each of two boat crews deployed up to eight large trammel nets (net dimensions: 91.4-meter [m] long $\times 1.8$-m deep; two 30.5-centimeter [cm] bar mesh outer panels and one 3.8-cm bar mesh inner panel). Nets were set perpendicular to shore beginning as close to shore as possible; distance from shore for a given set was influenced to some extent by prevailing winds. The first set of nets was allowed to soak for about 2 hours before being retrieved, at which time captured suckers were removed from the nets and transferred to floating net pens. After all suckers were transferred to net pens, the nets were set a second time at new locations and the crews returned to process fish captured in the first net sets. Overall, a typical sampling day resulted in 16-28 net sets, and about 300 nets were set on average in a given season. In 2011, 2012, 2014, and 2015, Reclamation also conducted trammel net sampling for part of the season (table 1).

During processing, the species and sex of each sucker were determined based on external characteristics (Markle and others, 2005), and each fish was measured to the nearest millimeter (mm) fork length (FL). Suckers were scanned for the presence of a PIT tag, and untagged fish were injected with a tag in the ventral abdominal musculature anterior to the pelvic girdle. We used tags operating at 125 kilohertz $(\mathrm{kHz})$ prior to fall 2005, but all fish collected during 2005-2019 were tagged with $134 \mathrm{kHz}$ full-duplex tags because of the improved read range of the higher frequency tags. Recaptured fish that had been previously tagged with $125 \mathrm{kHz}$ tags were re-tagged with $134 \mathrm{kHz}$ tags because the remote antennas that were installed in Willow Creek beginning in 2006 were only able to detect the higher frequency tags. 
Table 1. Timing and summary information for trammel net sampling in Clear Lake Reservoir, California, 2004-19.

[Average water level (feet above mean sea level) across the sampling dates in a given year is taken from Reclamation records for the gage at Clear Lake Dam, which has data available for the entire study period (available at https:/www.usbr.gov/pn-bin/inventory.pl?site=LRS\&ui=true). Reclamation gage records for the west lobe of the reservoir are available beginning in fall 2010. At water levels in the reservoir below about 4,523 feet (the approximate maximum lake level prior to the construction of Clear Lake Dam), the dam channel is disconnected from the rest of the reservoir, and the water level in the west lobe can be lower than the water level measured at the dam gage. For years 2010 and 2012-16 when water level was below 4,523 feet, the average water level measured at the west lobe gage is also given, in parentheses. Water level in the west lobe in 2004, 2005, and 2009 may have been lower than the value that is given. An asterisk (*) following the year in the left column indicates that Reclamation also conducted trammel net sampling. In those years, the columns net sets, nets with suckers captured, and sucker individuals report data as "USGS/Reclamation." The two values in parentheses in the Sucker Individuals column are not mutually exclusive, and the two crews occasionally captured the same fish in the same season]

\begin{tabular}{lllllcr}
\hline Year & $\begin{array}{c}\text { Sampling dates (Number } \\
\text { of days sampled) }\end{array}$ & $\begin{array}{c}\text { Average water level } \\
\text { at dam }\end{array}$ & Net sets & $\begin{array}{c}\text { Nets with } \\
\text { suckers } \\
\text { captured }\end{array}$ & $\begin{array}{c}\text { Average net } \\
\text { soak time } \\
\text { (hours) }\end{array}$ & Sucker individuals \\
\hline 2004 & Oct 12-Nov 4 (16) & $4,521.9$ & 338 & 174 & 2.7 & 581 \\
2005 & Sep 19-Oct 14 (19) & $4,521.7$ & 495 & 365 & 2.2 & 1,867 \\
2006 & Sep 18-Oct 6 (14) & $4,528.4$ & 367 & 276 & 2.1 & 1,085 \\
2007 & Sep 17-Oct 11 (15) & $4,523.8$ & 281 & 223 & 2.1 & 1,653 \\
2008 & Sep 15-Oct 2 (12) & $4,523.5$ & 264 & 201 & 2.1 & 1,090 \\
2009 & Sep 23-Oct 15 (14) & $4,521.8$ & 297 & 280 & 2.2 & 2,617 \\
2010 & Sep 20-Oct 21 (14) & $4,522.1(4,520.6)$ & 256 & 233 & 2.0 & 1,704 \\
$2011^{*}$ & Sep 19-Oct 14 (16) & $4,526.0$ & $181 / 97$ & $162 / 87$ & 2.3 & $894(609 / 287)$ \\
$2012^{*}$ & Sep 17-Oct 11 (15) & $4,522.1(4,522.1)$ & $345 / 72$ & $308 / 67$ & 2.3 & $2,051(1,590 / 468)$ \\
2013 & Sep 23-Oct 31 (13) & $4,522.2(4,521.2)$ & 285 & 277 & 2.4 & 2,486 \\
$2014 *$ & Sep 29-Oct 22 (14) & $4,522.1(4,518.8)$ & $288 / 33$ & $210 / 29$ & 2.6 & $2,540(2,433 / 112)$ \\
$2015 *$ & Sep 28-Oct 22 (15) & $4,522.1(4,518.5)$ & $403 / 52$ & $307 / 48$ & 2.3 & $2,596(2,330 / 274)$ \\
2016 & Oct 3-Oct 27 (14) & $4,522.0(4,522.0)$ & 291 & 221 & 2.9 & 1,899 \\
2017 & Sep 25-Oct 18 (14) & $4,529.6$ & 484 & 269 & 2.6 & 2,303 \\
2018 & Oct 1-Oct 25 (15) & $4,527.0$ & 450 & 377 & 2.0 & 1,741 \\
2019 & Sep 30-Oct 24 (15) & $4,529.6$ & 265 & 256 & 2.6 & 2,633 \\
\hline
\end{tabular}

Although three separate sucker taxa (including Klamath largescale suckers [Catostomus snyderi] and the two endangered species) are putatively present in Clear Lake Reservoir, field identification to separate Klamath largescale suckers (KLS) from SNS is challenging and sometimes subjective. Furthermore, genetic analyses to date have not supported the unique identity of these two species among individuals in the Lost River subbasin (Dowling and others, 2016; Smith and others, 2020). Because of this confusion about the distinctiveness of these two taxa, we present fall trammel net capture summaries according to the field identification of individuals, but we then combine SNS and KLS for analyses such as size composition and capture-recapture (denoted as SNS-KLS). Catches of individuals identified as KLS have always been much lower than for individuals identified as SNS, so the effect of this aggregation on analyses is small. Identification of LRS is straightforward based on external morphological characters, even though individuals in Clear Lake Reservoir display morphological differences compared to individuals in Upper Klamath Lake.

We compared the size composition of captured suckers from our fall trammel net sampling throughout the study period. A previous report included size composition data from trammel net sampling as far back as 1993 (Barry and others, 2009). In this report, we include data from 2004 to 2019 and only individuals $300 \mathrm{~mm}$ FL or greater. Fork length data were used to assess changes in the size structure of the LRS and SNS-KLS populations over time. Length data were grouped separately for each sex within each population. This assessment provides evidence about recruitment of new individuals to the spawning populations. However, the trammel nets select for individuals larger than $300 \mathrm{~mm}$ FL, so any inferences are affected by this selectivity. Some individuals smaller than 300 $\mathrm{mm}$ FL, especially SNS-KLS, are probably mature and contribute to the spawning populations, but we do not effectively capture those individuals. Furthermore, our fall sampling occurs outside of the spawning season, and the maturity status of most captured individuals cannot be determined because they do not express gametes. Some individuals larger than 300 $\mathrm{mm}$ FL, especially LRS, may not be mature. Therefore, our assessment of population dynamics based on size composition does not precisely relate to the adult or spawning populations but rather to the proportion of each population that is larger than $300 \mathrm{~mm}$ FL. 
Occasional trammel net and trap net sampling that included PIT-tagging has occurred in other parts of the reservoir at other times of the year as far back as the early 1990s. These efforts were conducted primarily by Reclamation and by the U.S. Geological Survey. We do not report on these efforts except to note that some PIT-tagged individuals from these efforts were recaptured or detected on remote antennas during the study period. If individuals were recaptured with $125 \mathrm{kHz}$ tags, we retagged them with $134 \mathrm{kHz}$ tags, as noted previously. Some individuals with $125 \mathrm{kHz}$ tags had been at large for more than ten years before we recaptured them. Regardless of where and when individuals were originally tagged outside of our usual fall trammel net sampling, they were included in the results presented here once they were recaptured.

\section{Spring Passive Integrated Transponder Tag Detections on Remote Antennas}

The operation of remote PIT tag antennas in Willow Creek was incorporated into the study beginning in spring 2006, and these efforts were continued through spring 2019 (table 2). Antennas were installed in Willow Creek about 2.5 kilometers $(\mathrm{km})$ upstream of where the creek exits its canyon on the east side of the reservoir (figs. 1 and 2). Six large rectangular antennas were placed in an upright, pass-through orientation and located end to end to cover as much of the width of the channel as possible (antenna dimensions: $3 \mathrm{~m}$ long $\times 0.75 \mathrm{~m}$ tall). In particularly high flow years such as 2006, 2011, 2017, and 2019, substantial portions of the creek cross-section were beyond the range of the antennas.

Because of low numbers of detections on the Willow Creek antennas in low flow years when spawning migrations were trivial, an additional array of antennas was installed in the strait between the lobes beginning in spring 2014 (fig. 1). These antennas were installed each year from 2014 to 2017 (table 2). The antennas were placed across the deepest/dredged channel on the east end of the strait about $750 \mathrm{~m}$ from where the strait joins the east lobe. The channel at this location was approximately $20 \mathrm{~m}$ wide and about $1 \mathrm{~m}$ deep. Up to eight large rectangular antennas were placed on the substrate in a pass-over orientation and located end to end in two crosschannel arrays (antenna dimensions: $6 \mathrm{~m}$ long $\times 0.75 \mathrm{~m}$ wide). In years with low water levels, 2014 and 2015, the antennas covered nearly the entire width of the channel that was deep enough for fish passage during the spawning season. In 2016 and 2017, when water levels were higher, a substantial amount of water on either side of the channel allowed fish to pass beyond the range of the antennas. Because of high water levels in spring of 2017, the array in the strait had to be removed at the end of March.

Suckers that had been previously tagged with $134 \mathrm{kHz}$ PIT tags were detected by antennas as they traversed the east lobe and ascended Willow Creek, providing information about the timing and magnitude of the spawning migrations. Antennas at both locations were installed as early as possible each year given access and water conditions in the reservoir and the creek. In some years, such as 2006 and 2008, antennas in Willow Creek detected suckers the same day that they were installed, indicating that some early migrants might have been missed. In other years, such as 2009, 2010, and 2018, considerable time passed between the installation date and the date the first sucker was detected.

\section{Willow Creek Water Temperature and Instream Flow}

Because the timing of spawning migrations was expected to be influenced at least in part by water temperature, we installed temperature loggers at the Willow Creek antenna site to record water temperature at hourly intervals beginning in 2007. We were unable to recover the temperature loggers in 2010, so we do not have data for that spawning season. In 2014, Reclamation began recording water temperature at the gage on Willow Creek two river kilometers upstream from our remote antenna array. We confirmed that the two measurements of water temperature were similar in 2014-2016 and used the Reclamation records in all years in which they were available.

In order to compare the magnitude of spawning migrations with the flows in Willow Creek across the study years, we assembled a set of estimates for inflows to the reservoir based on a number of different sources. The instream flows in the creek were not gaged for discharge until November 2013, but stage height at the station was recorded beginning in May 2012. Therefore, we have estimates of inflow to the reservoir (daily average discharge in cubic feet per second $\left[\mathrm{ft}^{3} / \mathrm{s}\right]$ converted to acre-feet) for the spawning seasons in 2014-2019 and a prediction for 2013 based on the stage height-discharge relationship established from data collected since November 2013. However, for the earlier portions of our study period and farther back into the period of record for the reservoir, the only consistent information available is water levels measured at the gage at Clear Lake Dam.

Because the long-term period of record at the reservoir includes only water levels recorded at the dam, we sought to create a consistent way to estimate inflows to the reservoir during the spawning season throughout the period of record based only on water levels. A large proportion of the record available to us consists only of end-of-month (EOM) water levels at the dam gage, so we used these EOM values to estimate spawning season inflows to the reservoir throughout the period of record. A complete description of our methodology for computing reservoir inflows through the spawning seasons in the period 1919-2019, as well as comparisons to other sources of information about inflow estimates, is given in appendix 1. Briefly, we determined the smallest and largest values for EOM water level on the ascending limb of the reservoir hydrograph during the spawning season, considering the five values for end-of-January through end-of-May. We related these water levels to the gage height-capacity relationship 
Table 2. Summary information for remote passive integrated transponder tag antenna sampling in Willow Creek and the strait between the lobes of Clear Lake Reservoir, California, during the spawning seasons of 2006-19.

[The last sucker detection in a given year can be a detection of an individual that was detected earlier in the year, but the total count of suckers detected in a given year is a count of individuals and excludes re-detections. Water level (feet [ft] above mean sea level) is taken from Reclamation records for the gage at Clear Lake Dam (available at https://www.usbr.gov/pn-bin/inventory.pl?site=LRS\&ui=true). Minimum (maximum) water level refers to the lowest (highest) average daily water level measured between January 25 and the day of the last sucker detection in Willow Creek, or June 15 in 2004 and 2005 . At water levels in the reservoir below about 4,523 ft, the dam channel and the mouth of Willow Creek are disconnected from the rest of the reservoir. At water levels in the reservoir below about 4,524 ft, sucker access to Willow Creek for individuals migrating through the east lobe is impeded. In 2004, water level exceeded 4,524 ft by February 17. In 2005, water level did not reach 4,524 ft until May 9. In 2015 and 2016, the antenna array in the strait between the lobes was operated into the summer such that later detections on that array were not necessarily of migrating fish. The antenna array in the strait was removed on March 29, 2017. Estimated cumulative February-May inflow is provided for relative comparisons among years; details are provided in appendix 1 (*see appendix 1 for details regarding the underestimated inflow for 2016). Abbreviations: NA, not applicable; TAF, thousand acre-feet]

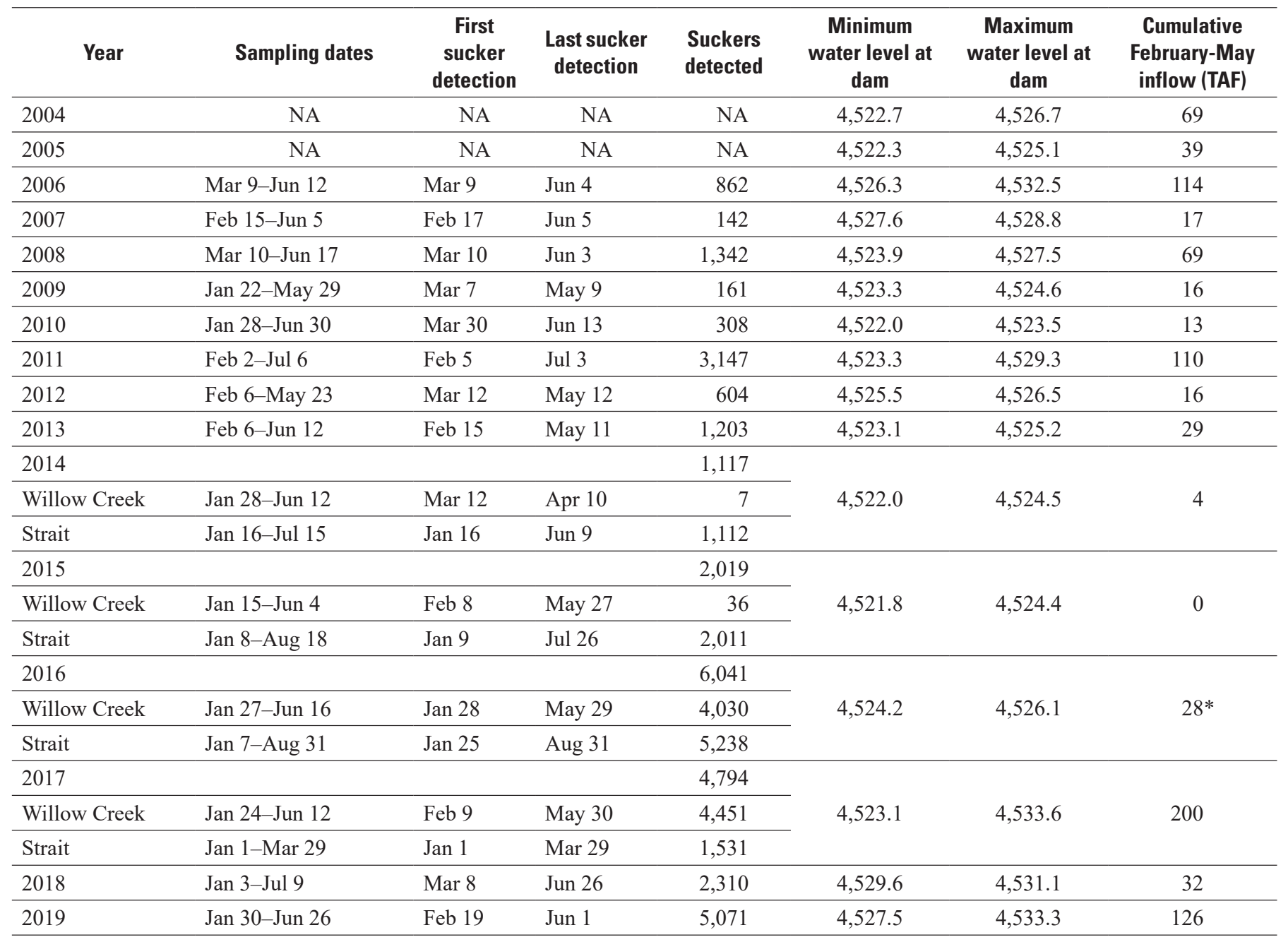

for the reservoir provided by Reclamation to determine the volume of the reservoir at the two points in time. We used the difference between these two values as a starting point for the estimated inflow to the reservoir, and added the total amount of water released from the dam over the same period (February-May). Our inflows computed in this way underestimate actual inflows because they do not account for seepage losses and evaporation from the reservoir surface, but these effects are expected to be insignificant for our purposes (appendix 1).
We use our estimated inflows only in a relative way to make consistent comparisons among spawning seasons throughout the period of record. We evaluate the frequency of low, moderate, and high inflow years with regard to spawning migrations to understand how our data on spawning migrations from 2006 to 2019 relate to the longer record. Our estimated inflows based on EOM dam gage records for the spawning season are shown for 2004-19 in table 2 to provide context for the detections on the remote antennas during the spawning migrations. 


\section{Capture-Recapture Analysis of Annual Survival}

To estimate annual survival of PIT-tagged suckers, we used a type of capture-recapture model that allows for the incorporation of both physical captures during the fall sampling periods and re-encounters of tagged suckers through detection on the remote antennas during the spring sampling periods (beginning in 2006). This type of model was developed by Barker $(1997,1999)$, originally as a way to incorporate information from dead recoveries and live resightings of animals (for example, waterfowl) outside the sampling period in which animals were captured and tagged. In our study, detections of PIT-tagged suckers on the remote antennas in Willow Creek and the strait during spring were treated as live resightings. Encounters that occurred between fall sampling periods were essential to parameter estimation because of low recapture probabilities for trammel net sampling, which are common in fisheries capture-recapture studies (Hewitt and others, 2010). Without the remote detections, most individuals would not be encountered again after tagging such that model fitting would be difficult and survival estimates would be imprecise and prone to bias. Because spawning migrations into Willow Creek are impeded in some years, detections on remote antennas in the strait in 2014-16 were particularly important. The remote antennas in Willow Creek could not detect $125 \mathrm{kHz}$ PIT tags, so capture-recapture analyses were restricted to individuals tagged with $134 \mathrm{kHz}$ tags beginning in 2005. Individuals tagged with $125 \mathrm{kHz}$ tags and re-tagged with $134 \mathrm{kHz}$ tags when recaptured after 2004 entered the analysis on the occasion when they were re-tagged.

Capture-recapture analysis for suckers in Clear Lake Reservoir is focused on the same statistical populations used in size composition analyses, denoted as "LRS" and "SNSKLS." As such, estimated survival rates do not explicitly apply to just adult or spawning populations, but rather to the proportion of the populations that are larger than $300 \mathrm{~mm}$ FL. Individuals that were captured and measured at less than 300 $\mathrm{mm}$ FL were not included in encounter histories for modeling unless they were recaptured and measured at $300 \mathrm{~mm}$ FL or greater. Their encounter histories in the analysis start with their first capture with a measurement $300 \mathrm{~mm}$ FL or greater. Individuals captured and PIT-tagged during sampling other than fall trammel net sampling (2004-18) enter capturerecapture analyses when they are first captured in trammel net sampling. Encounter histories for analysis were constructed by summarizing captures during fall sampling periods and detections in the spring.
From the Barker model, we obtained maximum likelihood estimates of annual survival probability $(S)$, the probability of a live fish being recaptured in a fall sampling period ( $p$; referred to as recapture probability), and a number of other parameters related to the detection (resighting) process that occurs between the fall sampling periods. The other parameters included in the full Barker model are listed below.

$r_{i} \quad$ the probability a fish that dies between fall sampling periods is found dead and the tag is recovered/detected

$R_{i} \quad$ the probability a fish that survives from one fall sampling period to the next is detected at some point in the spring between those periods

$R_{i}^{\prime} \quad$ the probability a fish that dies between fall sampling periods, without being found dead, is detected alive in the spring between those periods before it dies

$F_{i} \quad$ the probability a fish at risk of capture in a fall sampling period is at risk of capture in the next fall sampling period

$F^{\prime}{ }_{i} \quad$ the probability a fish not at risk of capture in a fall sampling period is at risk of capture in the next fall sampling period

Because we have only live resightings (detections) during the interval between fall sampling periods and these detections occur in the same geographical area as physical captures in the fall, $r$ and $F^{\prime}$ are 0 and $F$ is 1.0 (Conner and others, 2015). These parameters can be estimated in studies in which live resightings and dead recoveries can occur outside of the sampling area, such as hunting of waterfowl during migration. In exploratory analyses, we fit models in which we fixed the $r$ and $F$ parameters and also fit models that allowed those parameters to be estimated $[r(.) ; F()$.$] . Results were always$ similar between these two approaches, so we fixed these parameters in all models used for inference. The parameters $R$ and $R^{\prime}$ in the Barker models allow $S$ to be estimated precisely despite the low recapture probabilities ( $p$ ), and those parameters also protect $S$ from bias that would occur with low $p$ in the absence of resighting information. Survival estimates from this study apply to the interval between fall sampling periods, and we refer to the estimates according to the year in which most of that interval occurs. For example, we refer to survival in 2006 as the time between fall sampling periods in 2005 and 2006. 
The standard assumptions of capture-recapture models apply, including: (1) tags are not lost, or overlooked when individuals are re-encountered; (2) fall sampling periods are short relative to the interval between fall sampling periods for which survival is estimated; and (3) there is no unmodeled variability among the tagged individuals (heterogeneity) in survival probability, recapture probability, or other model parameters associated with the resighting process. Violations of these assumptions are minor and are in part addressed in Hewitt and others (2017). Some heterogeneity in recapture probability could occur when the distribution of tagged fish does not completely overlap with the distribution of sampling effort. For example, in years when water level in the reservoir is high, some fish remain in the east lobe after spawning (Banet and others, in press); these fish would not be susceptible to capture unless trammel net sampling occurs in the east lobe. Heterogeneity in recapture probabilities has less effect on $S$ estimates in Barker models than it would on apparent survival estimated in a Cormack-Jolly-Seber model because the resightings (detections) correct for those deficiencies, at least somewhat. The assumption of a lack of heterogeneity in the resighting process could be violated when spawning migrations are impeded and fish are not exposed to resighting in Willow Creek.

We considered models that included effects of both sex and time (year) on all parameters, as well as reduced models with fewer effects on parameters. We considered models in which $S$ varied as a function of sex because past analyses have shown that female suckers often have higher survival than males (Janney and others, 2008; Hewitt and others, 2017). We also expected sex to be important for $p$ because of differences in reproductive behavior (Burdick and others, 2015). We expected time to be important for $p$ and $R$ because of annual differences in sampling intensity and the effects of lake level and Willow Creek flows on spawning migrations. Owing to expected annual variation in model parameters, all models included time as the simplest possible effect on all parameters. Specifically, for each parameter, we entertained three possible models: (1) an interaction between sex and time, which estimates annual parameters independently for males and females; (2) an additive effect of sex and time, which allows for annual estimates of each parameter but a constant difference between males and females among years; and (3) an effect of time only, which estimates annually varying parameters but assumes no difference between sexes. Note that, as in many other capturerecapture designs, the last estimates of $S$ and $p$ are confounded in the likelihood and cannot be separately estimated in models that include interactive sex and time effects. The final estimate of $S$ applies to the time period between fall sampling in 2017 and fall sampling in 2018, which we label as 2018.

The models used in the analyses were specified and fitted in program MARK (White and Burnham, 1999). We used Akaike's information criterion corrected for small sample bias and adjusted for overdispersion (quasilikelihood
AICc [QAICc]) as a statistical criterion to evaluate competing models (Burnham and Anderson, 2002). The overdispersion parameter, $\hat{c}$, was estimated using the median $\hat{c}$ procedure in program MARK (for LRS, $\hat{c}=1.059$; for SNSKLS, $\hat{c}=1.137)$. All model likelihoods were constructed using a logit link function. During initial phases of model fitting, we found that the default optimization routine, the Newton-Raphson algorithm, sometimes converged to a local rather than global maximum likelihood. Program MARK also provides simulated annealing as an alternative optimization routine that is more robust in finding the global maximum likelihood. The drawback to this approach is that computational time is often on the order of hours to fit a single model. To minimize model run time, we used a screening approach to first identify the top competing models, and then to ensure those models had converged to the global maximum likelihood. First, we fit the fully interactive model using simulated annealing. Then we used the parameter estimates from this model as the initial parameter values when fitting all models using the Newton-Raphson algorithm. We found that this approach tended to produce negative log-likelihood values for a given model that were within a few points of the same model fit by simulated annealing. We proceeded by focusing on the set of models that had QAICc values within 15 units of the top model when they were fit using the Newton-Raphson algorithm. We re-fit each model in this set using simulated annealing. Finally, we used the model-specific parameter estimates produced by simulated annealing as initial values to re-fit each model with the Newton-Raphson algorithm. For this last step, the negative log-likelihood was always nearly identical for the two optimization methods, but this approach ensured that all model selection statistics and standard errors were estimated using the same optimization routine for all models in the final model set.

We used a two-stage model selection process to identify the set of most plausible models. First, we identified the set of most parsimonious models for recapture and resighting parameters. We fit all possible model structures for $p, R$, and $R$ ' paired with the fully interactive model for survival ( $\operatorname{sex} \times$ time), resulting in 27 possible models. For the second stage, we retained all model structures from the first stage that had QAICc values within 15 units of the top model, and we fit models that combined each of those structures with all possible model structures for survival. We report the resulting set of models that had QAICc values within 15 units of the top model. Akaike weights $\left(w_{i}\right)$ are reported as a measure of the relative weight among the models, or the likelihood of each model being the best model in the set given the data. Rather than making inferences from only the best model in the set, parameter estimates were model-averaged using the $w_{i}$ as weights. Model-averaged parameter estimates account for model selection uncertainty in the estimated precision of the parameters and thus produce unconditional estimates of variances and standard errors (Buckland and others, 1997). 


\section{Results}

\section{Sucker Catches in Fall Trammel Net Sampling}

Sucker catches were usually higher in years when the water level in the reservoir was lower, presumably because lower water levels concentrate fish and increase capture efficiency (table 1). We captured between 115 and 650 LRS (average $=308$ ) during fall trammel net sampling each year during 2004-19 (table 3). Catches of LRS in the most recent 4 years all exceeded the long-term average, with 2018 and 2019 being the highest two catches on record. Notably low catches occurred in 2008, 2010, and 2011. The sex ratio of captured LRS has consistently been close to 1:1 or somewhat femalebiased (average $=0.83$ male:female $\left[\sigma^{\lambda}:\right.$ : $]$ ). The percentage of LRS catch made up of individuals that had been captured and tagged in previous years was low in all years during the study period (12 percent or less; fig. 3).

In nearly all years within the study period, the majority of the fall trammel net catch was made up of individuals identified as shortnose suckers (table 3). Catch totals for SNS ranged between 347 and 2,273 (average $=1,448$ ), with the greatest catches in 2014 and 2015. Catches of SNS in 2006, 2008, and 2011 were notably low, about half of the long-term average. In contrast to LRS, the sex ratio of captured SNS has been consistently and strongly biased towards females (average $=0.45 \hat{\delta}:$ ) , with the exception of 2019. The percentage of the SNS catch made up of individuals that had been captured and tagged in previous years increased rather steadily for both males and females through 2018 (fig. 3). By 2018, recaptures made up over 21 percent of the male catch and over 38 percent of the female catch. In contrast to the more variable results for LRS, female SNS were always a larger proportion of the recaptures than males.

Prior to 2012, catches of individuals identified as Klamath largescale suckers ranged from 34 to 280 fish. Catches of individuals identified as KLS have been 12 or fewer individuals in every year since 2012 (table 3). The larger catches in the earlier years and smaller catches in the more recent years should not be interpreted as a decrease in the population of that species in the reservoir. Rather, the confusing nature of identification for KLS and SNS in the reservoir led to different subjective conclusions about identification depending on the personnel conducting the sampling. In earlier years, personnel were more likely to identify individuals as KLS, whereas very few individuals were identified as KLS in the more recent years. For size composition and capture-recapture analyses, SNS and KLS individuals were combined (table 4).

Between 16 and 205 captured suckers each year were not identified as one of the three named taxa for one reason or another. One reason for individuals lacking a definitive identification is that suckers around $300 \mathrm{~mm}$ FL and smaller are difficult to correctly identify, especially in Clear Lake Reservoir and elsewhere in the Lost River subbasin where introgression is apparently more common (Smith and others, 2020). For example, the largest catch of unidentified suckers occurred in 2019 and 88 percent of those individuals were less than 300 mm FL (table 3). However, in many years the unidentified individuals included larger suckers; these fish either had confusing morphological characters or had been called multiple different species in their history of captures. When the history of captures for an individual included only SNS, KLS, or hybrid interpretations involving those two taxa, such individuals were included in the SNS-KLS group (table 4). However, the individuals are included in the unidentified sucker group in table 3 .

\section{Spring Sucker Detections on Remote Passive Integrated Transponder Tag Antennas}

The remote antennas in Willow Creek detected between 7 and 5,071 PIT-tagged suckers in a given spawning season (table 2). The number of individuals detected was lower in years when flows were low in Willow Creek and in years when access to Willow Creek through the east lobe was impeded by low reservoir water levels. Water levels below about 4,524 $\mathrm{ft}$ (as measured at Clear Lake Dam) impede access through the east lobe and into the dam channel, and thus directly limit access to Willow Creek. Detections in Willow Creek during times when water level was below about 4,524 ft are probably from individuals that were residing in the dam channel. The threshold effect of water level at about $4,524 \mathrm{ft}$ is well demonstrated by the remote detections in Willow Creek in 2011 (appendix 2).

The combination of both low instream flows and low reservoir water level occurred in 2009, 2010, 2014, and 2015, and resulted in particularly weak spawning migrations in 2014 and 2015 when only 7 and 36 suckers were detected in Willow Creek. In 2010, nearly all of the detections occurred during a short-term increase in flows that occurred in late April and early May as a result of an isolated precipitation event (appendix 2). Because of the low reservoir water level, all of these individuals must have been residing in the dam channel prior to migration. Similarly, there was little instream flow in 2014 except for a short-term discharge event that began and peaked on March 10 and tapered off over the next week. All five LRS detections occurred in connection with that flow event. Only a single SNS-KLS was detected on April 4, 2014. Low water levels hindered access to Willow Creek for at least part of the season in 2011 and 2013 as well, but moderate to high inflows in Willow Creek in those years raised the water level during the season to allow sufficient access and provide for a moderate to strong spawning migration. Despite sufficient water levels for access to Willow Creek in 2007 and 2012, instream flows were low enough to limit spawning migrations to some extent in those years. 


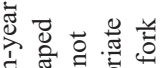

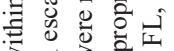

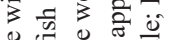

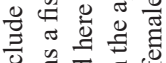

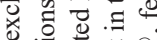

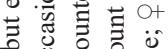
of

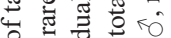

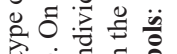

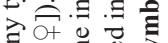

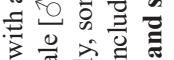

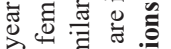

的语

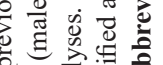

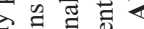

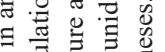

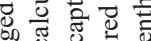

$\Xi$

응

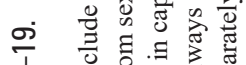

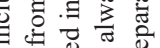

궁

하응

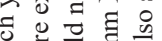

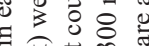

6.

记

5。

政

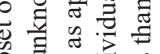

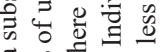

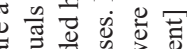

굴

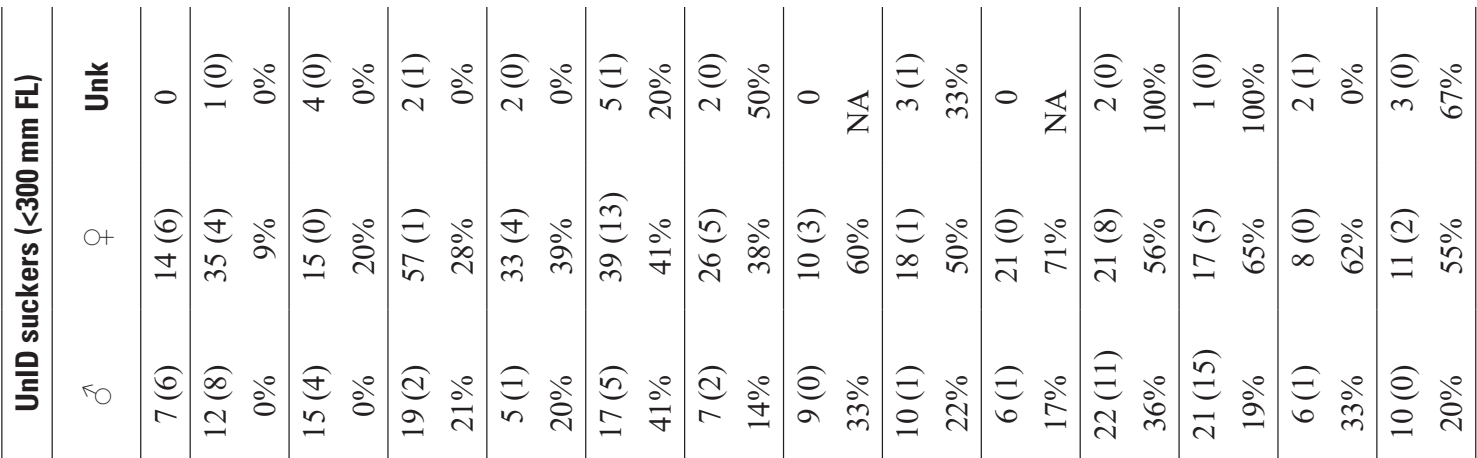

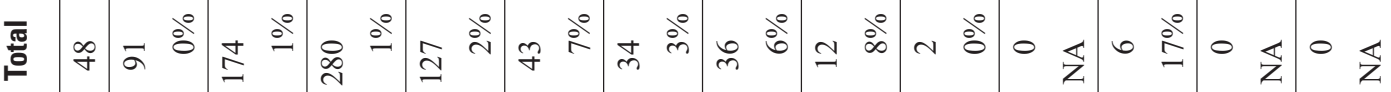

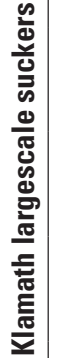

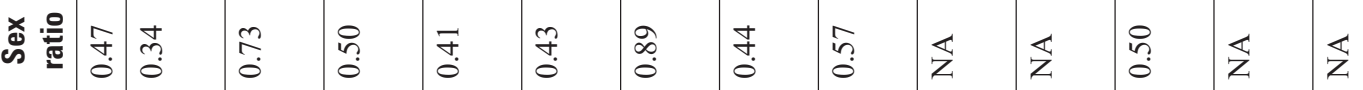

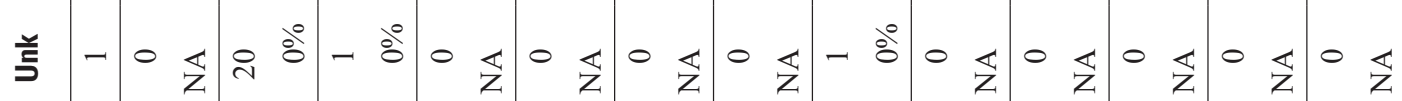

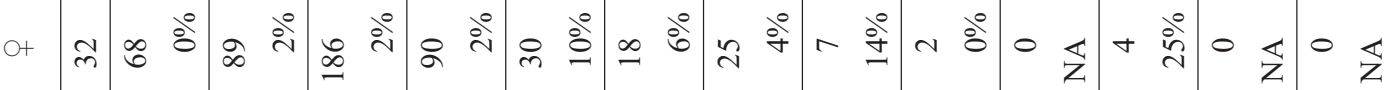

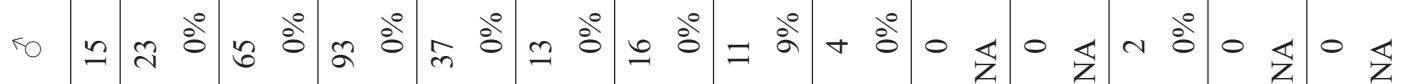

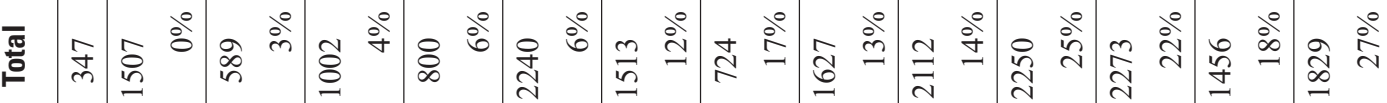

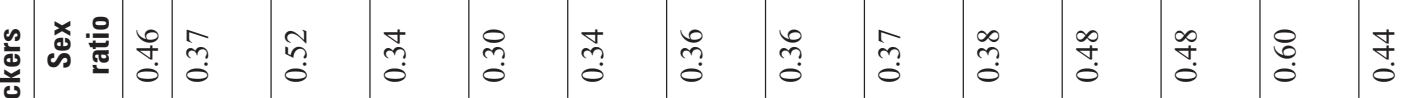

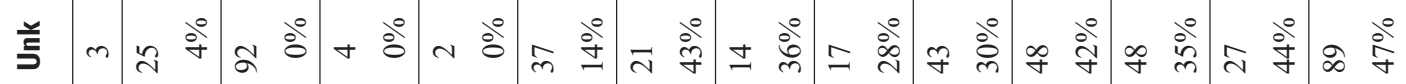

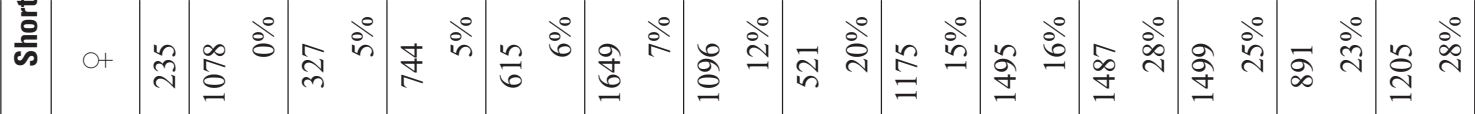

잉

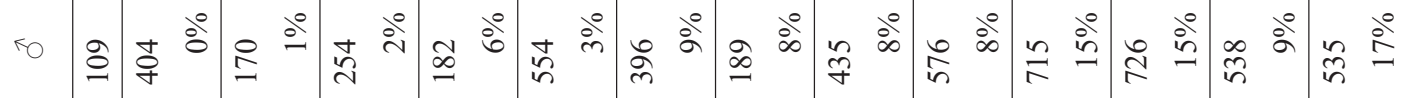

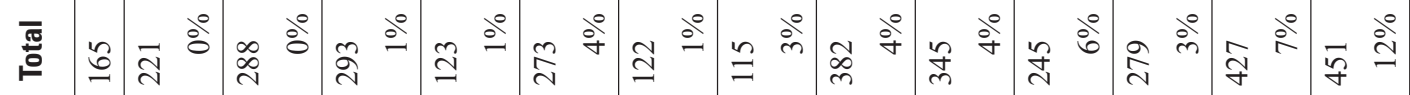

政

5

कo

额

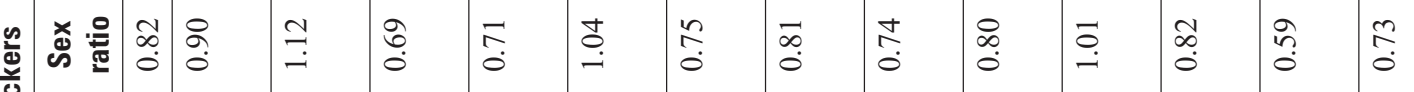

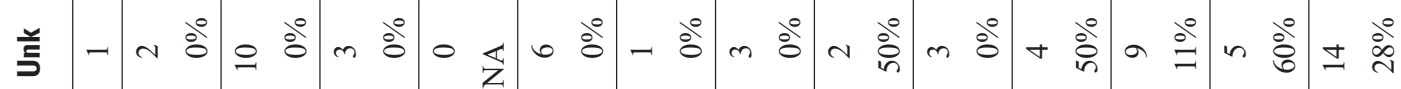

웡

들

0

离

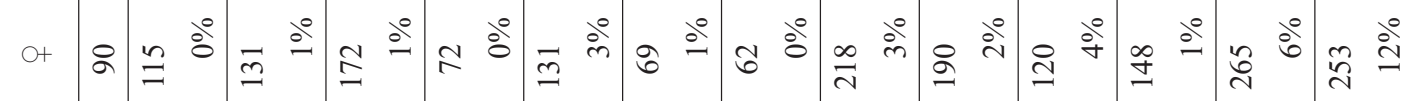

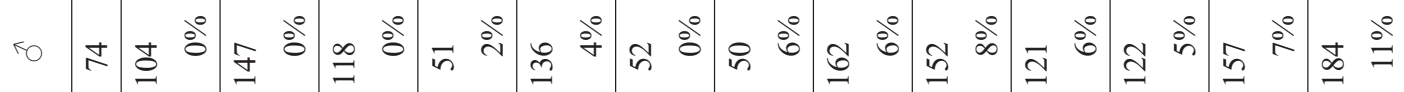

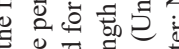

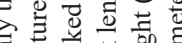

额券

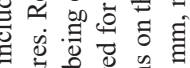

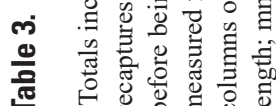

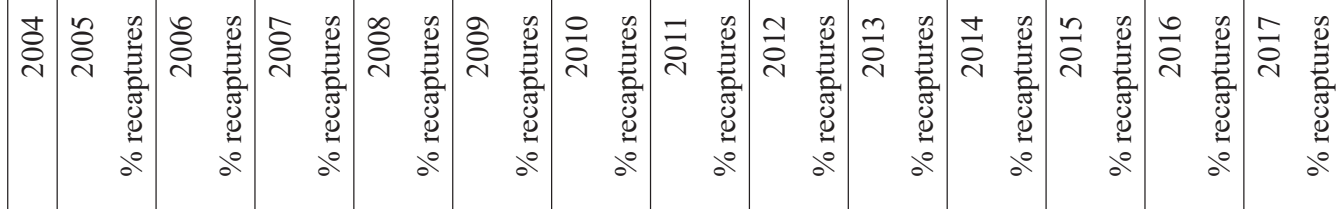


Results 13

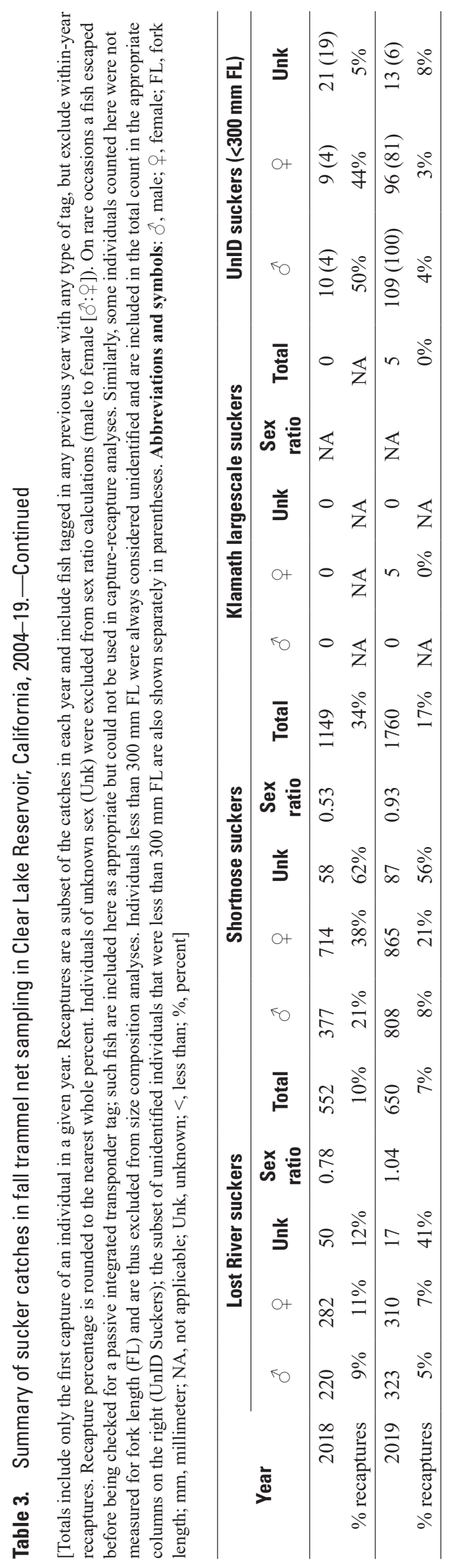




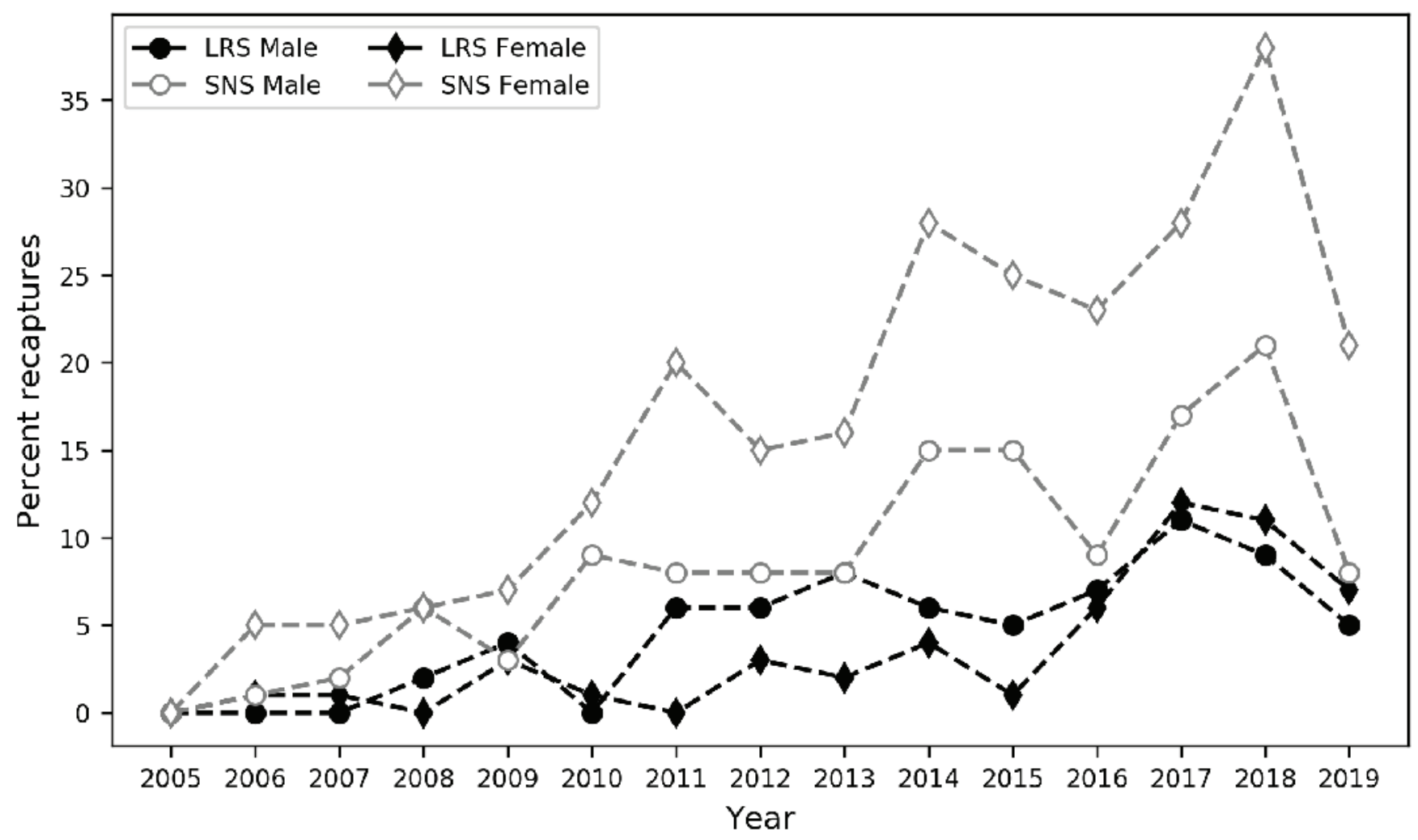

Figure 3. Percentage of fall trammel net catches made up of recaptured individuals for Lost River suckers (Deltistes luxatus; LRS) and shortnose suckers (Chasmistes brevirostris; SNS) in Clear Lake Reservoir, California, 2005-19. 
Table 4. Suckers classified as "SNS-KLS" (shortnose sucker [Chasmistes brevirostris] and Klamath largescale sucker [Catostomus snyderi] combined) that were captured in fall trammel net sampling in Clear Lake Reservoir, California, 2004-19.

[Totals include only the first capture of an individual in a given year. Recaptures are a subset of the catches in each year and include fish tagged in any previous year with any type of tag but exclude within-year recaptures. Recapture percentage is rounded to the nearest whole percent. Individuals of unknown sex (Unk) were excluded from sex ratio calculations (male to female [ $\hat{\delta}:$; ] ). On rare occasions a fish escaped before being checked for a passive integrated transponder tag; such fish are included here as appropriate but could not be used in capture-recapture analyses.

Similarly, some individuals counted here were not measured for fork length and are thus excluded from size composition analyses. Individuals less than 300 millimeters fork length are excluded from these counts. Abbreviations and Symbols: $\widehat{\partial}$, male;, , female; SNS-KLS, shortnose sucker and Klamath largescale sucker combined]

\begin{tabular}{|c|c|c|c|c|c|}
\hline \multirow{2}{*}{ Year } & \multicolumn{5}{|c|}{ SNS-KLS } \\
\hline & $\hat{\sigma}$ & q & Unknown & Sex ratio & Total \\
\hline 2004 & 121 & 268 & 4 & 0.45 & 393 \\
\hline 2005 & 425 & 1,165 & 25 & 0.36 & 1,615 \\
\hline$\%$ Recaptures & $0 \%$ & $0 \%$ & $4 \%$ & & $0 \%$ \\
\hline 2006 & 234 & 422 & 113 & 0.55 & 769 \\
\hline$\%$ Recaptures & $1 \%$ & $5 \%$ & $0 \%$ & & $3 \%$ \\
\hline 2007 & 356 & 968 & 5 & 0.37 & 1,329 \\
\hline$\%$ Recaptures & $2 \%$ & $5 \%$ & $0 \%$ & & $5 \%$ \\
\hline 2008 & 222 & 726 & 4 & 0.31 & 952 \\
\hline$\%$ Recaptures & $5 \%$ & $7 \%$ & $0 \%$ & & $6 \%$ \\
\hline 2009 & 571 & 1,689 & 38 & 0.34 & 2,298 \\
\hline$\%$ Recaptures & $4 \%$ & $7 \%$ & $16 \%$ & & $7 \%$ \\
\hline 2010 & 413 & 1,124 & 23 & 0.37 & 1,560 \\
\hline$\%$ Recaptures & $9 \%$ & $13 \%$ & $43 \%$ & & $12 \%$ \\
\hline 2011 & 203 & 550 & 14 & 0.37 & 767 \\
\hline$\%$ Recaptures & $8 \%$ & $20 \%$ & $36 \%$ & & $17 \%$ \\
\hline 2012 & 434 & 1,175 & 20 & 0.37 & 1,629 \\
\hline$\%$ Recaptures & $8 \%$ & $15 \%$ & $30 \%$ & & $14 \%$ \\
\hline 2013 & 576 & 1,511 & 43 & 0.38 & 2,130 \\
\hline$\%$ Recaptures & $8 \%$ & $17 \%$ & $30 \%$ & & $15 \%$ \\
\hline 2014 & 717 & 1,491 & 50 & 0.48 & 2,258 \\
\hline$\%$ Recaptures & $15 \%$ & $28 \%$ & $44 \%$ & & $25 \%$ \\
\hline 2015 & 731 & 1,506 & 49 & 0.49 & 2,286 \\
\hline$\%$ Recaptures & $16 \%$ & $25 \%$ & $37 \%$ & & $22 \%$ \\
\hline 2016 & 539 & 891 & 27 & 0.60 & 1,457 \\
\hline$\%$ Recaptures & $9 \%$ & $23 \%$ & $44 \%$ & & $18 \%$ \\
\hline 2017 & 538 & 1,206 & 90 & 0.45 & 1,834 \\
\hline$\%$ Recaptures & $17 \%$ & $28 \%$ & $48 \%$ & & $27 \%$ \\
\hline 2018 & 378 & 713 & 58 & 0.53 & 1,149 \\
\hline$\%$ Recaptures & $21 \%$ & $38 \%$ & $62 \%$ & & $34 \%$ \\
\hline 2019 & 809 & 874 & 88 & 0.93 & 1,771 \\
\hline$\%$ Recaptures & $8 \%$ & $21 \%$ & $56 \%$ & & $17 \%$ \\
\hline
\end{tabular}


An interesting detection occurred on the Willow Creek antennas in 2014. A small juvenile sucker (species unknown; $70 \mathrm{~mm}$ standard length), which was PIT-tagged by U.S. Fish and Wildlife Service (USFWS) on August 27, 2013, in North Fork Willow Creek near the Road 4808 crossing just downstream of the Oregon border, was detected on the tail end of the singular flow event that occurred in that season, on April 10, 2014. Because of its small size at the time of capture, this fish was given a $9 \mathrm{~mm} 134 \mathrm{kHz}$ PIT tag, which has a reduced detection range compared to the $12 \mathrm{~mm}$ PIT tags given to larger suckers. The most likely explanation for the detection at the Willow Creek array is that this fish migrated downstream on its own and thus traveled more than $35 \mathrm{~km}$ of stream distance. The tag from this fish was later detected on the bird nesting colony on Last Chance Island in the west lobe of the reservoir, in October 2015. Another possible explanation for the April, 2014, detection at the Willow Creek array is that the fish was consumed by a bird and the tag was inside the bird when it was detected on the Willow Creek antennas in April 2014, but it seems unlikely that the bird would approach the stand-up antennas and that the small PIT tag would be detectable through the body of the bird even if it did.

In years with sufficient access and instream flows, spawning migrations into Willow Creek began early in the season, more or less as soon as ice was out of the creek and off of the reservoir (appendix 2). In some years, migrants were detected in late January or early February. Winter weather and associated poor road conditions hindered the timely installation of the Willow Creek antennas in some years, and the early parts of the spawning migrations were likely missed in 2006 and 2008 (table 2). Upstream spawning migrations were typically complete by the end of April and few new migrants were detected after early May in any year.

We had both complete temporal coverage of strong spawning migrations as well as water temperature data in 6 years: 2011, 2013, and 2016-19. In those years, the timing of the migrations in terms of the number of new individuals migrating past the Willow Creek antennas appeared to be strongly controlled by water temperature. The number of new individuals passing the antennas increased when the average daily water temperature increased and slowed or stopped completely when the water temperature decreased, a pattern similar to what has been observed in the Williamson River for migrations from Upper Klamath Lake. However, in contrast to migrations in the Williamson River, which appear to also be controlled by a temperature threshold (approximately 10 degrees Celsius $\left[{ }^{\circ} \mathrm{C}\right.$ ] for LRS and $12{ }^{\circ} \mathrm{C}$ for SNS), LRS and SNS-KLS in Willow Creek both migrated whenever average daily water temperatures were increasing. In some years, early migrants were passing the antennas when the water temperature was as low as $2-3{ }^{\circ} \mathrm{C}$ (appendix 2).

The remote antennas in the strait between the east and west lobes of the reservoir detected between 1,112 and 5,238 PIT-tagged suckers in 2014-17 (table 2). The number of individuals detected was substantially lower in 2014 and 2015 during extreme drought conditions when the water level was low in the strait and the east lobe. Despite the antennas not being able to cover the entire passable channel in 2016 due to higher water levels, more than twice as many suckers were detected on the strait antennas in that year. In 2016, when access through the east lobe to Willow Creek was not impeded, detections on the strait antennas preceded detections in Willow Creek by about 2 weeks (appendix 2). Suckers continued to be detected on the strait antennas as long as there was water in the channel.

The number of LRS and SNS-KLS detected on the Willow Creek antennas generally increased through time as more individuals in the populations were tagged, provided that water level and instream flows did not hinder the spawning migrations (table 5). With few exceptions, more male LRS than female LRS were detected on the Willow Creek antennas, in contrast to the sex ratio in the fall trammel net captures. The sex ratio for SNS-KLS was similar between the fall trammel net captures and the individuals detected on the Willow Creek antennas, strongly favoring females.

The strait antennas were critical in providing detections of LRS and SNS-KLS individuals that were not detected in Willow Creek, especially in the drought years of 2014 and 2015. When detections across all antennas were combined in 2016 , detections of both taxa increased greatly compared to previous years as a result of high instream flows and higher water levels. The large number of detections on the strait antennas in 2014 and 2015 and on all antennas in 2016 provided the data necessary to inform estimates of annual survival using capture-recapture.

\section{Historical Reservoir Inflows in Context of Sucker Spawning Migrations (1919-2016)}

We examined estimated inflows to the reservoir using the EOM dam gage approach over the period 1919-2005 (appendix 1, fig. 1.1), excluding the Dust Bowl years of 1931-36, in order to compare the effects of inflows on spawning migrations in the past with what we observed in this study from 2006 to 2019. Based on the Willow Creek PIT tag detections, we considered that spawning was possible in years with as little as 20 thousand acre-feet (TAF) of inflow and that spawning was not impeded much at all in years with 30-35 TAF or more. Of course, the degree to which spawning was inhibited would depend on how the runoff occurred throughout a given season. One big discharge pulse might allow more fish to move upstream but perhaps not go as far or have as long of a spawning period as in years with the same inflow spread out over a longer time period. We tabulated our estimated inflows for the 81 years in the period of record in increments of 5 TAF: 10 years $<20$ TAF; 5 years $20-25$ TAF; 6 years $25-30$ TAF; 2 years $30-35$ TAF; and 58 years $>35$ TAF. Depending on where the line is drawn as a spawning inflow threshold between 20 and 35 TAF, as few as 72 percent of years and as many as 88 percent of years in the long-term record would have experienced Willow Creek inflows sufficient for spawning. 
Table 5. Detections of Lost River suckers (Deltistes luxatus; LRS) and shortnose (Chasmistes brevirostris) and Klamath largescale suckers (Catostomus snyderi) combined (SNS-KLS) on the remote passive integrated transponder (PIT) tag antennas in Willow Creek and the strait channel at Clear Lake Reservoir, California, 2006-19.

[Detections are counts of individual suckers at a given location and exclude re-detections of the same fish at the same location within a year. In 2014-17, the same individuals were often detected at both the Willow Creek and strait antennas. In those years, the total counts for the year are given above the locationspecific counts and include all individuals detected at either location. Individuals tagged prior to fall 2005 with $125 \mathrm{kHz}$ PIT tags could not be detected on the remote antennas and those fish are excluded from this summary unless they were recaptured and re-tagged with a $134 \mathrm{kHz}$ PIT tag. Fish are included in the detection counts without regard to their size, and some included fish were less than 300 millimeters fork length at their last physical capture before detection.

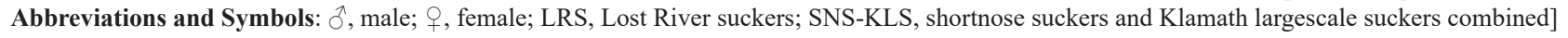

\begin{tabular}{|c|c|c|c|c|c|c|c|c|c|c|}
\hline \multirow{2}{*}{ Year } & \multicolumn{5}{|c|}{ LRS } & \multicolumn{5}{|c|}{ SNS-KLS } \\
\hline & $\pi$ & q & Unknown & Sex ratio & Total & $\sigma^{\lambda}$ & 우 & Unknown & Sex ratio & Total \\
\hline 2006 & 55 & 32 & 0 & 1.72 & 87 & 223 & 538 & 8 & 0.41 & 769 \\
\hline 2007 & 37 & 11 & 0 & 3.36 & 48 & 26 & 59 & 5 & 0.44 & 90 \\
\hline 2008 & 192 & 149 & 6 & 1.29 & 347 & 266 & 678 & 40 & 0.39 & 984 \\
\hline 2009 & 44 & 29 & 2 & 1.52 & 75 & 19 & 66 & 1 & 0.29 & 86 \\
\hline 2010 & 13 & 14 & 1 & 0.93 & 28 & 76 & 199 & 2 & 0.38 & 277 \\
\hline 2011 & 236 & 190 & 3 & 1.24 & 429 & 697 & 1942 & 37 & 0.36 & 2676 \\
\hline 2012 & 194 & 137 & 5 & 1.42 & 336 & 62 & 193 & 5 & 0.32 & 260 \\
\hline 2013 & 272 & 245 & 4 & 1.11 & 521 & 176 & 482 & 15 & 0.37 & 673 \\
\hline 2014 & 225 & 274 & 5 & 0.82 & 504 & 156 & 433 & 12 & 0.36 & 601 \\
\hline Willow Creek & 3 & 2 & 0 & 1.50 & 5 & 0 & 1 & 0 & NA & 1 \\
\hline Strait & 223 & 273 & 5 & 0.82 & 501 & 156 & 432 & 12 & 0.36 & 600 \\
\hline 2015 & 171 & 141 & 3 & 1.21 & 315 & 567 & 1089 & 23 & 0.52 & 1679 \\
\hline Willow Creek & 6 & 1 & 0 & 6.00 & 7 & 13 & 16 & 0 & 0.81 & 29 \\
\hline Strait & 168 & 141 & 3 & 1.19 & 312 & 567 & 1084 & 23 & 0.52 & 1674 \\
\hline 2016 & 374 & 545 & 9 & 0.69 & 928 & 1605 & 3649 & 94 & 0.44 & 5348 \\
\hline Willow Creek & 262 & 239 & 7 & 1.10 & 508 & 1134 & 2294 & 55 & 0.49 & 3483 \\
\hline Strait & 320 & 506 & 6 & 0.63 & 832 & 1333 & 3294 & 88 & 0.40 & 4715 \\
\hline 2017 & 361 & 534 & 8 & 0.68 & 903 & 1051 & 2666 & 72 & 0.39 & 3789 \\
\hline Willow Creek & 345 & 460 & 5 & 0.75 & 810 & 988 & 2493 & 69 & 0.40 & 3550 \\
\hline Strait & 88 & 201 & 5 & 0.44 & 294 & 312 & 856 & 24 & 0.36 & 1192 \\
\hline 2018 & 353 & 275 & 6 & 1.28 & 634 & 436 & 1179 & 33 & 0.37 & 1648 \\
\hline 2019 & 533 & 556 & 15 & 0.96 & 1104 & 1138 & 2666 & 97 & 0.43 & 3901 \\
\hline
\end{tabular}

Ignoring the effect of low reservoir water levels on spawning access to Willow Creek, inflows during our study were lower than was typical in the period of record and would have limited spawning to some extent in about half of the years. During the 16 years of our study, Willow Creek inflow was sufficient for spawning in only 44-63 percent of the years by the same criteria (table $2 ; 6$ years $<20$ TAF; 0 years $20-25$ TAF; 2 years $25-30$ TAF; 1 year 30-35 TAF; and 7 years $>35$ TAF). Although we only monitored spawning migrations in Willow Creek beginning in 2006, we assume that inflows were sufficient in 2004 and 2005 based on our estimated inflows $>35 \mathrm{TAF}$. We note, however, that spawning migrations of some magnitude occurred during our study even in 4 years with estimated Willow Creek inflow less than 20 TAF. For example, inflow was estimated at 16 TAF in 2012, and both species made a spawning migration. Although the SNS-KLS migration was relatively small for that taxa, as expected, the LRS migration could be considered moderate (appendix 2).

\section{Size Composition in Fall Trammel Net Catches}

The presence of small LRS (300-400 mm FL) in the trammel net catches in some years indicated intermittent recruitment during the study period (fig. 4). At the start of the study in 2004, most LRS were relatively small, with few larger than $550 \mathrm{~mm}$ FL. The median fork lengths of LRS generally increased from 2004 to 2014. In 2007, a new cohort of smaller fish was evident in the catch, but this cohort appeared to decrease in abundance through 2008 and 2009. A less abundant cohort of smaller LRS was detected in 2012. By 2014, 
$\boldsymbol{A}$

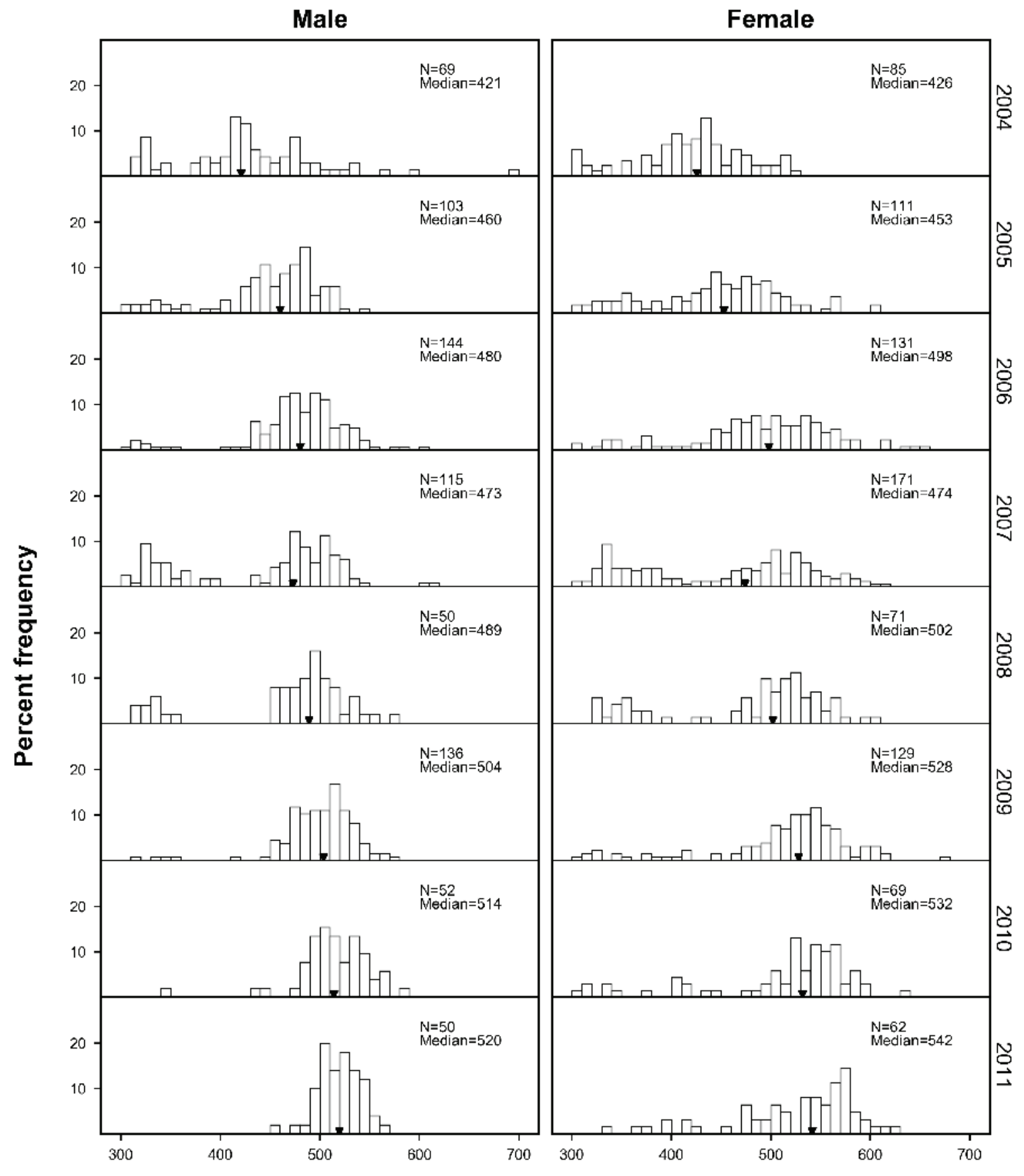

Fork length (millimeters)

Figure 4. Frequency histograms of fork lengths of male and female Lost River suckers (Deltistes luxatus) captured in trammel nets in Clear Lake Reservoir, California, during fall sampling, 2004-19. Only individuals measured at 300 millimeters or greater fork length are included. Inverted triangles along the $x$-axis indicate the median fork length for the data in each panel. The median fork length and the number of individuals included in each panel are printed in the top right of each panel. 

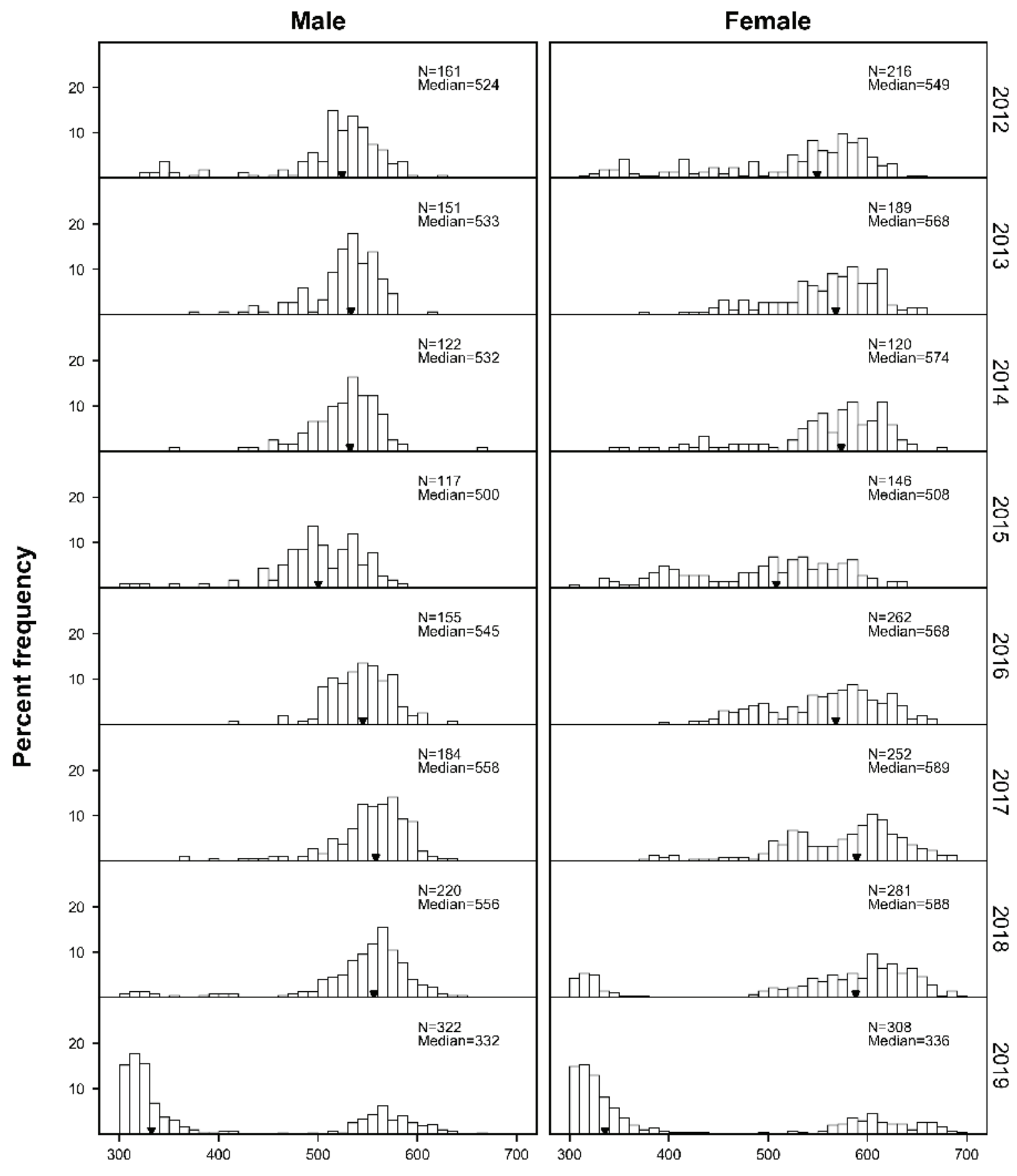

Fork length (millimeters)

Figure 4.-Continued 
the size distributions of LRS were relatively unimodal and the median fork length was $531 \mathrm{~mm}$ for males and $568 \mathrm{~mm}$ for females. In 2015, a new cohort of smaller LRS was evident in the catch, particularly for females, and the median fork length decreased for both sexes. The most substantial new cohort of LRS was detected in catches at the end of the study period. Smaller individuals were first captured in 2018 and made up the majority of the catch of both sexes in 2019. The presence of this cohort decreased the median lengths of both sexes of LRS to just over $330 \mathrm{~mm}$ FL.

Similar to LRS, the time series of size distributions for SNS-KLS showed that recruitment of new cohorts occurred intermittently (fig. 5). However, for SNS-KLS, inference about the magnitude of recruitment based on the size distributions from trammel net catches is more challenging because of the smaller size of this taxa. In 2004, the median fork length of both sexes was approximately $330 \mathrm{~mm}$ FL, and very few of these individuals were larger than $400 \mathrm{~mm}$ FL. The median fork lengths of SNS-KLS increased through 2008. The median fork lengths of both sexes decreased in 2009 and a new cohort of smaller fish was evident in the size distributions in 2009 and 2010. The size distributions were similar from 2011 to 2014 , and then a more obvious new cohort of smaller SNSKLS was present in the catch in 2015 and 2016. Similar to LRS, the most substantial new cohort of SNS-KLS was detected in catches at the end of the study period. In 2019, the size distributions were strongly bimodal and the majority of the catch was made up of fish smaller than $350 \mathrm{~mm}$ FL.

\section{Capture-Recapture Analysis of Annual Survival}

\section{Lost River Suckers}

From the start of our contemporary monitoring program in fall 2004 through fall trammel net sampling in 2018, we have captured, PIT-tagged, and released over 2,000 female and over 1,600 male LRS (table 6). Of those, 88 females and 72 males were tagged with $125 \mathrm{kHz}$ tags in 2004 and have not been re-tagged with $134 \mathrm{kHz}$ tags. It is unknown what proportion of those fish with $125 \mathrm{kHz}$ tags are still at large and thus cannot be detected on remote antennas, but through fall sampling in 2014 and 2015 only one individual with a 125 $\mathrm{kHz}$ tag was recaptured (in 2014). In addition to the fish we have tagged since 2004, a substantial number of juveniles and larger suckers were tagged with $125 \mathrm{kHz}$ PIT tags in 1993-96 and 2000. We suspect that few of those fish remain at large in the population, and we did not recapture any of them in our fall trammel net sampling between 2004 and 2015.

Across all PIT-tagged fish released in 2004-18, excluding recaptures within the same fall season of tagging, we subsequently recaptured or remotely detected 74 percent of females and 85 percent of males on at least one occasion through spring 2019. Without remote detections in the spring, modeling of survival would be very limited for LRS as very few were ever physically recaptured in fall trammel net sampling (table 6). The strait antennas were especially important in years like 2014 and 2015, when very few detections occurred in Willow Creek. Spring detections showed that a number of suckers PIT-tagged in 2005 continued to persist in the lake through 2019 (table 6).

Modeling results indicated strong support for an additive effect of sex and time on survival of LRS (table 7). The difference in survival between the sexes was small, with male survival lower than female survival by 5 percent or less (fig. 6 ; table 8). The survival estimate for both sexes in 2007 was at the upper boundary of one. Model selection indicated strong support for interactive sex $\times$ time variation in recapture probabilities, even though estimates in some years with no recaptures were estimated as zero (on the boundary). The top model showed that recapture probabilities were universally small (less than 0.06 ) and that males tended to have slightly higher recapture probabilities (table 8). There was strong support for an additive effect of sex and time on $R^{\prime}$, and estimates indicated that males were as much as 11 percent more likely than females to be detected on remote antennas in the spring during the year that they died. Estimates of $R^{\prime}$ were rather imprecise. In contrast, a fully interactive sex $\times$ time structure was favored for $R$, and estimates were more precise. Males had higher, sometimes substantially higher, resighting probabilities than females. Resighting probabilities were highest in years with unimpeded access to Willow Creek and large inflows, such as 2011 and 2017.

Survival for LRS was between 0.74 and 0.96 for all years except 2009, 2013, and 2015 (fig. 6). In those 3 years, survival was much lower at $0.57-0.67$, indicating that approximately 40 percent of the individuals larger than $300 \mathrm{~mm}$ FL died in those years. Estimates were somewhat imprecise in the earlier years when re-encounter data were more sparse.

\section{Shortnose/Klamath Largescale Suckers}

From fall 2004 to fall 2018, we captured, PIT-tagged, and released over 12,000 female and over 5,500 male SNS-KLS (table 9). Of those, 253 females and 125 males were tagged with $125 \mathrm{kHz}$ tags in 2004 and have not been re-tagged with $134 \mathrm{kHz}$ tags. It is unknown what proportion of those fish with $125 \mathrm{kHz}$ tags are still at large and thus cannot be detected on remote antennas, but through fall sampling in 2014 and 2015 only one individual with a $125 \mathrm{kHz}$ tag was recaptured (in 2015). In addition to the fish we have tagged since 2004, a substantial number of juveniles and larger suckers were tagged with $125 \mathrm{kHz}$ PIT tags in 1993-1996 and 2000. We suspect that few of those fish remain at large in the population. Across all PIT-tagged fish released during 2004-18, excluding recaptures within the same fall season of tagging, we subsequently recaptured or remotely detected 65 percent of females and 67 percent of males on at least one occasion through spring 2019. 


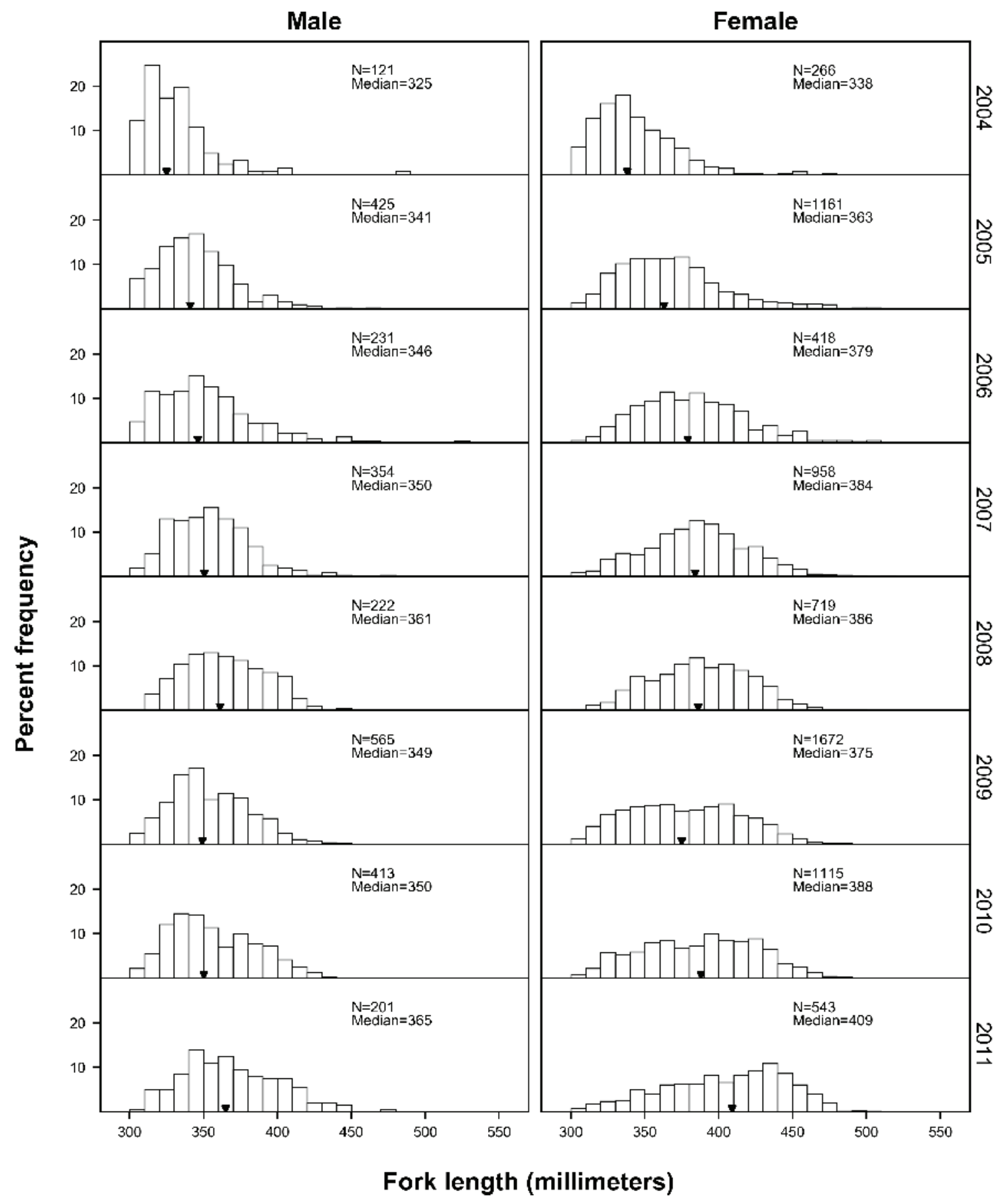

Figure 5. Frequency histograms of fork lengths of male and female shortnose (Chasmistes brevirostris) and Klamath largescale suckers (Catostomus snyderi) combined captured in trammel nets in Clear Lake Reservoir, California, during fall sampling, 2004-19. Only individuals measured at $300 \mathrm{~mm}$ FL or greater are included. Inverted triangles along the $x$-axis indicate the median fork length for the data in each panel. The median fork length and the number of individuals included in each panel are printed in the top right of each panel. 
B

SNS-KLS

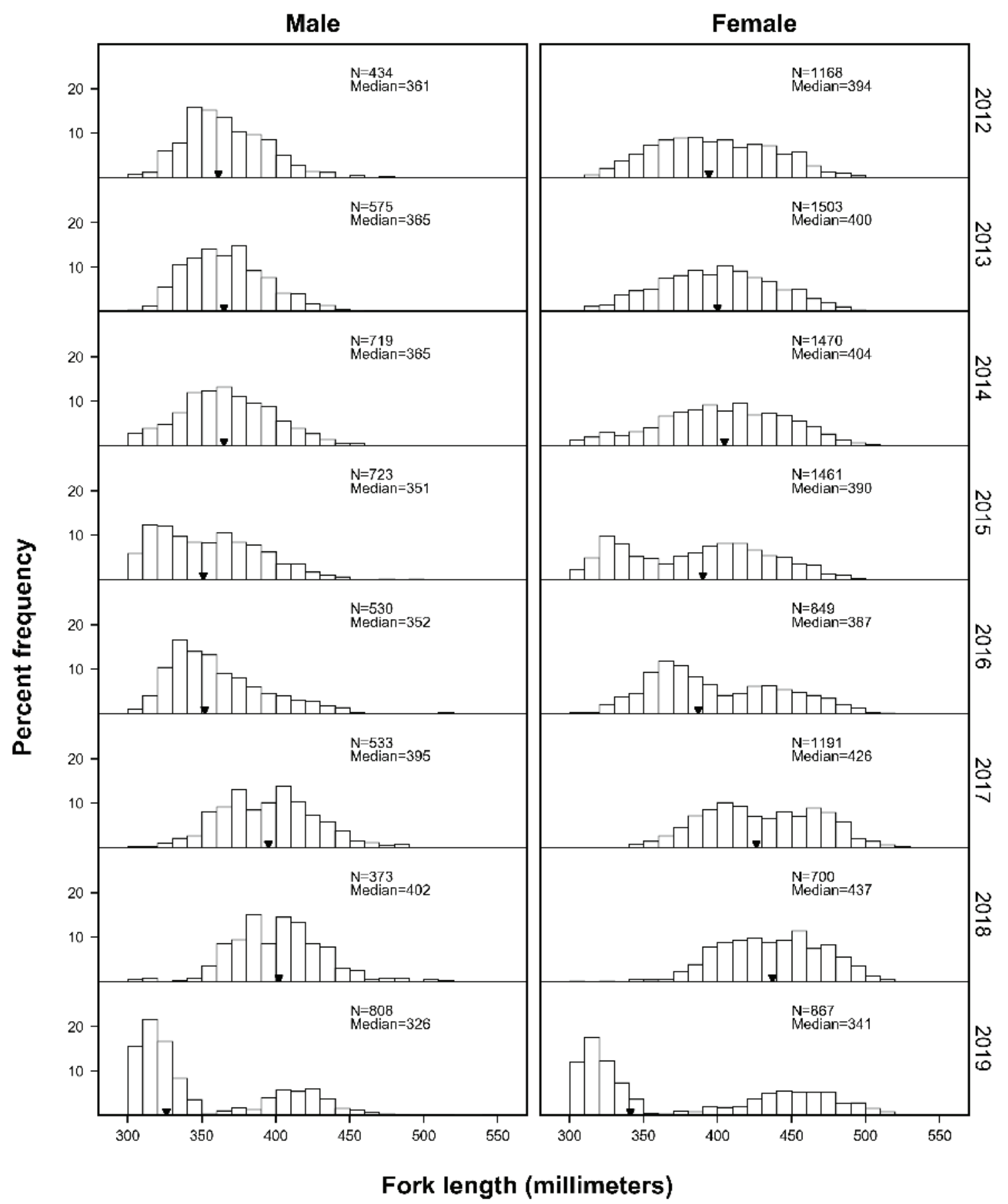

Figure 5.-Continued 


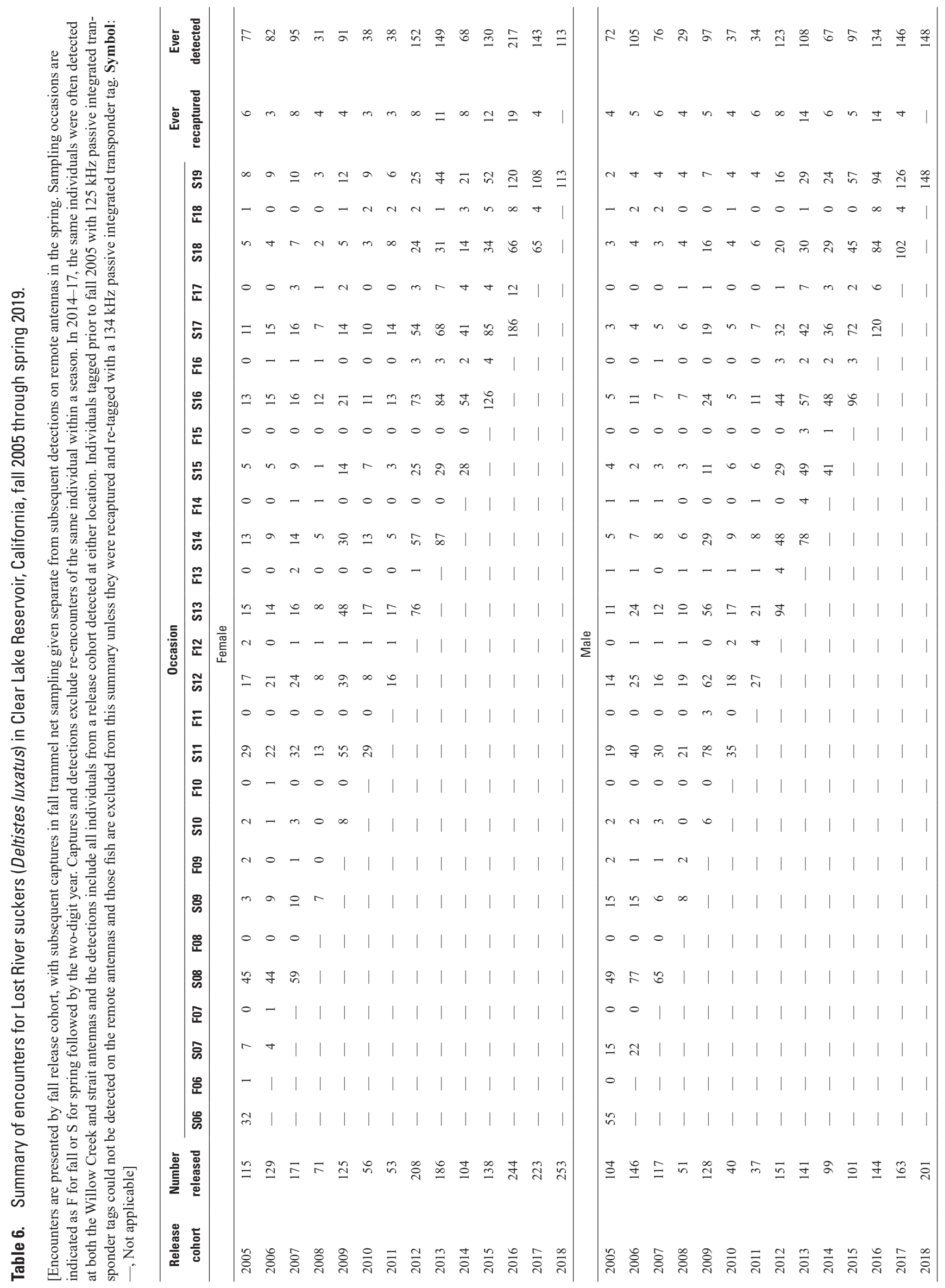


Table 7. Model selection results for the Barker capture-recapture models fitted to the data for Lost River suckers in Clear Lake Reservoir, California, 2005-19.

[Akaike's Information Criterion corrected for small sample size and overdispersion (quasilikelihood AICc [QAICc]) was used to compare the candidate models. In the final model set, only plausible models ( $\triangle$ QAICc less than 15 ) and the full model are shown. In the model names, a $\times$ symbol indicates fully interactive effects and a + symbol indicates additive effects. The best model in the set is presented first, and $\triangle$ QAICc values are the difference between the QAICc value of a given model and that of the best model. Akaike weights $\left(w_{\mathrm{i}}\right)$ provide a measure of the relative weight of each model or the likelihood of it being the best model in the set given the data. Number of parameters $(K)$ is the total number that is theoretically estimable in the model]

\begin{tabular}{|c|c|c|c|c|c|}
\hline Model & $K$ & OAICc & $\triangle 0 A I C c$ & $w_{i}$ & Deviance \\
\hline$S($ sex + time $) p($ sex $\times$ time $) r(0) R($ sex $\times$ time $) R^{\prime}($ sex + time $) F(1) F^{\prime}(0)$ & 84 & $18,322.3$ & 0.0 & 0.973 & $3,031.1$ \\
\hline$S\left(\right.$ time) $p\left(\right.$ sex $\times$ time) $r(0) R($ sex $\times$ time $) R^{\prime}(\mathrm{sex}+$ time $) F(1) F^{\prime}(0)$ & 83 & $18,332.2$ & 9.9 & 0.007 & $3,043.0$ \\
\hline$S\left(\right.$ time) $p\left(\right.$ sex $\times$ time) $r(0) R($ sex $\times$ time $) R^{\prime}$ (time) $F(1) F^{\prime}(0)$ & 82 & $18,332.9$ & 10.6 & 0.005 & $3,045.8$ \\
\hline$S\left(\right.$ time) $p\left(\right.$ sex + time) $r(0) R($ sex $\times$ time $) R^{\prime}(\mathrm{sex}+$ time $) F(1) F^{\prime}(0)$ & 71 & $18,333.7$ & 11.4 & 0.003 & $3,069.0$ \\
\hline$S($ time $) p($ sex $\times$ time $) r(0) R($ sex $\times$ time $) R^{\prime}$ (time) $F(1) F^{\prime}(0)$ & 70 & $18,334.1$ & 11.8 & 0.003 & $3,071.4$ \\
\hline$S(\mathrm{sex} \times$ time $) p(\mathrm{sex}+$ time $) r(0) R(\mathrm{sex} \times$ time $) R^{\prime}($ time $) F(1) F^{\prime}(0)$ & 84 & $18,334.6$ & 12.2 & 0.002 & $3,043.3$ \\
\hline$S($ sex $\times$ time $) p($ sex $\times$ time $) r(0) R($ sex $\times$ time $) R^{\prime}($ sex + time $) F(1) F^{\prime}(0)$ & 97 & $18,334.8$ & 12.5 & 0.002 & $3,016.9$ \\
\hline$S($ sex $\times$ time $) p($ sex $\times$ time $) r(0) R($ sex $\times$ time $) R^{\prime}($ time $) F(1) F^{\prime}(0)$ & 96 & $18,334.8$ & 12.5 & 0.002 & $3,019.0$ \\
\hline$S($ sex $\times$ time $) p($ sex + time $) r(0) R($ sex $\times$ time $) R^{\prime}($ sex + time $) F(1) F^{\prime}(0)$ & 85 & $18,335.0$ & 12.6 & 0.002 & $3,041.6$ \\
\hline$S($ sex $\times$ time $) p($ time $) r(0) R($ sex $\times$ time $) R^{\prime}$ (time $) F(1) F^{\prime}(0)$ & 83 & $18,337.1$ & 14.7 & 0.001 & $3,047.9$ \\
\hline$S($ sex $\times$ time $) p($ sex $\times$ time $) r(0) R($ sex $\times$ time $) R^{\prime}(\mathrm{sex} \times$ time $) F(1) F^{\prime}(0)$ & 110 & $18,351.7$ & 29.4 & 0.000 & $3,007.1$ \\
\hline
\end{tabular}




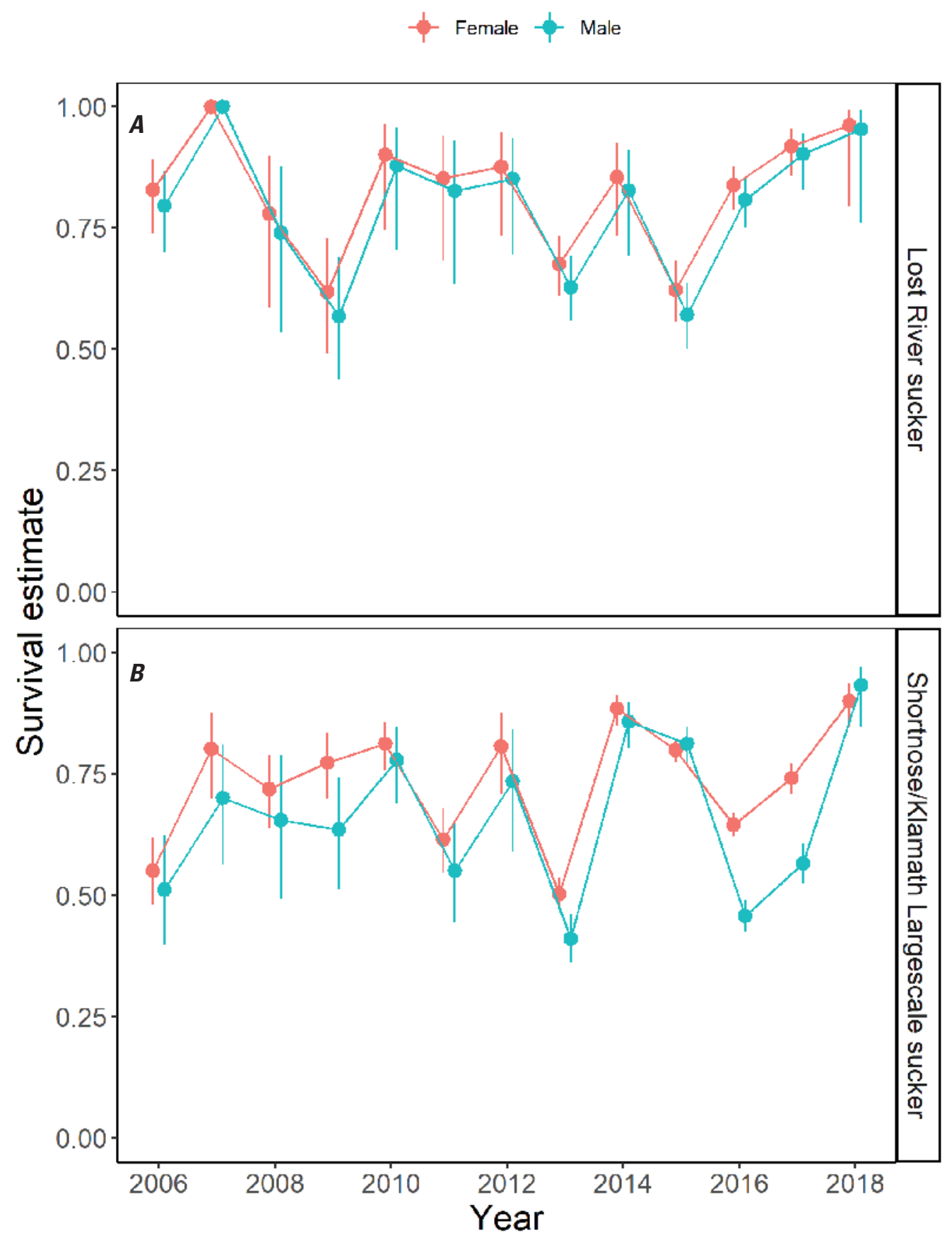

Figure 6. Estimates of annual survival probability with 95 percent confidence intervals for Lost River suckers (Deltistes luxatus) and shortnose suckers (Chasmistes brevirostris) and Klamath largescale suckers (Catostomus snyderi) combined in Clear Lake Reservoir, California, 2006-18. Survival probabilities apply to the time between fall sampling periods and are labeled with the year that includes most of that time; for example, survival labeled as 2006 applies to the time between fall sampling in 2005 and 2006. The estimates in 2007 for Lost River suckers are on the boundary at 1.0, indicating estimation problems due to sparse re-encounter data. 
Table 8. Demographic parameter estimates for Lost River suckers (Deltistes luxatus) in Clear Lake Reservoir, California.

[Model-averaged estimates of annual survival probabilities (S), recapture probabilities $(p)$, survivor resighting probabilities (R), and non-survivor resighting probabilities ( $\left.\mathrm{R}^{\prime}\right)$, with 95 percent confidence intervals (CI) for all estimates. Estimates on the boundary at 0.0 or 1.0 (B) are shaded gray]

\begin{tabular}{|c|c|c|c|c|c|c|c|c|c|}
\hline Sex & Year & S est & $\mathrm{S} \mathrm{Cl}$ & $p$ est & $p \mathrm{Cl}$ & R est & R Cl & R' est & $\mathrm{R}^{\prime} \mathrm{Cl}$ \\
\hline Female & 2006 & 0.83 & $0.74-0.89$ & 0.010 & $0.00-0.07$ & 0.33 & $0.24-0.43$ & $0.0 \mathrm{~B}$ & NA \\
\hline Female & 2007 & $1.0 \mathrm{~B}$ & NA & 0.004 & $0.00-0.03$ & 0.05 & $0.03-0.09$ & $0.0 \mathrm{~B}$ & NA \\
\hline Female & 2009 & 0.62 & $0.49-0.73$ & 0.013 & $0.00-0.04$ & 0.06 & $0.03-0.11$ & 0.08 & $0.04-0.16$ \\
\hline Female & 2010 & 0.90 & $0.75-0.97$ & 0.003 & $0.00-0.02$ & 0.04 & $0.02-0.07$ & 0.03 & $0.00-0.20$ \\
\hline Female & 2012 & 0.88 & $0.73-0.95$ & 0.021 & $0.01-0.05$ & 0.38 & $0.32-0.44$ & 0.23 & $0.07-0.55$ \\
\hline Female & 2013 & 0.67 & $0.61-0.73$ & 0.008 & $0.00-0.03$ & 0.34 & $0.29-0.40$ & 0.50 & $0.39-0.60$ \\
\hline Female & 2014 & 0.85 & $0.73-0.93$ & 0.004 & $0.00-0.02$ & 0.42 & $0.37-0.48$ & 0.42 & $0.23-0.63$ \\
\hline Female & 2015 & 0.62 & $0.56-0.68$ & $0.0 \mathrm{~B}$ & NA & 0.22 & $0.18-0.27$ & 0.26 & $0.18-0.35$ \\
\hline Female & 2016 & 0.84 & $0.79-0.88$ & 0.037 & $0.02-0.06$ & 0.93 & $0.90-0.95$ & 0.71 & $0.54-0.84$ \\
\hline Male & 2007 & $1.0 \mathrm{~B}$ & NA & $0.0 \mathrm{~B}$ & NA & 0.16 & $0.12-0.22$ & $0.0 \mathrm{~B}$ & NA \\
\hline Male & 2008 & 0.74 & $0.54-0.88$ & $0.0 \mathrm{~B}$ & NA & 0.69 & $0.61-0.77$ & 0.20 & $0.02-0.70$ \\
\hline Male & 2009 & 0.57 & $0.44-0.69$ & 0.035 & $0.02-0.08$ & 0.17 & $0.12-0.24$ & 0.13 & $0.07-0.22$ \\
\hline Male & 2010 & 0.88 & $0.71-0.96$ & $0.0 \mathrm{~B}$ & NA & 0.04 & $0.02-0.08$ & 0.05 & $0.01-0.28$ \\
\hline Male & 2011 & 0.83 & $0.63-0.93$ & 0.012 & $0.00-0.04$ & 0.80 & $0.74-0.84$ & 0.38 & $0.14-0.70$ \\
\hline Male & 2012 & 0.85 & $0.69-0.94$ & 0.036 & $0.02-0.07$ & 0.67 & $0.60-0.73$ & 0.33 & $0.10-0.67$ \\
\hline Male & 2013 & 0.63 & $0.56-0.69$ & 0.040 & $0.02-0.07$ & 0.62 & $0.55-0.68$ & 0.61 & $0.49-0.71$ \\
\hline Male & 2014 & 0.83 & $0.69-0.91$ & 0.024 & $0.01-0.05$ & 0.51 & $0.44-0.57$ & 0.53 & $0.32-0.73$ \\
\hline
\end{tabular}




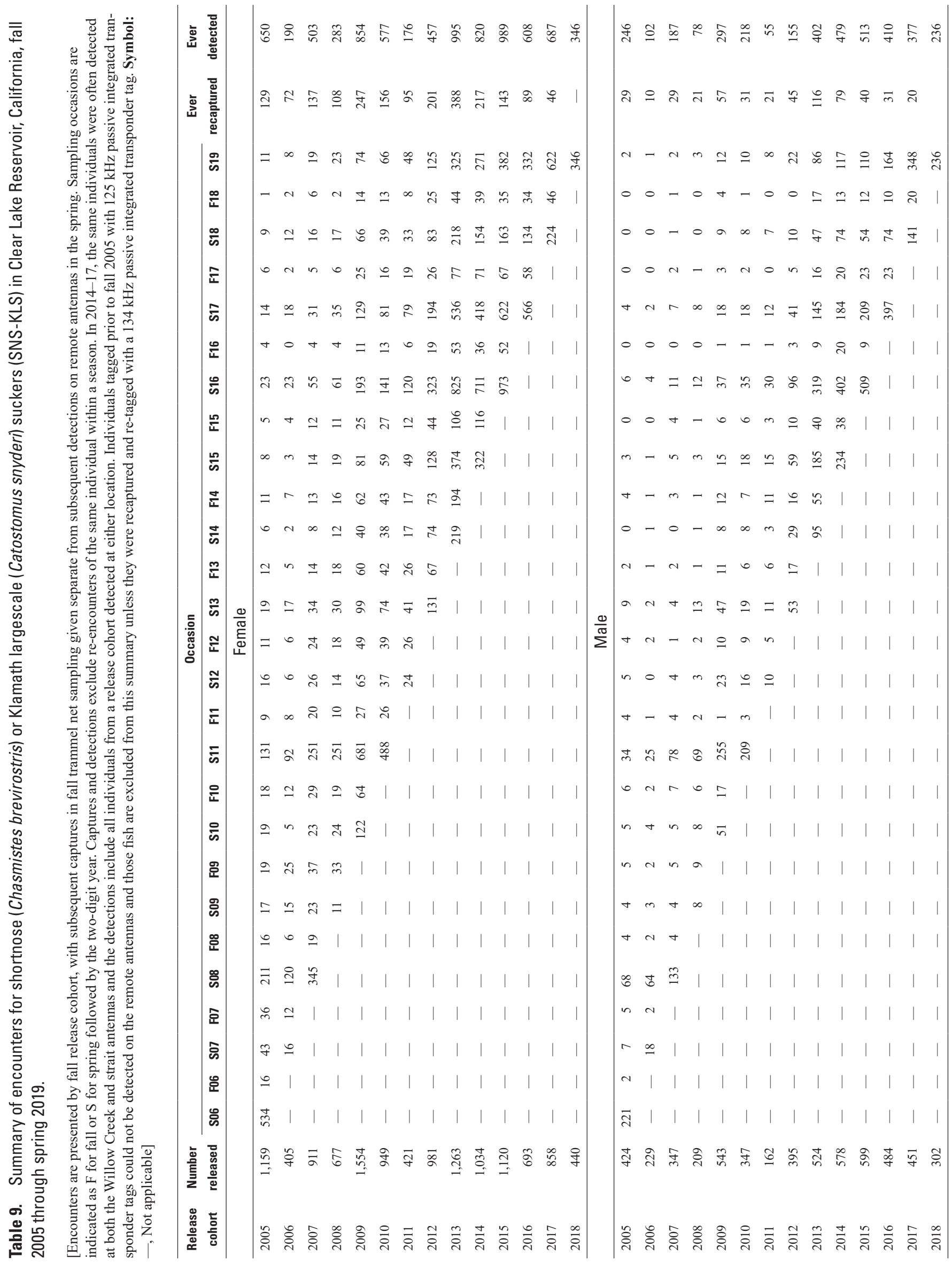


Capture-recapture model selection strongly supported an interactive sex $\times$ time effect on survival of SNS-KLS (table 10). Survival estimates were quite variable over time, ranging from 0.41 to 0.93 (fig. 6). Female survival was higher than male survival in all years except 2015 and 2018, when the estimates were nearly the same (table 11). The largest differences in survival between the sexes were estimated in 2016 and 2017, when 19 percent and 17 percent more males died than females. Model selection supported an additive effect of sex and time on recapture probabilities, and no estimates were on the boundary. Recapture probabilities were somewhat higher than for LRS, but were still rather small (less than 0.18; table 11). In contrast to LRS, SNS-KLS females had slightly higher recapture probabilities than males. Both of the top models included an additive effect of sex and time on $R^{\prime}$, though less supported models in the plausible set included only a time effect. Model-averaged estimates of $R^{\prime}$ for both sexes of SNSKLS were on a boundary at zero in 2012 , but were otherwise more similar between the sexes and more precise compared to the estimates for LRS. Similar to model results for LRS, a fully interactive sex $\times$ time structure for $R$ was included in the top model. However, the second best model included an additive effect of sex and time. All model-averaged estimates of $R$ for SNS-KLS were reasonably precise, and resighting probabilities were similar between the sexes.

Survival for SNS-KLS was low for both sexes in 2006, 2011, and 2013, and male SNS-KLS had relatively low survival in 2016 and 2017 as well. Survival for SNS-KLS was lower on average than for LRS, as expected based on life span, but both sexes of SNS-KLS had higher survival than LRS in 2009, 2014, and 2015. Both LRS and SNS-KLS had low estimated survival in 2013.

Table 10. Model selection results for the Barker capture-recapture models fitted to the data for shortnose sucker (Chasmistes brevirostris) and Klamath largescale sucker (Catostomus snyderi) combined in Clear Lake Reservoir, California, 2005-19.

[Akaike's Information Criterion corrected for small sample size and overdispersion (quasilikelihood AICc [QAICc]) was used to compare the candidate models. In the final model set, only plausible models ( $\triangle$ QAICc less than 15 ) and the full model are shown. In the model names, a $\times$ symbol indicates fully interactive effects and the + symbol indicates additive effects. The best model in the set is presented first, and $\triangle$ QAICc values are the difference between the QAICc value of a given model and that of the best model. Akaike weights $\left(w_{\mathrm{i}}\right)$ provide a measure of the relative weight of each model or the likelihood of it being the best model in the set given the data. Number of parameters $(K)$ is the total number that is theoretically estimable in the model]

\begin{tabular}{|c|c|c|c|c|c|}
\hline Model & $K$ & OAICC & $\triangle Q A I C c$ & $w_{i}$ & Deviance \\
\hline$S($ sex $\times$ time $) p($ sex + time $) r(0) R($ sex $\times$ time $) R^{\prime}(\mathrm{sex}+$ time $) F(1) F^{\prime}(0)$ & 85 & 80523.3 & 0.0 & 0.746 & 8056.6 \\
\hline$S($ sex $\times$ time $) p($ sex + time $) r(0) R($ sex + time $) R^{\prime}($ sex + time $) F(1) F^{\prime}(0)$ & 72 & 80526.0 & 2.7 & 0.195 & 8085.4 \\
\hline$S($ sex $\times$ time $) p($ sex + time $) r(0) R($ sex + time $) R^{\prime}($ time $) F(1) F^{\prime}(0)$ & 71 & 80532.8 & 9.5 & 0.007 & 8094.2 \\
\hline$S($ sex $\times$ time $) p($ sex $\times$ time $) r(0) R($ sex $\times$ time $) R^{\prime}(\operatorname{sex} \times$ time $) F(1) F^{\prime}(0)$ & 110 & 80558.6 & 35.3 & 0.000 & 8041.7 \\
\hline
\end{tabular}


Table 11. Demographic parameter estimates for shortnose (Chasmistes brevirostris) and Klamath largescale suckers (Catostomus snyderi) combined in Clear Lake Reservoir, California.

[Model-averaged estimates of annual survival probabilities (S), recapture probabilities $(p)$, survivor resighting probabilities (R), and non-survivor resighting probabilities $\left(\mathrm{R}^{\prime}\right)$, with 95 percent confidence intervals $(\mathrm{CI})$ for all estimates. Estimates on the boundary at $0.0(\mathrm{~B})$ are shaded gray]

\begin{tabular}{|c|c|c|c|c|c|c|c|c|c|}
\hline Sex & Year & S Est & $\mathrm{S} \mathrm{Cl}$ & $p$ Est & $p \mathrm{Cl}$ & R Est & $\mathrm{R} \mathrm{Cl}$ & R' Est & $\mathrm{R}^{\prime} \mathrm{Cl}$ \\
\hline Female & 2006 & 0.55 & $0.48-0.62$ & 0.023 & $0.01-0.04$ & 0.62 & $0.56-0.67$ & 0.27 & $0.21-0.35$ \\
\hline Female & 2007 & 0.80 & $0.70-0.88$ & 0.052 & $0.04-0.07$ & 0.06 & $0.05-0.09$ & 0.04 & $0.01-0.12$ \\
\hline Female & 2009 & 0.77 & $0.70-0.83$ & 0.075 & $0.06-0.09$ & 0.04 & $0.03-0.06$ & 0.01 & $0.00-0.08$ \\
\hline Female & 2010 & 0.81 & $0.76-0.86$ & 0.060 & $0.05-0.07$ & 0.06 & $0.05-0.07$ & 0.08 & $0.05-0.12$ \\
\hline Female & 2012 & 0.81 & $0.71-0.88$ & 0.084 & $0.07-0.10$ & 0.09 & $0.08-0.11$ & $0.0 \mathrm{~B}$ & NA \\
\hline Female & 2013 & 0.50 & $0.47-0.53$ & 0.160 & $0.14-0.18$ & 0.17 & $0.15-0.19$ & 0.13 & $0.11-0.15$ \\
\hline Female & 2014 & 0.88 & $0.85-0.91$ & 0.179 & $0.16-0.19$ & 0.14 & $0.13-0.16$ & 0.19 & $0.14-0.26$ \\
\hline Female & 2015 & 0.80 & $0.77-0.82$ & 0.130 & $0.12-0.14$ & 0.30 & $0.28-0.33$ & 0.32 & $0.28-0.37$ \\
\hline Female & 2016 & 0.65 & $0.62-0.67$ & 0.080 & $0.07-0.09$ & 0.98 & $0.97-0.98$ & 0.71 & $0.68-0.75$ \\
\hline Male & 2007 & 0.70 & $0.56-0.81$ & 0.038 & $0.03-0.05$ & 0.06 & $0.03-0.11$ & 0.04 & $0.01-0.14$ \\
\hline Male & 2008 & 0.65 & $0.49-0.79$ & 0.024 & $0.02-0.03$ & 0.46 & $0.39-0.53$ & 0.30 & $0.21-0.40$ \\
\hline Male & 2009 & 0.64 & $0.51-0.74$ & 0.056 & $0.05-0.07$ & 0.04 & $0.02-0.07$ & 0.01 & $0.00-0.10$ \\
\hline Male & 2010 & 0.78 & $0.69-0.85$ & 0.044 & $0.04-0.05$ & 0.07 & $0.05-0.09$ & 0.10 & $0.07-0.15$ \\
\hline Male & 2011 & 0.55 & $0.44-0.65$ & 0.033 & $0.03-0.04$ & 0.81 & $0.73-0.88$ & 0.38 & $0.30-0.46$ \\
\hline Male & 2012 & 0.73 & $0.59-0.84$ & 0.063 & $0.05-0.07$ & 0.11 & $0.08-0.14$ & $0.0 \mathrm{~B}$ & NA \\
\hline Male & 2013 & 0.41 & $0.36-0.46$ & 0.122 & $0.11-0.14$ & 0.19 & $0.15-0.24$ & 0.15 & $0.13-0.19$ \\
\hline Male & 2014 & 0.86 & $0.80-0.90$ & 0.137 & $0.12-0.15$ & 0.15 & $0.12-0.18$ & 0.23 & $0.17-0.31$ \\
\hline
\end{tabular}

\section{Discussion}

The spawning migrations, changes in size composition, and annual survival of endangered sucker populations in Clear Lake Reservoir are dynamic. Our monitoring of the populations that began in 2004, with a focus on re-encountering PITtagged individuals, has now yielded substantial insight into these dynamics. Trammel net sampling in the fall has been successful at capturing suckers and thousands of individuals of each endangered taxon have been PIT-tagged. However, rates at which PIT-tagged fish are recaptured in trammel nets during fall sampling, particularly for LRS, are too low for capturerecapture modeling to be effective for estimating survival or abundance. Beginning in 2006, the use of remote antennas in the lower part of Willow Creek to detect (re-encounter) PIT-tagged individuals has described in detail the factors that influence the timing, magnitude, and overall success of the spawning migrations. Detections in Willow Creek, combined with detections on an array of remote antennas in the strait between the reservoir lobes in 2014-17, provided sufficient re-encounters to allow capture-recapture modeling of annual survival. Installation of the remote PIT tag antenna array in the strait between the lobes was essential to modeling efforts, providing detections of suckers even when spawning migrations into Willow Creek were impeded or limited by low instream flows. 


\section{Inference about Recruitment from Changes in Size Composition}

Inference about recruitment based on long-term changes in the size composition of suckers captured in trammel nets in Clear Lake Reservoir is more complex than for the sucker populations in Upper Klamath Lake. In a previous report, we presented length composition data from trammel net catches in the reservoir dating back to 1993 (Barry and others, 2009). Those data showed that the population of LRS "turned over," transitioning from a relatively homogeneous population of larger individuals $500-700 \mathrm{~mm}$ FL to one comprised of smaller individuals 300-450 mm FL. The transition occurred over a relatively short time frame between 1996 and the early 2000s, suggesting that substantial mortality had occurred for the larger individuals and a large new cohort of individuals had joined the population. This new cohort was first observed as substantial catches of LRS 300-350 mm FL in 1996, but the sex of those individuals was not determined (Leeseberg and others, 2007). Past monitoring at Clear Lake Reservoir showed that spawning migrations were severely impeded or blocked by low lake levels and low instream flows in 1992, but that many years were adequate for spawning between 1993 and 2002. Trap net catches in 1993 indicated that a particularly strong year class of suckers (taxa unknown) was produced in that year (Scoppettone and others, 1995), and it seems reasonable that at least the 1993 year class contributed to the new cohort observed in the 2000 trammel net catches.

By 2004 at the start of this study, very few LRS were captured that were larger than $550 \mathrm{~mm}$ FL. From 2004 to 2014, the new cohort of smaller individuals that were first captured in 2000 remained the dominant cohort of individuals in the trammel net catches. By 2014, the size composition was similar to the size composition of LRS that were captured in 1993 before the turnover (Barry and others, 2009). However, new cohorts of smaller individuals $300-400 \mathrm{~mm}$ FL were evident in a number of years, including 2007, 2008, and 2012. These cohorts of smaller fish may actually be more abundant than they appear based on trammel net catches because of the known selectivity of the nets for fish larger than $300 \mathrm{~mm}$ FL.

The smaller individuals in the 2004 catches were likely spawned between 1996 and 2000, a period with high water levels and moderate to high flows in Willow Creek. The cohort first observed in substantial numbers in 2007 may have included individuals from that period as well, but probably also individuals spawned in 2002. Instream flows were low in 2001 and probably prevented a substantial spawning migration that year. The cohort of smaller individuals observed in 2012 was likely spawned in 2006 and 2008, but spawning in 2004 may have contributed as well. A new cohort of smaller female LRS was evident in trammel net catches in 2015. This cohort was not as apparent in catches of male LRS, but the median size of male LRS decreased substantially in 2015. This new cohort likely includes fish spawned in 2011, but the larger size of this cohort (350-450 mm FL) indicates that fish from spawning in 2006 and 2008 are probably also included.
Finally, a large new cohort of smaller LRS was first captured in 2018 and made up the majority of the catch in 2019. These fish were likely spawned between 2011 and 2013 (Bart and others, 2020).

Despite the addition of new cohorts of smaller individuals in a number of years, the time series of size composition plots seem to show that the vast majority of these new LRS cohorts observed through 2012 died before growing to 400 $\mathrm{mm}$ FL. In particular, the cohort first observed as a substantial part of the catches in 2007 did not appear to survive and grow over the next few years. The exception to this pattern appears to be the size composition of females observed in 2015, which may include individuals surviving from spawning as far back as 2006. Small suckers of either LRS or SNS-KLS are sometimes misidentified as females when captured in trammel nets in the fall, but are observed to be males when recaptured at larger sizes. Therefore, the catches in 2015 may actually include more males and the new cohort may be more balanced between the sexes. However, trammel net catches of LRS have tended to include more females, and it cannot be ruled out that the shift in median size for male LRS is at least partly due to mortality.

Similar to LRS, size composition data presented in Barry and others (2009) showed that the population of SNS-KLS transitioned from a relatively homogeneous population of larger individuals in 1996 (average size about $420 \mathrm{~mm} \mathrm{FL}$ ) to one comprised of smaller individuals (average size about $335 \mathrm{~mm} \mathrm{FL}$ ) by 2004. Although the total number of SNS-KLS captured in 2000 was relatively small, trammel net catches in that year showed the two size groups in approximately equal numbers. By 2004, very few SNS-KLS larger than $400 \mathrm{~mm}$ FL were captured in trammel nets. As with LRS, a substantial amount of mortality apparently occurred in a short time period for the larger individuals, and the new individuals were presumably spawned in years with sufficient instream flows back to at least 1993.

The time series of size composition for SNS-KLS from 2004 to 2019 shows that more recruitment occurs for SNSKLS than for LRS. However, interpretation of the changes in size composition is more challenging because the capture efficiency of the trammel nets is lower for smaller fish around $300 \mathrm{~mm}$ FL, and the size of newly recruited SNS-KLS overlaps more with that size range. The recruitment of new cohorts of smaller individuals is readily apparent in some years (for example, 2015 and 2019), but the size of the new cohorts relative to the remaining individuals is less clear. Changes in the shape of the distributions along with a decrease in the median size of captured individuals indicate some recruitment in other years as well (for example, 2009 and 2012).

Similar to LRS, the smaller individuals in the 2004 catches were likely spawned between 1996 and 2000, a period with high water levels and moderate to high flows in Willow Creek. Spawning in 2004, 2006, and 2008 probably contributed new recruits to the catches in 2009-12, but connecting spawning years with the recruitment of new cohorts is not as straightforward as it is for Lost River suckers. Spawning 
in 2011 probably contributed substantially to the large new cohort of small SNS-KLS of both sexes that were captured in 2015 and 2016. However, given their large size at capture and the growth rate of SNS-KLS in Clear Lake (Bart and others, 2020), we cannot rule out that these fish were spawned in 2006-08. By 2017, this new cohort was not readily detectable in the size composition due to growth. A large, distinct new cohort of smaller SNS-KLS of both sexes was detected in the catch in 2019. Because spawning migrations were so limited in 2014 and 2015, it is reasonable to consider that these fish may have been spawned in 2016. Annual juvenile sucker monitoring with trap nets indicated that the 2016 cohort of SNS-KLS in Clear Lake averaged less than $200 \mathrm{~mm}$ FL in 2017 and less than about $220 \mathrm{~mm}$ FL in 2018 (Bart and others, 2020). This cohort appeared to be no longer vulnerable to trap nets in 2019. Given annual growth rates, it is unlikely that the majority of the 2016 year class was greater than $300 \mathrm{~mm}$ FL by 2019. The small SNS-KLS captured in trammel nets in 2019 may represent the largest individuals of the 2016 cohort, or these fish may have been spawned prior to 2014. Tracking this cohort over the next few years will help to determine which of these explanations is correct.

\section{Spawning Migrations, Survival, and Population Dynamics}

From 2006 to 2019, spawning migrations were unimpeded for most or all of the spawning season in years with sufficient instream flows in Willow Creek (8 of 14 years), but access to Willow Creek was impeded for at least part of the spawning period in other years due to low water levels in the reservoir. For both LRS and SNS-KLS, upstream spawning movements within a season were not correlated with the magnitude of instream flows, but rather occurred when water temperatures were increasing and slowed or stopped when water temperatures were decreasing. These results are similar to findings for LRS and SNS that spawn in tributaries to Upper Klamath Lake, as well as other suckers in the western U.S. (Fraser and others, 2017, and references therein). Migrations of both LRS and SNS-KLS began as early as late January when water temperatures were as low as $2-3^{\circ} \mathrm{C}$. The control that water temperature exerted on the upstream migrations was most evident in years when access to Willow Creek was unimpeded or impeded only for a short time and instream flows were high, including 2006, 2008, 2011, and 2016-19 (appendix 2). In 2016-19, Reclamation data include discharge measurements in Willow Creek, and the pattern of discharge was not well correlated with water temperature or timing of the migrations. Increases in discharge were sometimes associated with increases in water temperature and other times were associated with decreases in water temperature. Thus, suckers were responding to fluctuations in water temperature rather than fluctuations in discharge.

Total detections on the Willow Creek remote PIT tag antennas indicated that the taxa differ in their willingness to navigate shallow water in order to spawn. Lost River suckers tended to migrate in relatively larger numbers than SNS in years with restrictive instream flows and reservoir water levels (for example, 2012). However, sex ratios indicate that the migrations in such years tended to be skewed to male LRS, which are smaller on average than female LRS. In contrast, in years with high instream flows such as 2017 and 2019, more female LRS were detected in Willow Creek than males. In general, the sex ratio of LRS detected in Willow Creek was almost always skewed towards males, despite far more females having been tagged in fall trammel net sampling. Capture-recapture models show that females have lower detection probabilities compared to males rather than lower survival. Recent results from a telemetry study indicate that LRS make less extensive migrations into the tributaries, so perhaps SNS-KLS require more instream flow to support more extensive migrations into a watershed where flows can be limited (Banet and others, in press). Given the apparent lower abundance of LRS overall, the more limited evidence of recruitment for LRS as compared to SNS-KLS, and the sex ratio that favors males more so than for SNS-KLS, concerns about population sustainability are likely greatest for LRS in the reservoir.

As noted above, it is challenging to infer changes in the age structure of the Clear Lake sucker populations or the magnitude of recruitment events based on size composition from fall trammel net sampling. Prior conclusions about robust populations or stable populations that showed diverse age structure were a product of the immediately preceding decade or two regarding recruitment. Based on the long-term history of estimated inflows, such a conclusion that was reached in 1993 would have reflected successful spawning in the mid1960s to mid-1970s and most of the early to mid-1980s. The larger fish in the population in the mid-1990s would have survived through a drought lasting from summer of 1991 to March of 1993. Although both taxa have added new recruits to their populations since 2004, it is not clear what the magnitude of those gains has been relative to the existing populations. Nonetheless, based on the evidence we have, it appears that SNS-KLS have added more individuals more often than LRS. Furthermore, we observed an apparent near-complete disappearance of the cohort of LRS first observed in trammel net catches in 2007; low estimated survival for LRS in 2008 and especially 2009 are correlated with the disappearance of this cohort. 
Predation by colonial nesting waterbirds, especially American white pelicans (AWPE) and double-crested cormorants (DCCO), is one factor contributing to low survival in some years (Evans and others, 2016). Estimated minimum predation rates on suckers in Clear Lake Reservoir were highest in 2009 and 2013 for both LRS and SNS-KLS, years with large colonies of AWPE, and were also relatively high for SNS-KLS in 2011 and LRS in 2015. Except for our estimated survival of SNS-KLS in 2009, which was about average, these years of high predation by birds correspond with low estimated annual survival from capture-recapture modeling. Although we do not have estimated predation rates for years after 2015, we do have data on the number of PIT tags recovered on nesting colonies relative to the number of PIT tags known to be at large in the populations. Of note is a large proportion of PIT tags recovered from male SNS-KLS in 2016, but not female SNS-KLS, which is in agreement with the particularly low estimated survival of males in that year. Future analyses of predation rates will provide more conclusive information about the contribution of predation to sucker survival, particularly for years after 2015.

Although research has not been conducted on the behavior of avian predators in this system, predation can occur during spawning migrations into and out of tributaries, or in the lake during the summer chick rearing period. Regarding behavior, AWPE are restricted to foraging in water of depth of about $3 \mathrm{ft}$ or less, whereas DCCO are pursuit divers that can forage throughout the reservoir. Bird predation during spawning is a function of when birds return to the Basin for nesting. In some years, fish began migrations early and would have been in the tributaries prior to the return of large numbers of DCCO or AWPE. However, late migrating suckers and fish returning to the reservoir after spawning could have been vulnerable to predation. Although the arrival of DCCO and AWPE in the Basin during spring depends on annual differences in weather patterns, both species tended to begin arriving in the area in the third week of February, with substantial numbers present in the second or third week of March. Future research is planned to elucidate the amount of predation that is due to each of the avian predators, but we note that AWPE are more numerous on Clear Lake nesting colonies, substantially so in most years (Evans and others, 2016).

Estimated annual survival was slightly higher on average for LRS than for SNS-KLS and higher for females compared to males, as expected based on results from Upper Klamath Lake (Hewitt and others, 2017). However, survival varied considerably among years and was often lower than has been observed for populations in Upper Klamath Lake. One year had low survival for both species (2013), but other years had low survival for only LRS $(2009,2015)$ or SNS-KLS (2006, 2011). Interestingly, in 2016 and 2017 survival was low only for male SNS-KLS, whereas female SNS-KLS and LRS survival was closer to average. In 2013, a year in which survival was relatively low for all suckers, reservoir water level and instream flows were just sufficient to allow both species to make a small to moderate spawning migration in a constrained time period. A possible explanation for the low survival is bird predation on fish migrating through shallow water. Regarding low survival of LRS in the drought year of 2015, telemetry data showed that LRS made a migration to the east lobe but could not access the dam channel and Willow Creek, apparently leading to mortality in the east lobe (Banet and others, in press). In that year, low reservoir water level appears to have discouraged a spawning migration by SNS-KLS. In 2016, reservoir water level was higher than in 2015 but still below $4,524 \mathrm{ft}$ for most of the spawning migrations, perhaps contributing to avian predation and low survival for male SNSKLS. In contrast, survival of all suckers was relatively high in 2010 and 2014, years in which low reservoir water level and low inflows appear to have prevented or discouraged any substantial spawning migrations. Lastly, survival of SNS-KLS was relatively low in years when conditions permitted long and extensive spawning migrations into the tributaries (2006, 2011, 2016, and 2017). Telemetry data in 2016 and 2017 showed the extent of these migrations and the pattern of SNSKLS migrating farther than LRS (Banet and others, in press). That study documented mortality of SNS-KLS that migrated far up into the tributaries, indicating that these fish were unable to return to the reservoir before flows receded.

Regarding assumptions of the Barker capture-recapture models, temporary emigration is a potential issue, mostly for SNS-KLS, because without more sampling in the tributaries we cannot inform the $F$ and $F^{\prime}$ parameters. By setting them to zero and one, respectively, we are assuming that all individuals return to the reservoir to be subject to capture or detection. One piece of evidence suggests that some SNS-KLS may not return to the lake after spawning and will instead reside in tributaries. In summer of 2016, while electrofishing in isolated in-channel spring pools in upper Willow Creek approximately $30 \mathrm{~km}$ upstream from Clear Lake Reservoir, biologists from USFWS captured an adult SNS-KLS that had been PIT-tagged and released in the reservoir many years prior. However, given the limited habitat suitable for suckers to hold over in the tributaries, we expect that the proportion of the population that expresses this behavior is small and has little effect on survival estimates. In a similar way, the distribution of suckers in the reservoir in the fall may not fully overlap with the area that can be targeted by trammel net sampling. Although the dominant behavior pattern is a migration out of the west lobe, into the tributaries to spawn, and then a return to the west lobe, individual behavior varies among years depending on the reservoir water level (Banet and others, in press).

The $F$ parameters in Barker models are linked to recaptures and recapture probability for their precision and bias, so our low recapture probabilities, especially for LRS, are also problematic for estimating $F$. Any increase in recapture probabilities would improve estimation. Future modeling could consider including "dead recovery" information from the recovery of sucker PIT tags on waterbird nesting colonies (Evans and others, 2016), as well as telemetry detections as live resightings outside of the sampling area, which are key to informing the $F$ and $F^{\prime}$ parameters. For avian predation, such models would have to account for uncertainty concerning the timing of death (consumption) and the related probability of 
encountering a PIT tag that is deposited on a colony, which is less than 1.0. This latter probability is the subject of ongoing research. Ideally, to cover all assumptions of the Barker models there would be antennas in various places throughout the tributaries, but this is logistically infeasible in some water years. The resighting parameters $R$ and $R^{\prime}$ can be challenging to estimate, particularly $R^{\prime}$ - the probability that a fish dies between fall sampling periods but is detected before it dies. In years when little spawning occurred and before the antennas were installed in the strait $(2007,2009,2010,2012)$, there are little data to inform these resighting parameters and estimates were often low, imprecise, or both. However, more informative and precise estimates in years with good spawning migrations and detections from the strait antennas allowed for more complex model structures and unbiased estimation of survival by compensating for the poor recapture probabilities in trammel nets (Conner and others, 2015).

Much has been learned about the factors that affect sucker population dynamics in Clear Lake. However, a more complete understanding of dynamics of survival and factors that contribute to mortality will be informed by more years of reliable survival estimates with contrast among the factors such as avian predation, the extent of spawning migrations, reservoir water level, and Willow Creek inflows. Planned research on avian predation will be particularly informative given the apparent role of predation in population dynamics. Future studies will estimate PIT tag deposition probabilities on waterbird nesting colonies, and thus more robust estimates of avian predation rates, as well as information about the extent of predation attributable to the two avian predators.

\section{Implications for Water Management}

Management of irrigation deliveries from Clear Lake and resulting changes in water surface elevation in the reservoir have direct effects on spawning success and apparent indirect effects on survival for endangered suckers. Low water level in the reservoir, as observed in many of the years during this study, was relatively uncommon outside of the 1930s Dust Bowl and a few other years (fig. 7). Our findings should be useful to management agencies as they seek to balance the needs for water for irrigation and the needs of endangered sucker populations in the reservoir, particularly during drought conditions.

Soon after the federal government listed the two sucker taxa as endangered in 1988 (USFWS, 1988), the Upper Klamath Basin experienced a substantial drought during water years of 1990-92. Clear Lake Reservoir and its watershed were affected and inflows to the reservoir were low (fig. 7). In 1991 and 1992, water levels were low enough in the reservoir that Reclamation and USFWS investigated the effects on suckers and eventually salvaged and relocated suckers from the east lobe dam channel. Because of the anticipated desiccation of the east lobe and dam channel by the end of the summer in 1992, an interim Biological Opinion (BO) was developed in January 1992 (USFWS, 1992a). That BO suggested a minimum water surface elevation of 4,524 ft during the spawning season (defined as February 1 to April 15) to protect connectivity with the tributaries for spawning adults and emigrating larvae. The $\mathrm{BO}$ noted that under normal conditions 80 percent or more of larvae would have emigrated by April 15, the usual start of irrigation season. The long-term operations $\mathrm{BO}$ issued in July 1992 (USFWS, 1992b) retained the suggested minimum surface elevation of 4,524 ft during the spawning season, and added a suggestion for $4,523 \mathrm{ft}$ as the minimum during the remainder of the year out of concern for suckers rearing and foraging in the east lobe. The east lobe desiccates at about $4,520 \mathrm{ft}$, and the reasoning was water levels lower than $4,523 \mathrm{ft}$ could increase risk of avian predation and perhaps allow water quality to deteriorate to unsatisfactory conditions, particularly over the winter. Noting that desiccation of the east lobe was nearly certain to occur in 1992, a further suggestion was made to maintain water elevations in the west lobe of at least 4,521 ft to protect suckers during extended droughts. Acknowledging natural variability in inflows for the watershed, the BO in July 1992 (USFWS, 1992b) allowed for operations to deviate from these suggestions in 4 out of 10 years, or up to 4 years consecutively. It also allowed for irrigation deliveries and desiccation of the east lobe in low water years as long as water level in the west lobe could be maintained at $4,521 \mathrm{ft}$ or higher as a refuge for suckers. These requirements envisioned that management of the water levels in the two lobes of the reservoir could be separated, suggested that east lobe water could be moved to the west lobe if needed, and also noted that establishment of a dike between the two lobes to maintain water in the west lobe at $4,521 \mathrm{ft}$ would be required in 1992. Finally, a minimum surface elevation of 4,522 ft in the dam channel would be required following irrigation season (October 1-April 14) as a refuge for suckers during extreme conditions when the west lobe was too low to be suitable.

Precipitation during the winter of 1992-93 ended the drought and the water level in Clear Lake Reservoir recovered. A new Biological Assessment (BA) issued in 1994 proposed to operate Clear Lake to maintain a minimum elevation of 4,521 $\mathrm{ft}$ on October 1 each year (USBR, 1994). The BA presented a spreadsheet model to show that this water level was sufficient in most years to meet the 4,519 ft "hard floor" in winter and the 4,524 ft minimum for spawning access the following spring. It was also expected that in an extended drought this water level would keep the reservoir from dropping below $4,519 \mathrm{ft}$ through the next year (with no releases for irrigation) in all but the three worst drought years observed since 1919 (1931, 1934, 1992). Multiple year droughts were considered to occur with low probability, but the BA noted that the 4,521 $\mathrm{ft}$ October 1 minimum provided some protection even during historic multiple year droughts. A sequence of 3 or more years of low inflows had only occurred in the 1930s Dust Bowl and 1959-61. Notably, the 1994 BA showed that the 4,521 ft October 1 target would not provide the $4,524 \mathrm{ft}$ water level needed for spawning access to the tributaries on February 1 or March 1 in more than 50 percent of years based on inflow exceedance calculations (USBR, 1994). However, it would provide 4,524 ft for spawning by April 1 in more than 70 percent of years. 


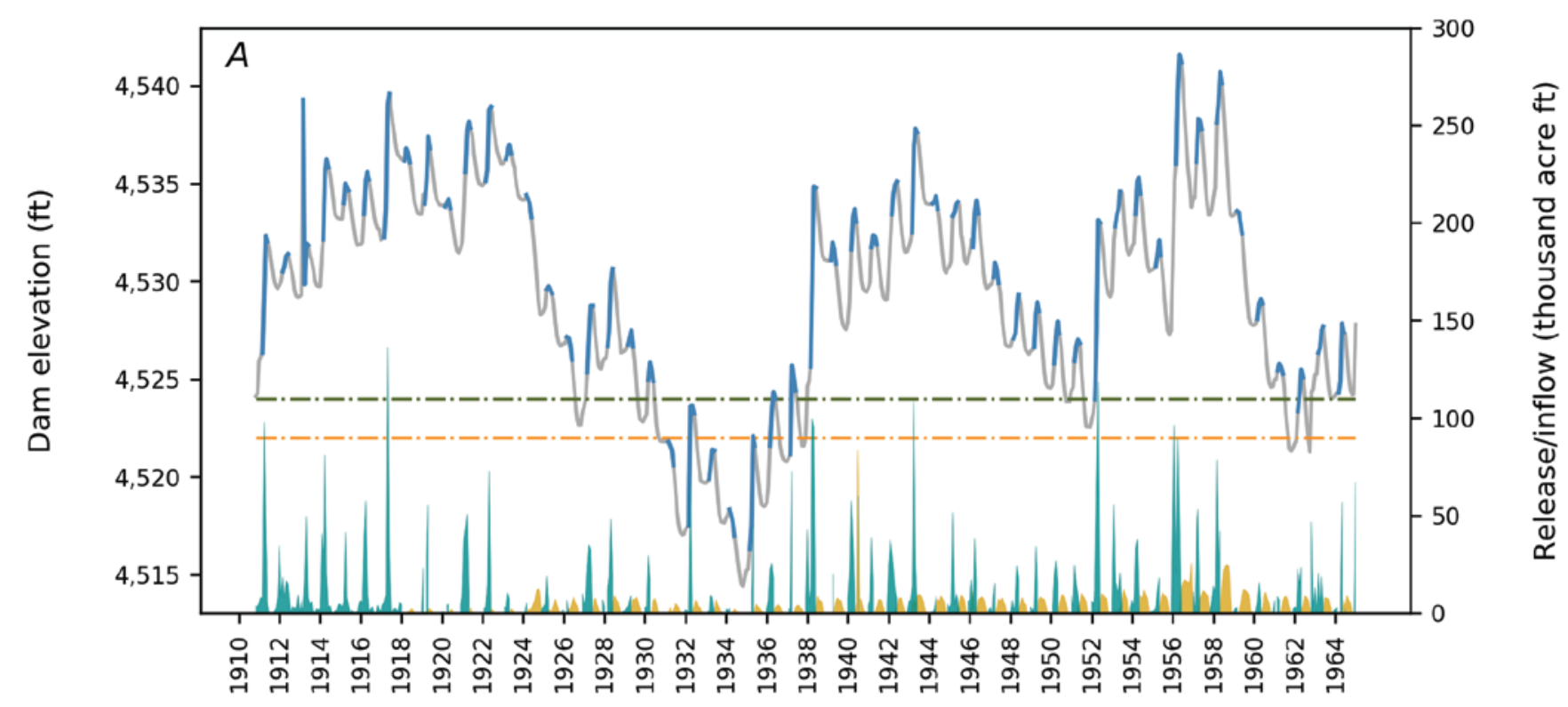

Year

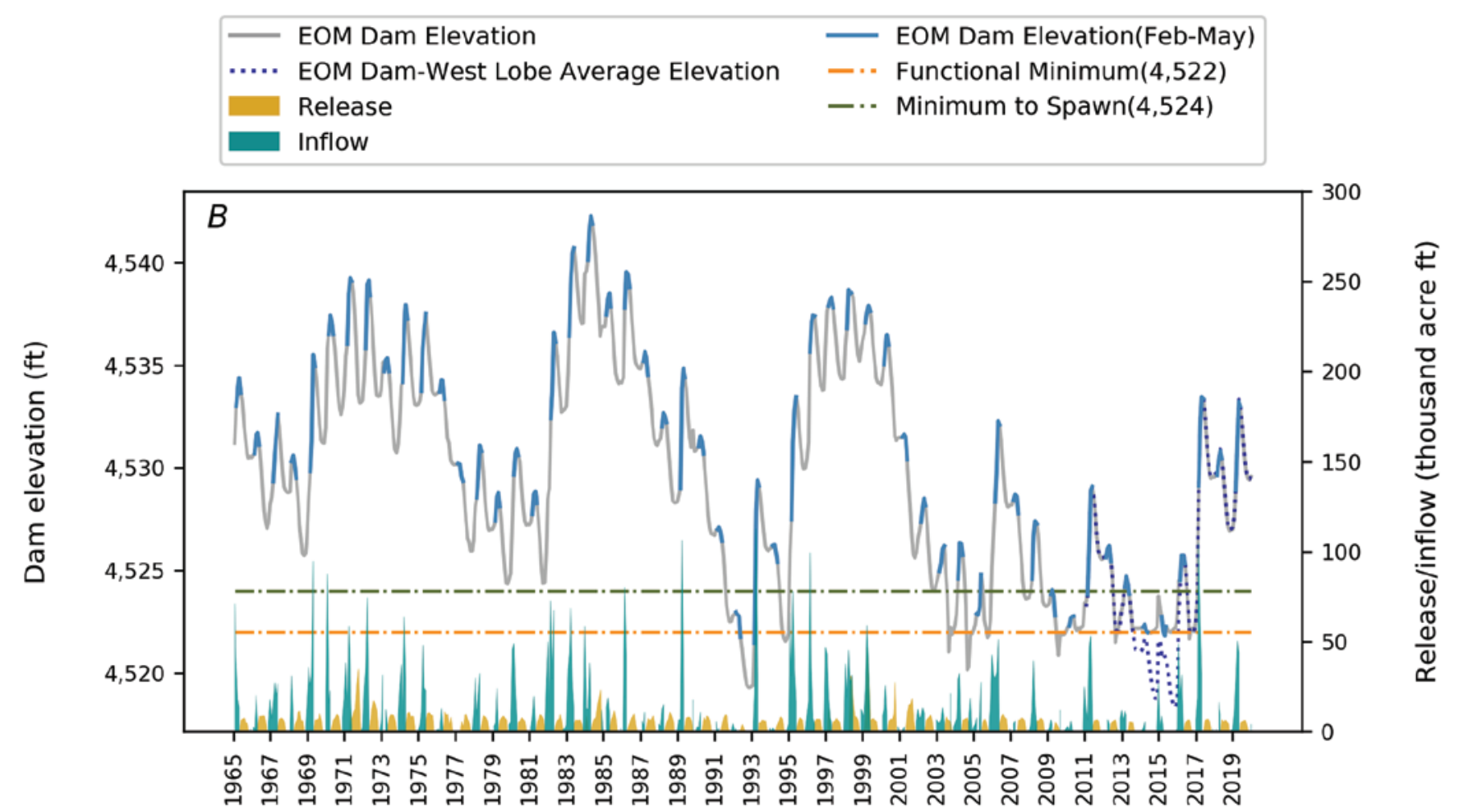

Year

Figure 7. End-of-month water surface elevations, Clear Lake Reservoir, California, 1910-2019. Elevations for February through May are highlighted in blue. For years after 2011 when a gage was added in the west lobe of the reservoir, elevations are averaged across that gage and the one at the dam. Sources for elevations, inflows, and releases are provided in appendix 1, figure 1.1. The approximate minimum water surface elevation needed for sucker spawning (4,524 feet) and the current operational minimum elevation $(4,522$ feet) are indicated with horizontal lines. 
In the 1994 BO (USFWS, 1994), the USFWS reviewed the BA modeling and requested a water conservation strategy, noting that the proposed operating floor of $4,521 \mathrm{ft}$ on its own would not provide adequate protection for suckers because of the potential for continued desiccation even without irrigation releases. The USFWS noted that the primary concern was the threat of winter kill with low water levels, and concluded that the reservoir should be managed to keep water levels well above the operating floor to reduce the chances of going into an extended drought with low water levels. Although Reclamation monitoring during the winters of 1991 and 1992 did not indicate that water quality conditions were threatening, the apparent condition of fish captured in the spring of 1993 was deemed to be poor and interpreted as having been caused by overwinter conditions. Nonetheless, the USFWS accepted the proposed operating floor of 4,521 ft because (1) water levels that low were very uncommon in the past, (2) Reclamation was not proposing to draw the reservoir down to the operating floor in every year, (3) it was unlikely that the "hard floor" of 4,519 ft would be reached even if the operating floor was reached by October 1, and (4) Reclamation provided assurances that in low inflow years irrigation deliveries would be curtailed if the operating floor was forecast to be crossed by October 1. Notably, irrigation deliveries would occur at a reduced level even when April 1 water level was below 4,524 $\mathrm{ft}$, the minimum surface elevation for spawning access to the tributaries (USFWS, 1994).

Following a period of high inflows during the latter half of the 1990s, relatively low inflows to the reservoir in the early 2000s coincided with a new consultation between Reclamation and USFWS that concluded in 2002 (USFWS, 2002). Water management in Clear Lake was changed to a system in which water years were categorized according to forecasted inflows, and irrigation deliveries would be managed to maintain water levels above end-of-month minimums calculated as the averages from the 10-year period 1990-99 (table 12). The 2002 BA repeated earlier cautions about the need for water levels above 4,524 ft for spawning access in the spring, the potential for adverse habitat and predation in the east lobe at water levels lower than $4,524 \mathrm{ft}$, and the possibility of multiple years of low water given the low recharge rate for the reservoir (USBR, 2002). In the water year categorization, only Dry and Critically Dry years were expected to have conditions that might negatively affect suckers. Subsequent consultations that concluded in 2008 and 2013 did not alter this approach, except that the 2013 BO eliminated the monthly water level minimums and reported only the proposed minimum for the end of September in a Critically Dry year (NMFS and USFWS, 2013). This surface elevation of $4,520.6 \mathrm{ft}$ at the end of the irrigation season was expected to occur in only 5 percent of years based on the period of record, but the $\mathrm{BO}$ noted that it had occurred in 2004 and 2010 and might be more common than the period of record indicated.
Similar to the 1994 consultation, the water level of 4,520.6 ft was considered to be the lowest end-of-September water level that would allow the water level to rise above 4,524 ft by the following March, providing access to spawning tributaries even in a Critically Dry year (table 12). For comparison, based on the period of record back to water year 1911, the average change in water level from the end of September to the end of February has been $1.6 \mathrm{ft}$ (range = $-0.9-8.6 \mathrm{ft}$ ). The water level has increased over that part of the year by $3.4 \mathrm{ft}$ in only 20 of 109 years (18 percent), and rarely in years that would be characterized as Critically Dry. Furthermore, our results show that spawning migrations can actually begin in late January to early February depending on water conditions, and sufficient access to the tributaries would be even less likely by that time. Finally, the minimum end-ofSeptember water level of 4,520.6 ft was below the functional (operational) minimum draw-down level of $4,522 \mathrm{ft}$ that had been noted in 1994 and was illustrated by water level records since that time (fig. 7).

Hydrology in the Clear Lake Reservoir watershed during our study did not meet the expectations that were developed in 2002 and that have continued to the present for Clear Lake operations. Water levels and inflows have overall been lower than in the preceding decades back to the Dust Bowl years (with the exception of the early 1990s). Low end-ofSeptember water levels have not been followed by increases to $4,524 \mathrm{ft}$ or above to allow spawning migrations to begin in February (fig. 8). Indeed, the water level in the spring was below that level at some point in the spawning season in more than half of the years during the study period. Water years have often resulted in water levels that would have in the past been considered Critically Dry, ending at water levels near the functional minimum of 4,522 ft more often than anticipated.

Our results regarding spawning access to the tributaries show that the 4,524 ft water level requirement, which has been mentioned repeatedly in past consultations, is still relevant. Furthermore, our results show that in nearly every year when access to the tributaries is unimpeded, the vast majority of fish begin their spawning migrations well before April 1. Our results also show that avian predation is indeed a concern for Clear Lake suckers, supporting minimum water level requirements in the east lobe that account for that risk. When water levels in the east lobe are 4,524 ft, most of the east lobe is less than $3 \mathrm{ft}$ deep, and migrating suckers are exposed to potential predation from both DCCO and AWPE. At such low water levels, migrating suckers also have to pass through a "pinch point" at the western end of the dam channel, where the water may be only $1-2 \mathrm{ft}$ deep. The 2013 BO indicates that the elevation of the reservoir bottom at that location is $4,522 \mathrm{ft}$, such that a water level of more than $4,525 \mathrm{ft}$ would be needed to provide $3 \mathrm{ft}$ depth at that point in the migration and some protection from avian predation (NMFS and USFWS, 2013). 
Table 12. End-of-month minimum water levels (ft above mean sea level) expected for Clear Lake Reservoir under the 2002/2008 proposed action across different water year types.

[Reproduced from the 2008 Biological Opinion (USFWS, 2008). The 2012 Biological Assessment (USBR, 2012) and 2013 Biological Opinion (NMFS and USFWS, 2013) simplified this table to a single entry for the end-of-September value for critically dry years, $4,520.6$ feet]

\begin{tabular}{lcccc}
\hline \multirow{2}{*}{ Month } & \multicolumn{4}{c}{ Water year type } \\
\cline { 2 - 5 } & Above average & Below average & Dry & Critically dry \\
\hline October & $4,531.2$ & $4,526.8$ & $4,522.5$ & $4,520.4$ \\
November & $4,531.0$ & $4,526.8$ & $4,522.5$ & $4,520.5$ \\
December & $4,531.5$ & $4,526.7$ & $4,522.8$ & $4,520.7$ \\
January & $4,532.4$ & $4,527.0$ & $4,522.9$ & $4,522.6$ \\
February & $4,531.9$ & $4,531.1$ & $4,527.0$ & $4,524.6$ \\
March & $4,534.6$ & $4,531.5$ & $4,527.1$ & $4,524.6$ \\
April & $4,535.3$ & $4,531.2$ & $4,526.9$ & $4,524.6$ \\
May & $4,535.3$ & $4,530.6$ & $4,526.4$ & $4,523.6$ \\
June & $4,534.7$ & $4,529.9$ & $4,525.7$ & $4,522.8$ \\
July & $4,533.8$ & $4,528.8$ & $4,524.5$ & $4,521.8$ \\
August & $4,532.8$ & $4,527.7$ & $4,523.5$ & $4,520.6$ \\
September & $4,532.1$ & $4,527.1$ & $4,522.8$ & $4,520.6$ \\
\hline
\end{tabular}




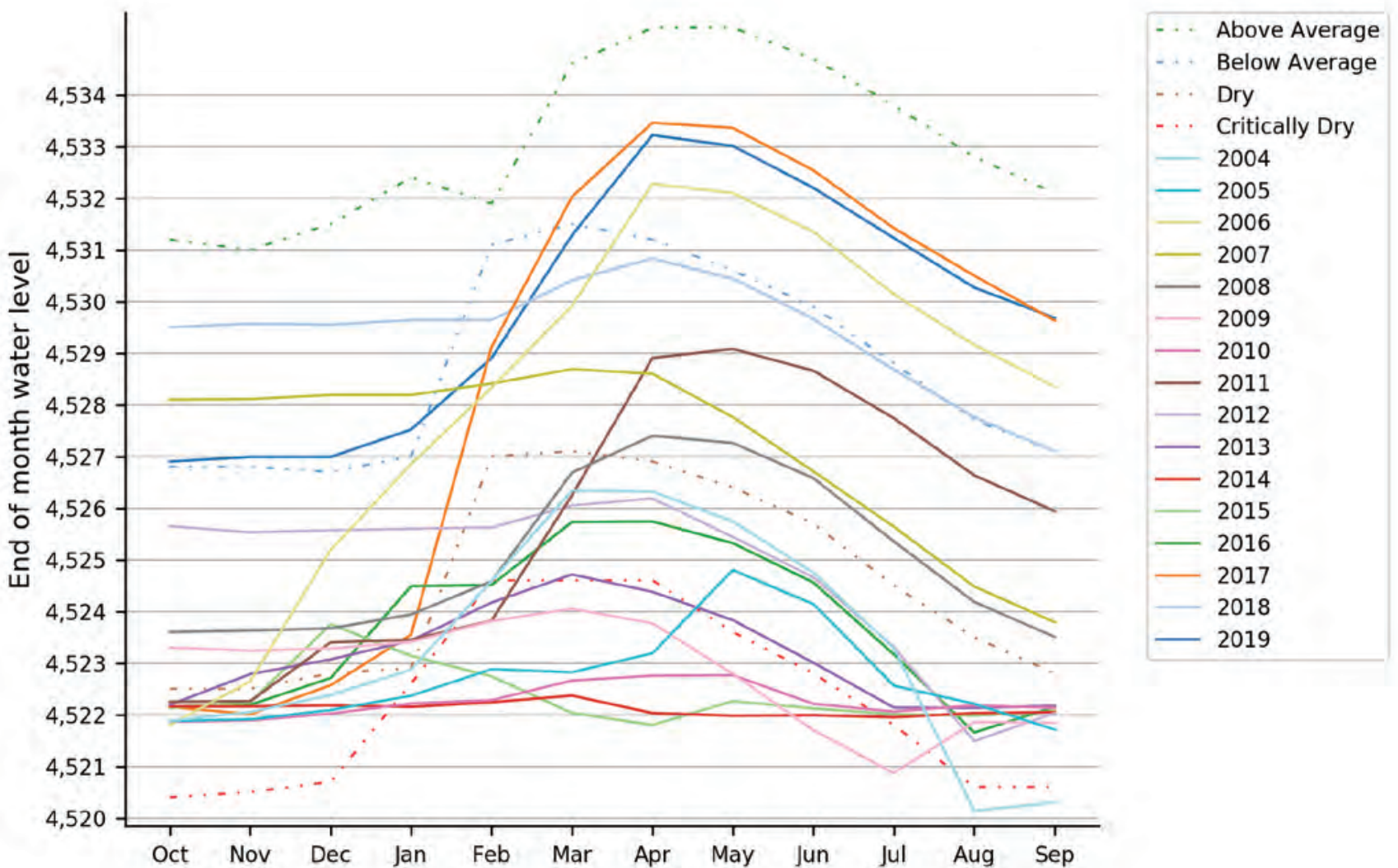

Figure 8. End-of-month water levels (ft above mean sea level) for water years 2004-19 as measured at the Clear Lake Dam, California. Also shown as dashed lines are the end-of-month water level requirements for different water year types, given in table 12. Note that end-of-September water levels are usually around 4,522 feet in low water years. Lower end-of-September levels tend to rebound quickly in October, and may be artifacts that occur at the gage at the end of the irrigation season.

\section{Acknowledgments}

We thank the numerous staff members from the U.S. Geological Survey Klamath Falls Field Station who assisted with data collection during the course of this study. We also appreciate assistance provided by the Klamath Area Office of the Bureau of Reclamation, which provided the funding for the study as part of its mission to manage, develop, and protect water and related resources in an environmentally and economically sound manner in the interest of the American public. We thank Ryan Bart, Toby Kock, and Danielle Hereford for reviewing drafts of this report.

\section{References Cited}

Andreasen, J.K., 1975, Systematics and status of the family Catostomidae in southern Oregon: Corvallis, Oregon, Oregon State University, Ph.D. thesis, 76 p.
Banet, N.V., Hewitt, D.A., Dolan-Caret, A., and Harris, A.C., [in press], Spatial and temporal distribution of radio-tagged Lost River and shortnose suckers in Clear Lake Reservoir, California, and associated spawning tributaries, 2015-2017: U.S. Geological Survey Open-File Report 2020-1061, 51 p, https://doi.org/10.3133/ofr20211061.

Barker, R.J., 1997, Joint modeling of live-recapture, tagresight, and tag-recovery data: Biometrics, v. 53, no. 2, p. 666-677, https://doi.org/10.2307/2533966.

Barker, R.J., 1999, Joint analysis of mark-recapture, resighting and ring-recovery data with age-dependence and markingeffect: Bird Study, v. 46, sup1, p. 82-91, https://doi.org/ 10.1080/00063659909477235.

Barry, P.M., Janney, E.C., Hewitt, D.A., Hayes, B.S., and Scott, A.C., 2009, Population dynamics of adult Lost River (Deltistes luxatus) and shortnose (Chasmistes brevirostris) suckers in Clear Lake Reservoir, California, 2006-08: U.S. Geological Survey Open-File Report 2009-1109, 18 p., https://doi.org/10.3133/ofr20091109. 
Bart, R.J., Burdick, S.M., Hoy, M.S., and Ostberg, C.O., 2020, Juvenile Lost River and shortnose sucker year-class formation, survival, and growth in Upper Klamath Lake, Oregon, and Clear Lake Reservoir, California_-2018 Monitoring Report: U.S. Geological Survey Open-File Report 2020-1064, 34 p., https://doi.org/10.3133/ofr20201064.

Buckland, S.T., Burnham, K.P., and Augustin, N.H., 1997, Model selection-An integral part of inference: Biometrics, v. 53, no. 2, p. 603-618, https://doi.org/10.2307/2533961.

Buettner, M., and Scoppettone, G., 1990, Life history and status of catostomids in Upper Klamath Lake, OregonReport from the National Fisheries Research Center: Reno Field Station, Nevada, 108 p.

Buettner, M.E., and Scoppettone, G.G., 1991, Distribution and information on the taxonomic status of the shortnose sucker (Chasmistes brevirostris) and Lost River sucker (Deltistes luxatus) in the Klamath River Basin, California-Report for the California Department of Fish and Game, Contract FG-8304: Reno Substation, Nevada, Seattle National Fishery Research Center, 102 p.

Burdick, S.M., Hewitt, D.A., Rasmussen, J.E., Hayes, B.S., Janney, E.C., and Harris, A.C., 2015, Effects of lake surface elevation on shoreline-spawning Lost River Suckers: North American Journal of Fisheries Management, v. 35, no. 3, p. 478-490, https://doi.org/10.1080/02755947.20 15.1017124 .

Burnham, K.P., and Anderson, D.R., 2002, Model selection and multimodel inference-A practical informationtheoretic approach 2nd ed.: New York, Springer, 488 p.

Ciotti, D., 2008, Evaporation from Clear Lake Reservoir in California: U.S. Bureau of Reclamation, Klamath Project, Mid-Pacific Region, Oregon, 9 p.

Cooperman, M., and Markle, D.F., 2003, Rapid out-migration of Lost River and shortnose sucker larvae from in-river spawning beds to in-lake rearing grounds: Transactions of the American Fisheries Society, v. 132, no. 6, p. 1138-1153, https://doi.org/10.1577/T02-130.

Conner, M.M., Bennett, S.N., Saunders, W.C., and Bouwes, N., 2015, Comparison of tributary survival estimates of Steelhead using Cormack-Jolly-Seber and Barker modelsImplications for sampling efforts and designs: Transactions of the American Fisheries Society, v. 144, no. 1, p. 34-47, https://doi.org/10.1080/00028487.2014.963254.

Cope, E.D., 1884, On the fishes of the recent and Pliocene lakes of the western part of the Great Basin, and of the Idaho Pliocene lake-Proceedings of the Academy of Natural Sciences of Philadelphia: Philadelphia, Pennsylvania, v. 35, p. 134-167.
Dowling, T.E., Markle, D.F., Tranah, G.J., Carson, E.W., Wagman, D.W., and May, B.P., 2016, Introgressive hybridization and the evolution of lake-adapted catostomid fishes: PLoS ONE, v. 11, no. 3, 27 p., https://doi.org/10.1371/ journal.pone.0149884.

Evans, A.F., Hewitt, D.A., Payton, Q., Cramer, B.M., Collis, K., and Roby, D.D., 2016, Colonial waterbird predation on Lost River and shortnose suckers in the Upper Klamath Basin: North American Journal of Fisheries Management, v. 36, no. 6, p. 1254-1268. https://doi.org/10.1080/0 2755947.2016.1208123.

Fraser, G.S., Winkelman, D.L., Bestgen, K.R., and Thompson, K.G., 2017, Tributary use by imperiled flannelmouth and bluehead suckers in the Upper Colorado River Basin: Transactions of the American Fisheries Society, v. 146, no. 5, p. 858-870, https://doi.org/10.1080/00028487.20 17.1312522 .

Gilbert, C.H., 1898, The fishes of the Klamath River Basin: Bulletin of the United States Fish Commission, v. 18, p. 1-13. [Also available at, https://www.krisweb.com/biblio/ klamath_usfc_gilbert_1898.pdf.].

Golden, M.P., 1969, The Lost River sucker, Catostomus luxatus (Cope): Oregon State Game Commission Central Region Administrative Report No. 1-69.

Hewitt, D.A., Janney, E.C., Hayes, B.S., and Shively, R.S., 2010, Improving inferences from fisheries capture-recapture studies through remote detection of PIT tags: Fisheries (Bethesda, Md.), v. 35, no. 5, p. 217-231, https://doi.org/ 10.1577/1548-8446-35.5.217.

Hewitt, D.A., and Hayes, B.S., 2013, Monitoring of adult Lost River and shortnose suckers in Clear Lake Reservoir, California, 2008-2010: U.S. Geological Survey OpenFile Report 2013-1301, 18 p., https://doi.org/10.3133/ ofr20131301.

Hewitt, D.A., Janney, E.C., Hayes, B.S., and Harris, A.C., 2017, Status and trends of adult Lost River (Deltistes luxatus) and shortnose (Chasmistes brevirostris) sucker populations in Upper Klamath Lake, Oregon, 2015: U.S. Geological Survey Open-File Report 2017-1059, 38 p., https://doi.org/10.3133/ofr20171059.

Hewitt, D.A., Janney, E.C., Hayes, B.S., and Harris, A.C., 2018, Status and trends of adult Lost River (Deltistes luxatus) and shortnose (Chasmistes brevirostris) sucker populations in Upper Klamath Lake, Oregon, 2017: U.S. Geological Survey Open-File Report 2018-1064, 31 p., https://doi.org/10.3133/ofr20181064. 
Janney, E.C., Shively, R.S., Hayes, B.S., Barry, P.M., and Perkins, D., 2008, Demographic analysis of Lost River sucker and shortnose sucker populations in Upper Klamath Lake, Oregon: Transactions of the American Fisheries Society, v. 137, no. 6, p. 1812-1825. https://doi.org/ 10.1577/T06-235.1.

Klamath County Historical Society, 1971, Applegate Trail, in Helfrich, D., ed., Klamath Echoes, no. 9.

Koch, D.L., Cooper, J.J., Contreras, G.P., and King, V., 1975, Survey of the fishes of the Clear Lake Reservoir drainage: Reno, Nevada, Center for Water Resources Research, Desert Research Institute, Project Report No. 37, 38 p.

Leeseberg, C.A., Barry, P.M., Whisler, P., and Janney, E.C., 2007, Monitoring of Lost River (Deltistes luxatus) and shortnose (Chasmistes brevirostris) suckers in Gerber and Clear Lake Reservoirs-Annual report 2004: Klamath Falls, Oregon, U.S. Geological Survey, 25 p.

Markle, D.F., Cavalluzzi, M.R., and Simon, D.C., 2005, Morphology and taxonomy of Klamath Basin Suckers (Catostomidae): Western North American Naturalist, v. 65, p. 473-489.

National Marine Fisheries Service and U.S. Fish and Wildlife Service (NMFS and USFWS), 2013, Biological opinions on the effects of proposed Klamath Project operations from May 31, 2013, through March 31, 2023, on five federally listed threatened and endangered species: Oregon and California, National Marine Fisheries Service Southwest Region Office and U.S. Fish and Wildlife Service Pacific Southwest Region Office, 607 p.

Perkins, D.L., and Scoppettone, G.G., 1996, Spawning and migration of Lost River suckers (Deltistes luxatus) and shortnose suckers (Chasmistes brevirostris) in the Clear Lake drainage, Modoc County, California: National Biological Service, California Science Center, Reno Field Station, Reno, Nevada, Final Report to the California Department of Fish and Game, $52 \mathrm{p}$.

Perkins, D.L., Kann, J., and Scoppettone, G.G., 2000, The role of poor water quality and fish kills in the decline of endangered Lost River and shortnose suckers in Upper Klamath Lake-U.S. Geological Survey final report to the Bureau of Reclamation, Contract 4-AA-29-12160: Oregon, Klamath Falls, 39 p.

Rasmussen, J.E., 2011, Status of Lost River and shortnose sucker: Western North American Naturalist, v. 71, no. 4, p. 442-455, https://doi.org/10.3398/064.071.0402.

Scoppettone, G.G., and Vinyard, G., 1991, Life history and management of four endangered lacustrine suckers, in Minckley, W.L., and Deacon, J.E., eds., Battle against extinction-Native fish management in the American West: Tucson, The University of Arizona Press, p. 359-377.
Scoppettone, G.G., Shea, S., and Buettner, M.E., 1995, Information on population dynamics and life history of shortnose suckers (Chasmistes brevirostris) and Lost River suckers (Deltistes luxatus) in Tule and Clear LakesNational Biological Service: Klamath Falls, Oregon, Reno Field Station, Nevada and Bureau of Reclamation, 79 p.

Smith, M., Von Bargen, J., Smith, C., Miller, M., Rasmussen, J., and Hewitt, D.A., 2020, Characterization of the genetic structure of four sucker species in the Klamath River Basin: U.S. Fish and Wildlife Service, Abernathy Fish Technology Center, Washington, $32 \mathrm{p}$.

Terwilliger, M.R., Reece, T., and Markle, D.F., 2010, Historic and recent age structure and growth of endangered Lost River and shortnose suckers in Upper Klamath Lake, Oregon: Environmental Biology of Fishes, v. 89, no. 3-4, p. 239-252, https://doi.org/10.1007/s10641-010-9679-9.

U.S. Bureau of Reclamation (USBR), 1994, Clear Lake Reservoir Reconsultation: U.S. Bureau of Reclamation, Klamath Project, Mid-Pacific Region, Oregon, 103 p.

U.S. Bureau of Reclamation (USBR), 2002, The final biological assessment, the effects of proposed actions related to the Klamath Project Operation (April 1, 2002 to March 31, 2012) on federally listed threatened and endangered species: U.S. Bureau of Reclamation, Klamath Project, Mid-Pacific Region, Oregon, 150 p.

U.S. Bureau of Reclamation (USBR), 2012, The Effects of the Proposed Action to Operate the Klamath Project from April 1, 2013 through March 31, 2023 on FederallyListed Threatened and Endangered Species: U.S. Bureau of Reclamation, Klamath Project, Mid-Pacific Region, Oregon, $364 \mathrm{p}$.

U.S. Fish and Wildlife Service (USFWS), 1988, Endangered and threatened wildlife and plants-Determination of endangered status for the shortnose sucker and Lost River sucker: Federal Register, v. 53, p. 27130-27134.

U.S. Fish and Wildlife Service (USFWS), 1994, Reinitiation of formal consultation of the long-term operation of the Klamath Project, with special reference to operations at Clear Lake Reservoir, on Lost River sucker, shortnose sucker, bald eagle, and American peregrine falconMemorandum to the Klamath Project: United States Bureau of Reclamation, Klamath Falls Office, Klamath Falls, Oregon, 16 p.

U.S. Fish and Wildlife Service (USFWS), 1992a, Formal consultation on the Effects of the 1992 Operation of the Klamath Project on the Lost River Sucker, Shortnose Suckers, and Bald Eagle, and American Peregrine Falcon, January 6, 1992: U.S. Fish and Wildlife Service, Klamath Falls Fish and Wildlife Office, Oregon, 6 p. 
U.S. Fish and Wildlife Service (USFWS), 1992b, Formal consultation on the Effects of the Long-term Operation of the Klamath Project on the Lost River Sucker, Shortnose Suckers, Bald Eagle, and American Peregrine Falcon, July 22, 1992: U.S. Fish and Wildlife Service, Klamath Falls Fish and Wildlife Office, Oregon, 62 p.

U.S. Fish and Wildlife Service (USFWS), 2002, Biological/ conference opinion regarding the effects of the Bureau of Reclamation's proposed 10-year operation plan for the Klamath Project and its effect on the endangered Lost River sucker (Deltistes luxatus), endangered shortnose sucker (Chasmistes brevirostris), threatened bald eagle (Haliaeetus leucocephalus), and proposed critical habitat for the Lost River and shortnose suckers: U.S. Fish and Wildlife Service, Klamath Falls Fish and Wildlife Office, Oregon, 204 p.
U.S. Fish and Wildlife Service (USFWS), 2008, Biological/ conference opinion regarding the effects of the Bureau of Reclamation's proposed 10-year operation plan (April 1, 2008 to March 31, 2018) for the Klamath Project and its effect on the endangered Lost and shortnose suckers: U.S. Fish and Wildlife Service, Klamath Falls Fish and Wildlife Office, Oregon, 233 p.

U.S. Fish and Wildlife Service (USFWS), 2012, Revised recovery plan for the Lost River sucker (Deltistes luxatus) and shortnose sucker (Chasmistes brevirostris): U.S. Fish and Wildlife Service, Pacific Southwest Region, Sacramento, California, $122 \mathrm{p}$.

White, G.C., and Burnham, K.P., 1999, Program MARKSurvival rate estimation from populations of marked animals: Bird Study, v. 46, sup1, p. 120-139, https://doi.org/ 10.1080/00063659909477239. 


\section{Appendix 1. Historical Clear Lake Reservoir Inflows}

\section{Methods}

Inflows to Clear Lake Reservoir, estimated at least in part based on changing reservoir water levels, were reported by month for 1910-93 in appendix A.2 of the 1994 Biological Assessment (BA) (USBR, 1994). A spreadsheet shared by Reclamation in 2012 and updated in 2019 gave monthly inflow values for the period 1961-2011. Most of the values in the spreadsheet for the months during the overlap period of 1961-93 did not match those from the 1994 BA appendix. Some adjustments had apparently been made to the methodology for calculating the inflows since 1994, but one source did not always give greater values than the other, so it was not clear what had changed. Although the values were typically similar, the summed spawning season inflows for FebruaryMay over the 33 years differed by more than $10 \mathrm{TAF}$ in 5 years. The difference in the values from the two sources for 1972 was an outlier and was driven by the monthly value for March, which was 30.8 TAF less in the spreadsheet than the March value in the 1994 BA appendix. This suggests that the value in the 1994 BA appendix might have been an error, so we do not include the year 1972 in further comparisons. Values from the spreadsheet were more often lower than the values from the $1994 \mathrm{BA}$ appendix, and the more extreme differences were in years where the spreadsheet values were lower. Subtracting the values from the 1994 BA appendix from the spreadsheet values, excluding 1972, gives the following summary information for the differences, in TAF: $\min =-13.1$, $\max =10.2$, avg $=-1.7$, median $=-1.3$, st. dev. $=6.0$. Because of these differences and because the two sources included different time periods, we did not use values from these sources directly.

Because the long-term period of record at the reservoir includes only water levels recorded at Clear Lake Dam, we sought to create a consistent way to estimate inflows to the reservoir during the spawning season throughout the period of record based only on those water levels. Based on data available online from Reclamation, water level at the dam was recorded on a nearly daily basis during the irrigation season (Apr 15-Sep 30) beginning in April 1986. Outside of the irrigation season, typically only one measurement is available each month and usually near the end of the month. Beginning in 1998 and continuing to present, online data are nearly continuous as daily values. Prior to 1986 and extending back to 1918 , the online records are about once a year, typically taken near the start of the calendar year. However, in appendix B of the 2013 joint National Marine Fisheries Service (NMFS)/ USFWS Biological Opinion (NMFS and USFWS, 2013), table 16.2.6 reports end-of-month elevations by month for the years 1905-2011 (provided by Reclamation). This suggests that substantially more water level data exist for Clear Lake Dam than were available online.
Because a large proportion of the long-term record that was available to us consisted only of EOM water levels at the dam, we used these EOM values to estimate spawning season inflows to the reservoir throughout the period of record. We used EOM values from table 16.2.6 in appendix B of the 2013 BO that covers the period October 1904-July 2010, and took values directly from the data available online for August 2010-September 2019 (NMFS and USFWS, 2013). We corrected three obvious typos where the values for a month were out of line with the values before and after them, and checked values from the appendix against the data available online where it overlapped. The three changes were: October 1989, from 4,531.82 to 4,530.82 ft; February 1913, from 4,539.3 to 4,529.3 ft; and May 1907, from 4,526.25 to $4,536.25 \mathrm{ft}$. None of these changes affected inflow estimates that we used in our analysis. We determined the smallest and largest values for EOM water level on the ascending limb of the reservoir hydrograph during the spawning season, considering the five values for end-of-January through end-of-May. We related these water levels to the gage height-capacity relationship for the reservoir provided by Reclamation to determine the volume of the reservoir at the two points in time, and the difference was used as a starting point for the estimated inflow to the reservoir. When water level did not increase between end-of-January and end-of-May, we assumed zero inflow. Although inflows were extremely low in a number of years, our approach assumed zero inflow only in 1931 and 2015. If water level increased across the season, but values after end-of-February were lower than any of the earlier values, those lower values were ignored as they did not provide information about inflows.

We added to our inflows the total amount of water released from Clear Lake Dam over the same period (February-May). A complete set of monthly values for releases from the dam for water years 1919-2019 was assembled from three sources:

1. Appendix A.5 in the 1994 BA from Reclamation (USBR, 1994) that included monthly total releases in acre-feet for April 1918 through December 1993. We summed the four values for February through May.

2. Average daily flow rates measured at Clear Lake Dam in cubic feet per second $\left(\mathrm{ft}^{3} / \mathrm{s}\right)$ for April 1986 through December 2011, which were provided from a USFWS Klamath Falls hydrologist, based on data from Reclamation. Values were converted to acre-feet and summed as monthly values, then February through May values were summed. For the values that overlapped with appendix A.5 in (1) above, fewer than 10 values differed, and the largest difference was only 0.305 TAF. We retained the values from appendix A.5 in the overlapping months. Values based on daily flow rates measured at the dam were used for the years 1994-99. 
3. Average daily flow rates measured at the dam in $\mathrm{ft}^{3} / \mathrm{s}$ for 2000-16, which were provided by Reclamation and handled in the same way as in (2). Where data overlapped with source (2) for 2000-11, only two values differed by 0.1 and $0.24 \mathrm{TAF}$. We used the values from this source (3) in those two cases.

Typically there were no releases during the spawning months except for April and May, but there were some exceptions when releases were made in January, February, or March. Because the dam release records prior to 1918 were not available and the records for 1918 were incomplete, we estimated reservoir inflow for water years 1919-2016 and based our analysis on that time period (fig. 1.1).

Our approach, which is based on EOM water levels, can underestimate the maximum water level during the spawning season because the water level can be higher at some time during the month and then decline by the end of the month. We compared the water levels through the season in each year when daily data were available (1986-2019). We concluded that this had only a small effect because the highest water level during the spawning season was typically well described by the March, April, or May EOM value, as the reservoir was typically increasing in water level through the season or at least not fluctuating dramatically. For confirmation, we compared our estimated inflows based on EOM values in 1986-2019, with calculations done the same way except using the minimum and maximum values from daily recorded water levels at the dam. We ignored isolated outlier values that did not fit the seasonal pattern, which were perhaps caused by wind events or operations at the dam, as well as values from isolated spikes lasting one to a few days that were far higher than values before and after; these occurred in only a few years such as 2014. Although we have no finer temporal resolution prior to 1986, we assume that patterns in water level through a season were similar in past years to what was observed in 1986-2019.

Our approach underestimates actual inflow because it does not account for seepage losses and evaporation from the reservoir surface. Seepage losses are small and evaporation during the spawning months is typically low (Ciotti, 2008). Furthermore, seepage and evaporation are not measured each year and thus any adjustment would be made in the same way through the season across years. Therefore, any changes would apply equally to all years and not affect relative comparisons among years in the period of record. Differences in solar radiation among months within a season and among seasons could be considered, but total adjustments for the spawning season would be small compared to the relative annual comparisons that we are focused on. Our approach does account for precipitation on the reservoir surface.

Finally, in very low water years, the east and west lobes of the reservoir would be separated at some point during the spawning season, and water levels at the dam would not necessarily represent the total amount of water in the reservoir. To examine the potential effects on our estimates based on EOM dam values in such years, we took guidance from recent years when both lobes were gaged (2011-19). For example, in 2011 and 2016, years following times when the west lobe and east lobe had become disconnected and the west lobe lowered considerably, substantial inflow would have occurred that filled the east and west lobes of the reservoir and this inflow would not have been entirely reflected in changes at the dam. The two gages did not start to read similar values until the water level was about $4,525 \mathrm{ft}$ on the dam gage in both of those years. When water levels persist at about 4,523 ft or below as measured at the dam for any considerable time, the lobes will separate and the west lobe will lower independently. If that continues beyond the end of January, such differences between the gage water levels are to be expected and the inflow estimates based on water level changes at the dam will be too low.

We examined the daily or EOM data for water level in all years during the period of record to determine when separation of the reservoir lobes was likely to have occurred. For 2011-19 when both lobes of the reservoir were gaged, we can correct the higher values at the dam to reflect lower levels in the west lobe. Indeed, EOM water levels given for 2011 in the 2013 BO appendix table 16.2.6 (NMFS and USFWS, 2013) when water level at the dam gage was below about 4,523 $\mathrm{ft}$ are reported as the lower of two values shown in online data, either the value for the west lobe gage or the average of the two gages (it was rare for the average to be the lower value). When water level at the dam gage was above 4,523 $\mathrm{ft}$, the average of the two gages was reported. We used those reported values in the appendix from 2011 and calculated the EOM values for 2012-19 in the same way to create a series of EOM values for 2011-19 that account for water levels in both lobes of the reservoir. In 2014, water levels at the dam gage never rose above $4,523 \mathrm{ft}$, so values from the west lobe were used for all months January to May. In 2015, the dam gage rose above 4,523 ft for about 2 weeks in February from a small flow event, but because the lobes were so separated (see appendix 2), we used values from the west lobe gage throughout that year as well. In 2016, the water level at the dam gage was above 4,523 ft in January-May, but the two lobes were widely separated until March. We used the average of the two gages as the EOM values for January-May but recognize and discuss later the substantial underestimation of inflow in 2016. Finally, to assess the effects of within-month fluctuations in water level not captured by EOM values, we used the daily data from both gages for this period (2011-19) with this approach (minimum of west lobe gage or gage average, depending on 4,523 ft threshold) to obtain minimum and maximum values for each spawning season.

We compare our estimates of spawning season inflows to other sources of inflow information described above for the period of record, and our estimates are likely to be less accurate than some other approaches. We also realize that the estimates are not likely to be useful outside of the context in which they are used here, because they only apply to the months of February-May during the spawning season. In some years, substantial inflow occurred in December and January, but it is unknown whether suckers would attempt to spawn before late January. 

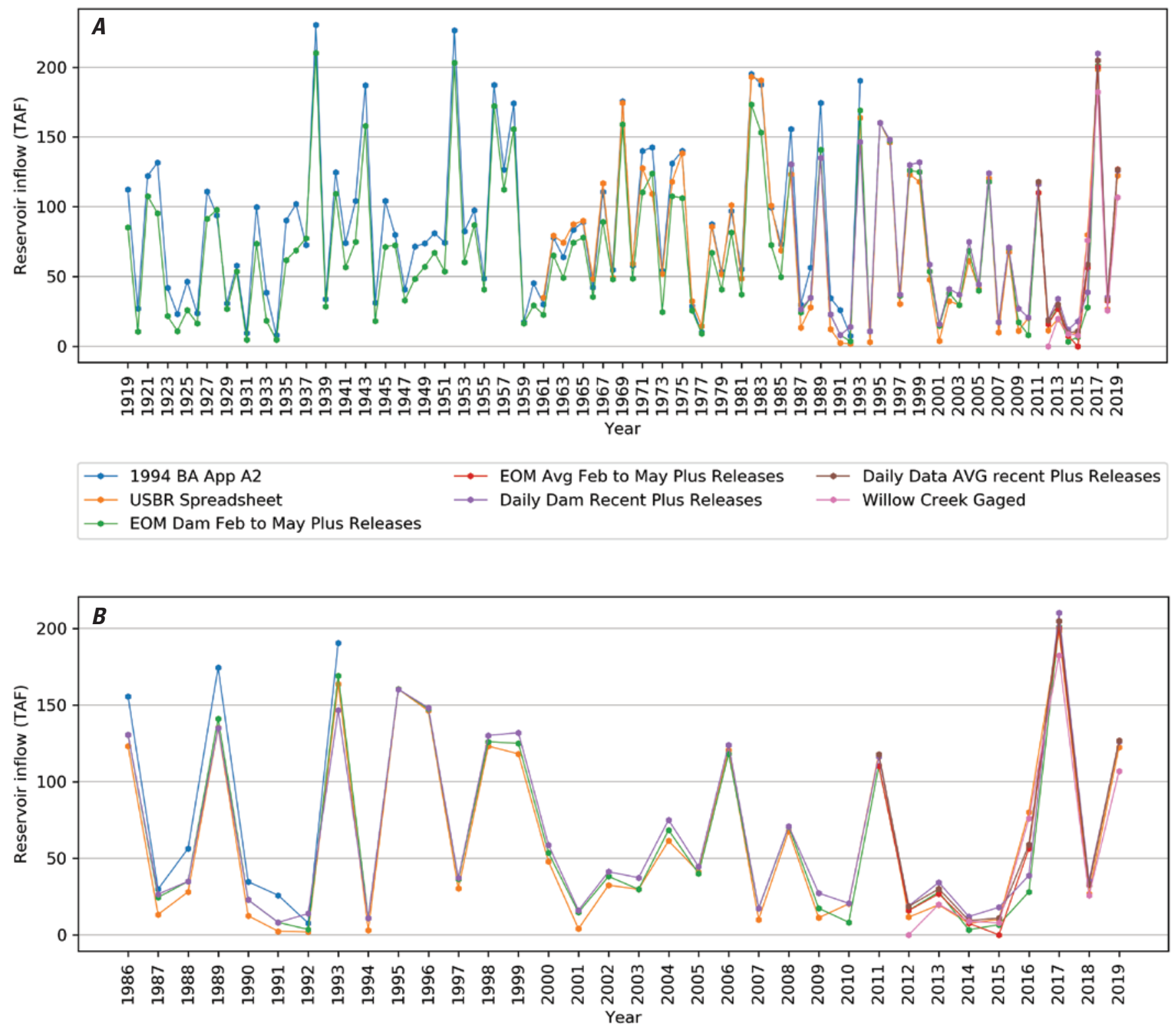

Figure 1.1. Inflows to Clear Lake Reservoir, California, during the spawning season (February-May) over the period of record, estimated or taken directly from a number of sources (in order as they appear in the legend). [1] Values for monthly reservoir inflow for 1919-93 from appendix A.2 of Reclamation's 1994 Biological Assessment (USBR, 1994), stated as including "native" inflow as well as precipitation on the reservoir surface, computed from reservoir inflow sheets; [2] values for monthly reservoir inflow for 1961-2019 from a spreadsheet provided to us by Reclamation in 2012, and updated in 2019; [3] the approach we developed to estimate inflow based on end-of-month (EOM) elevations from the gage at Clear Lake Dam; [4] same as approach in [3] but only for 2011-19 and using the average of EOM values from both dam and west lobe gages; [5] estimates based on changes across a season in dam gage water level using minimum and maximum values from daily data in the years 1986-2019 (for comparison with the EOM approaches); [6] same as approach in [5] but only for 2011-19 and using the average of daily data from both dam and west lobe gages; [7] inflows based on daily gaged measurements of Willow Creek discharge, 2013-19. 


\section{Inflow Estimates and Comparisons to Other Sources of Information}

Our calculations of estimated reservoir inflows during the February-May spawning season based on EOM water levels at the dam were broadly similar to other sources over the period 1919-2019 (fig. 1.1). As expected, our estimates were almost always lower than Reclamation values because our calculations did not account for seepage and evaporation whereas Reclamation calculations did. To provide a summary of the differences, we used values from appendix A.2 of the 1994 BA (USBR, 1994) in years 1919-1960 and values from the more recent Reclamation spreadsheet in years 1961-2019. Our estimates were greater than the Reclamation values in only 4 years, and the difference was substantial only in 1972 (14.4 TAF), a year of high inflow. However, we noted that the value in appendix 1.2 of the 1994 BA was higher than our estimate in that year. Subtracting our estimates from the Reclamation values gives the following summary information for the differences, in TAF: $\min =-14.4, \max =37.5$, avg $=15.9$, median $=$ 15.5 , st. dev. $=10.1$. The larger differences occurred in years when inflows were higher.

With regard to error that might occur in our estimates because of using EOM values rather than daily values, we examined the estimates for the period 1986-2019, where we could calculate inflows using both types of data. As expected, estimates based on daily data captured slightly higher maximum water levels in some years and gave higher estimates of inflows. However, the estimates based on EOM values were greater by a small amount in some years as well, wherein the daily data provided a slightly higher minimum or a slightly lower maximum than the reported EOM values; we did not pursue the reason for these small differences. The differences in the estimates from the two methods were only substantial in years of high inflows. Summary information for the extent to which estimates based on daily data were greater than our EOM estimates, in TAF, are: $\min =-5.9, \max =15.2$, avg $=$ 4.1 , median $=3.3$, st. dev. $=4.1$. Both this comparison and the comparison with the Reclamation values that include seepage and evaporation losses indicate that our calculations provide underestimates of reservoir inflows from Willow Creek during the spawning season.

For years in which water level data were available in both lobes of the reservoir, a comparison of the three ways of calculating inflows showed meaningful differences only in 2016 (table 1.1). The two gages differed by about $2 \mathrm{ft}$ at the beginning of 2011 and were less than $0.5 \mathrm{ft}$ apart by early February, such that the estimate for spawning season inflow is only slightly underestimated in that year. Our approach based on EOM values from the dam gage underestimated inflows in the extreme drought years of 2014 and 2015, but by any method the inflow was minimal in those years. In 2016, the preceding drought resulted in the water levels at the two gages differing by more than $4 \mathrm{ft}$ at the start of the year (appendix 2). Despite considerable inflows, the gages differed until mid-March such that any approach to estimating inflows based on reservoir water levels resulted in a large underestimate of the inflow in that year (table 1.1). We also compared the approaches based on water level with the direct calculations from measured discharge in Willow Creek in 2014-19. We expected our estimates based on reservoir water levels to be larger than Willow Creek inflows because our estimates could include inputs to the reservoir other than Willow Creek flows. Our prediction was correct except for 2016 and the extreme drought years of 2014 and 2015. Measured discharge in 2014 and 2015 showed that 8-9 TAF is an approximate baseline for Willow Creek inflows during years with minimal runoff from snowpack and other precipitation.

Table 1.1. Comparison of the three described methods for estimating spawning season (February-May) inflows to Clear Lake Reservoir, California, in years when water level data were available at gages in both lobes of the reservoir, 2011-19.

[Inflows calculated directly from gaged discharge in Willow Creek are given for comparison for 2014-19. At water levels in the reservoir below about 4,523 feet (the approximate maximum lake level prior to the construction of Clear Lake Dam), the dam channel is disconnected from the rest of the reservoir and water level in the west lobe can be lower than the water level measured at the dam gage. EOM, end-of-month]

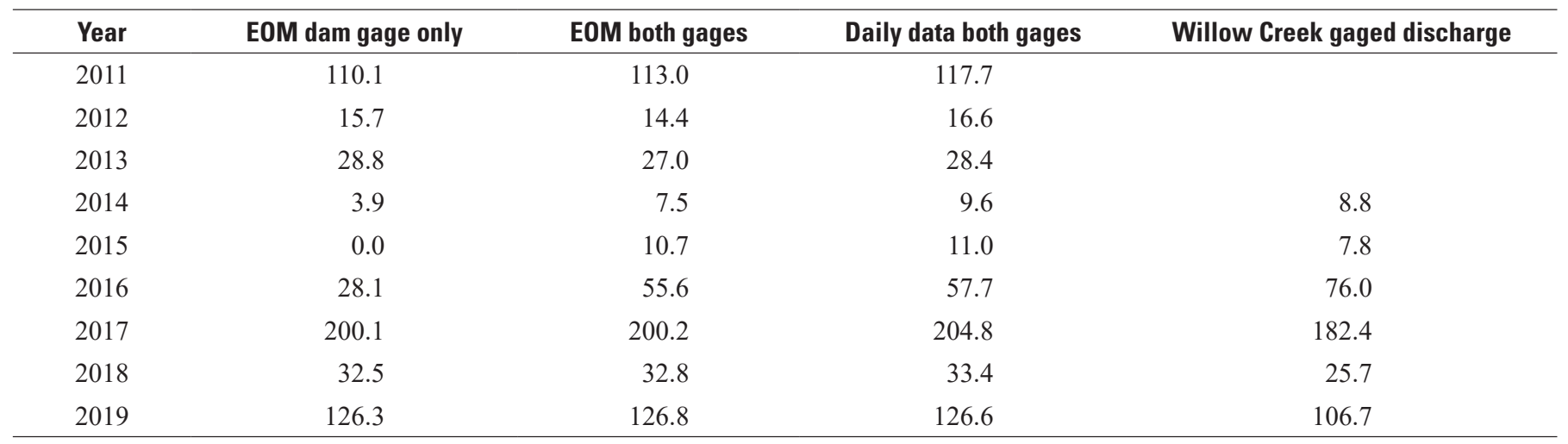


Given the effect on our estimate of inflow in 2016, we examined the daily or EOM data for water level in all years during the period of record to determine whether separation of the reservoir lobes was likely to have occurred. We determined that it may have had an effect on the inflow estimates to a degree that would have affected our conclusions about spawning in only 4 years: 1963, 2005, 2013, and 2016. In other years where underestimation appeared likely to have occurred, the estimated inflows were either so high or so low as to have no effect on our conclusions about spawning (high inflows regardless of underestimation in 1932, 1935, 1936, 1937, 1938, 1952, 1962, 1993, 2004, 2011, 2017; low inflows regardless of underestimation in 1931, 1933, 1934, 1992, 2009, 2010, 2014, 2015). During the Dust Bowl years from 1931 to 1936 , the water level was so consistently low that the east and west lobes were usually disconnected. Any spawning that occurred would likely have involved only fish that were residing in the dam channel. Because it was unclear whether the stage height-capacity relationship and measurements only at the dam would be appropriate for assessing changing volume under those conditions, we excluded the years 1931-36 from our long-term assessment of the period of record.

We examined in detail the extent to which our method of estimating inflows could underestimate inflows in years when the lobes of the reservoir were separated for a considerable period of time, and determined the following:

- For 1963, inflow is probably underestimated (estimate of 49 TAF), but inflow was high enough in that year not to have affected spawning. The data provided by Reclamation in the appendix from the 2013 BO show a jump in water level from 4,521.3 ft in September 1962 to $4,524.3 \mathrm{ft}$ in October 1962 to start the 1963 water year. This magnitude of increase across the month of October is not shown for any other year, and seems out of character with the hydrology of the reservoir. This may be an error, although the limited data for the 1962-63 water years online agree with the values in the document.

- For 2005, inflow is probably underestimated (estimate of 39 TAF), but it appears that inflow was high enough in that year not to have affected spawning.

- For 2013, it seems that inflow should be underestimated, but the gages in the two lobes were similar through the whole year. As a result, underestimation was probably small (estimate of $29 \mathrm{TAF}$ ). Regardless, the year 2013 was a borderline year for spawning being affected by inflows, with both sucker taxa making a moderate but delayed migration. Both species migrations were short, with almost all new sucker detections occurring in the first 2 weeks of March. The data for 2013 show that inflow around 30 TAF was sufficient for at least a moderate spawning migration.

- For 2016, the inflow is certainly underestimated because of the low water levels in the reservoir following the drought years of 2014-15. Although our estimate (28 TAF) indicates a potential limitation on spawning migrations, this was not the case (appendix 2; Banet and others, in press). If we used the west lobe gage water level in January and February in the 2016 series of EOM values, the estimated inflow would have been $82 \mathrm{TAF}$ compared to $56 \mathrm{TAF}$ from our approach based on monthly averages of the two gages. 


\section{Appendix 2. Timing and Magnitude of Sucker Detections at Remote Passive Integrated Transponder Tag Antenna Arrays, Reservoir Water Surface Elevation, Willow Creek Water Temperature, and Inflow from or Discharge in Willow Creek During the Spawning Migration in Each Year from 2006 to 2019}

For sucker detections, only the first detection of an individual at a given site in a given season is included. Detections at the Willow Creek PIT tag antenna array are included in all years, and detections at the straits array are also included as a separate plot (top panel) in 2014-17. Water surface elevation measured at the dam gage is included in all years, and water surface elevation measured at the west lobe gage is also included in 2011-19. Willow Creek water temperature was measured at the PIT tag antenna array in 2006-13 (but not available in 2010); in 2014-19 water temperature was measured at the Reclamation gage 2 kilometers upstream of the antenna array. Stage height at the Willow Creek gage was recorded beginning in May 2012, and discharge was recorded beginning in November 2013. Stage height is included in the figure for 2013 and discharge is included in the figures for 2014-19. Monthly reservoir inflow is included in the Figures for 2006-11; these values are taken directly from the spreadsheet provided by Bureau of Reclamation as described in appendix 1. The inflow values are plotted at the midpoint of the month to which they apply. No inflow, stage height, or discharge was available in 2012 . Note changing $y$-axis scales among figures.

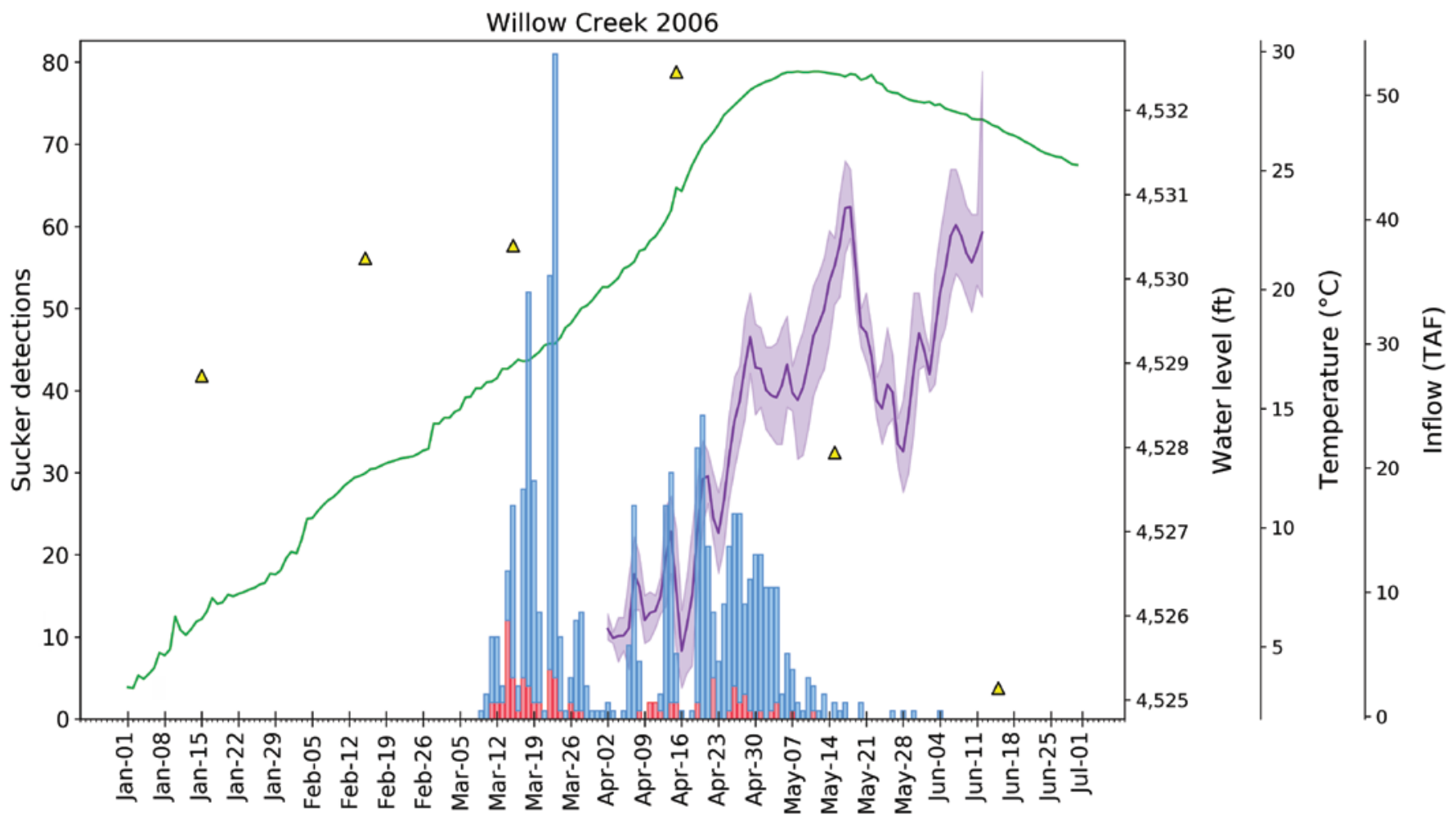

- Dam level — Temperature $\Delta$ Inflow $\square$ SNS-KLS LRS

Figure 2.1. Number of individual Lost River suckers (LRS) or shortnose sucker and Klamath largescale sucker combined (SNS-KLS) detected on passive integrated transponder antennas located in Willow Creek in 2006. Water level in Clear Lake Reservoir, California measured in feet ( $\mathrm{ft}$ ) above mean sea level at the Clear Lake Dam, daily mean and range in water temperatures in degrees Celsius $\left({ }^{\circ} \mathrm{C}\right)$, and calculated Willow Creek inflow in thousand acre-feet (AF) are shown for the 2006 sucker spawning season. 


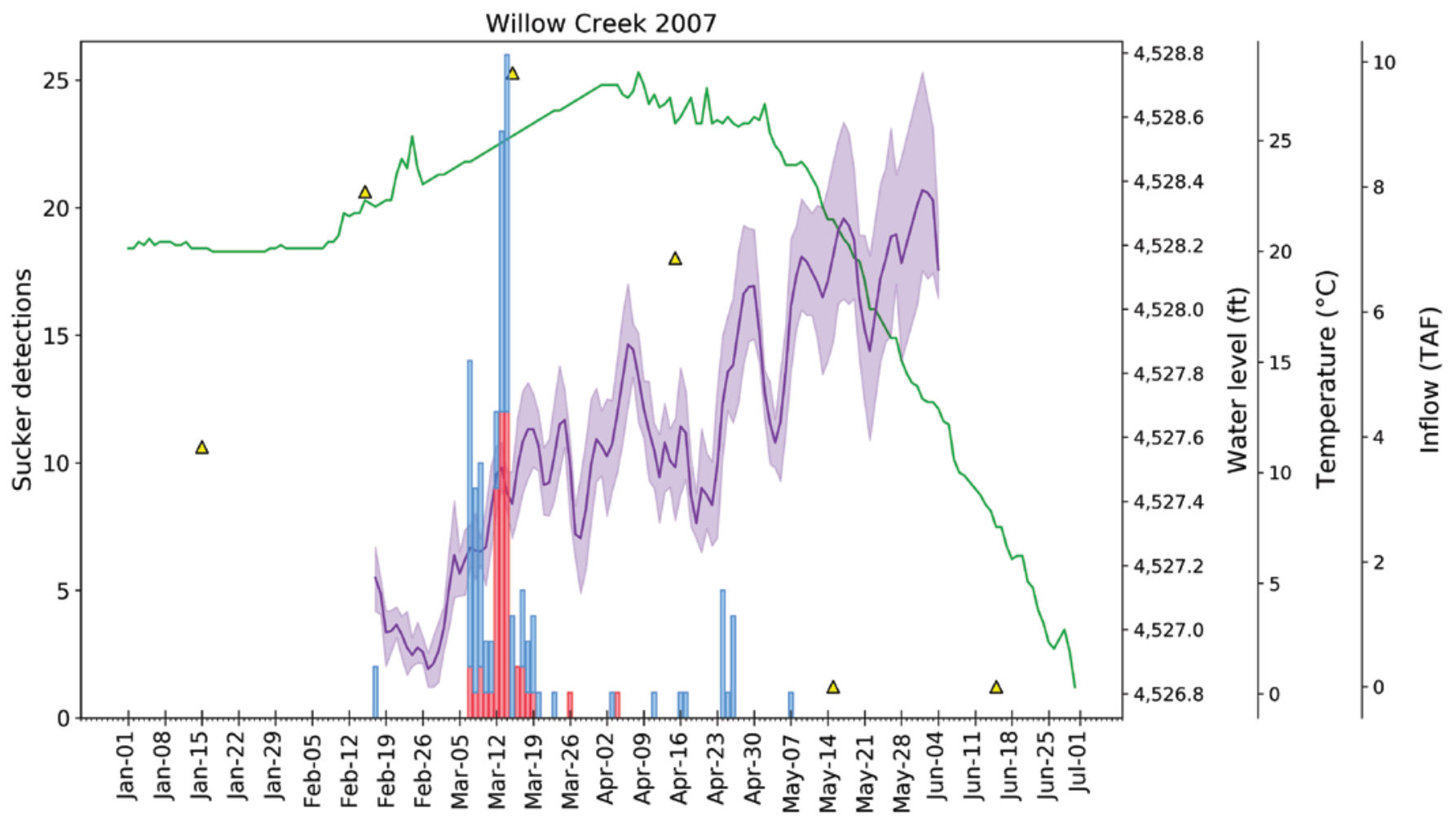

— Dam level - Temperature $\Delta$ Inflow SNS-KLS LRS

Figure 2.2. Number of individual Lost River suckers (LRS) or shortnose sucker and Klamath largescale sucker combined (SNS-KLS) detected on passive integrated transponder antennas located in Willow Creek in 2007. Water level in Clear Lake Reservoir, California measured in feet $(\mathrm{ft})$ above mean sea level at the Clear Lake Dam, daily mean and range in water temperatures in degrees Celsius $\left({ }^{\circ} \mathrm{C}\right)$, and calculated Willow Creek inflow in thousand acre-feet (AF) are shown for the 2007 sucker spawning season. 


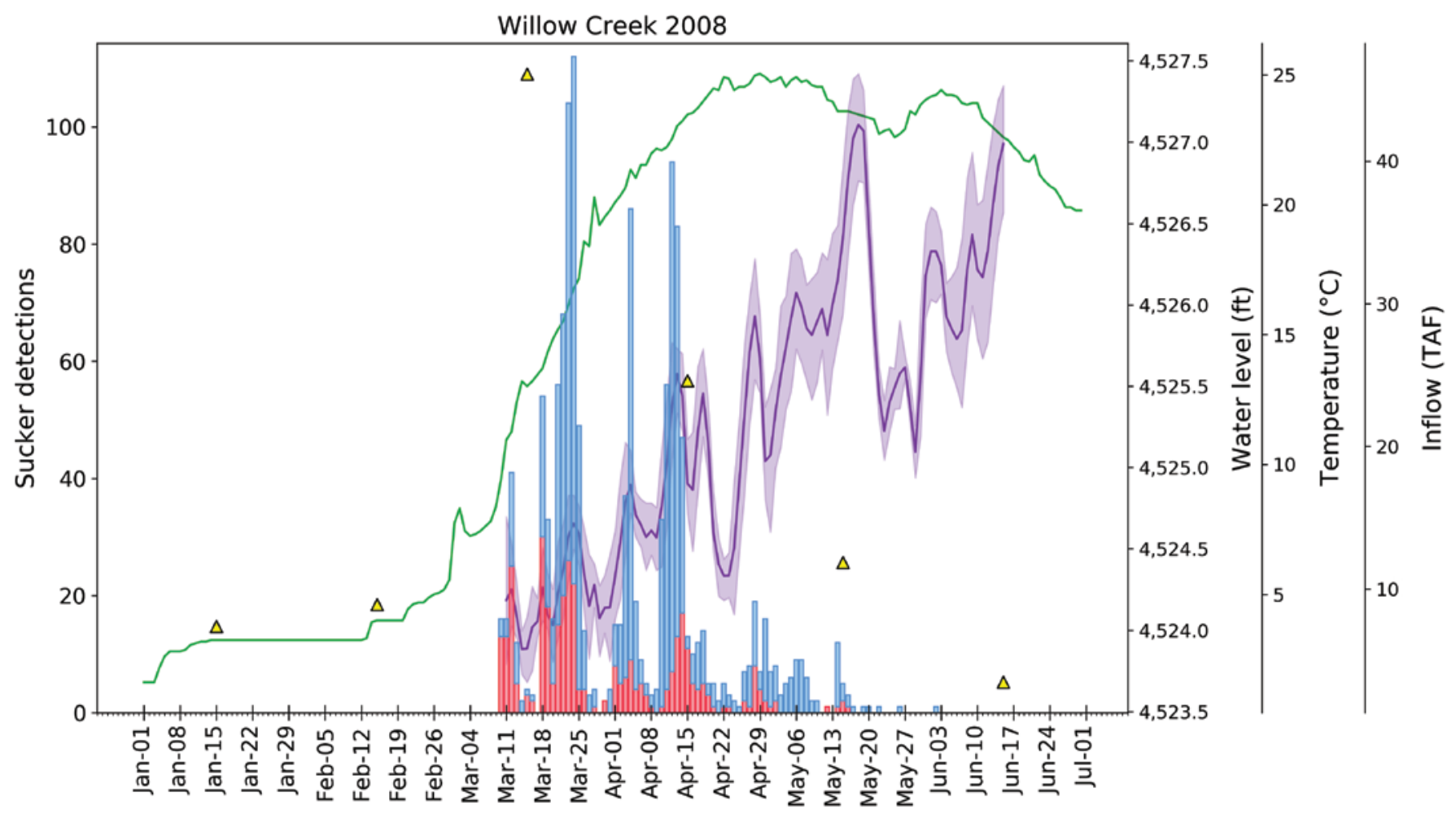

$$
\text { - Dam level — Temperature } \Delta \text { Inflow }=\text { SNS-KLS LRS }
$$

Figure 2.3. Number of individual Lost River suckers (LRS) or shortnose sucker and Klamath largescale sucker combined (SNS-KLS) detected on passive integrated transponder antennas located in Willow Creek in 2008. Water level in Clear Lake Reservoir, California measured in feet ( $\mathrm{ft}$ ) above mean sea level at the Clear Lake Dam, daily mean and range in water temperatures in degrees Celsius $\left({ }^{\circ} \mathrm{C}\right)$, and calculated Willow Creek inflow in thousand acre-feet (AF) are shown for the 2008 sucker spawning season. 


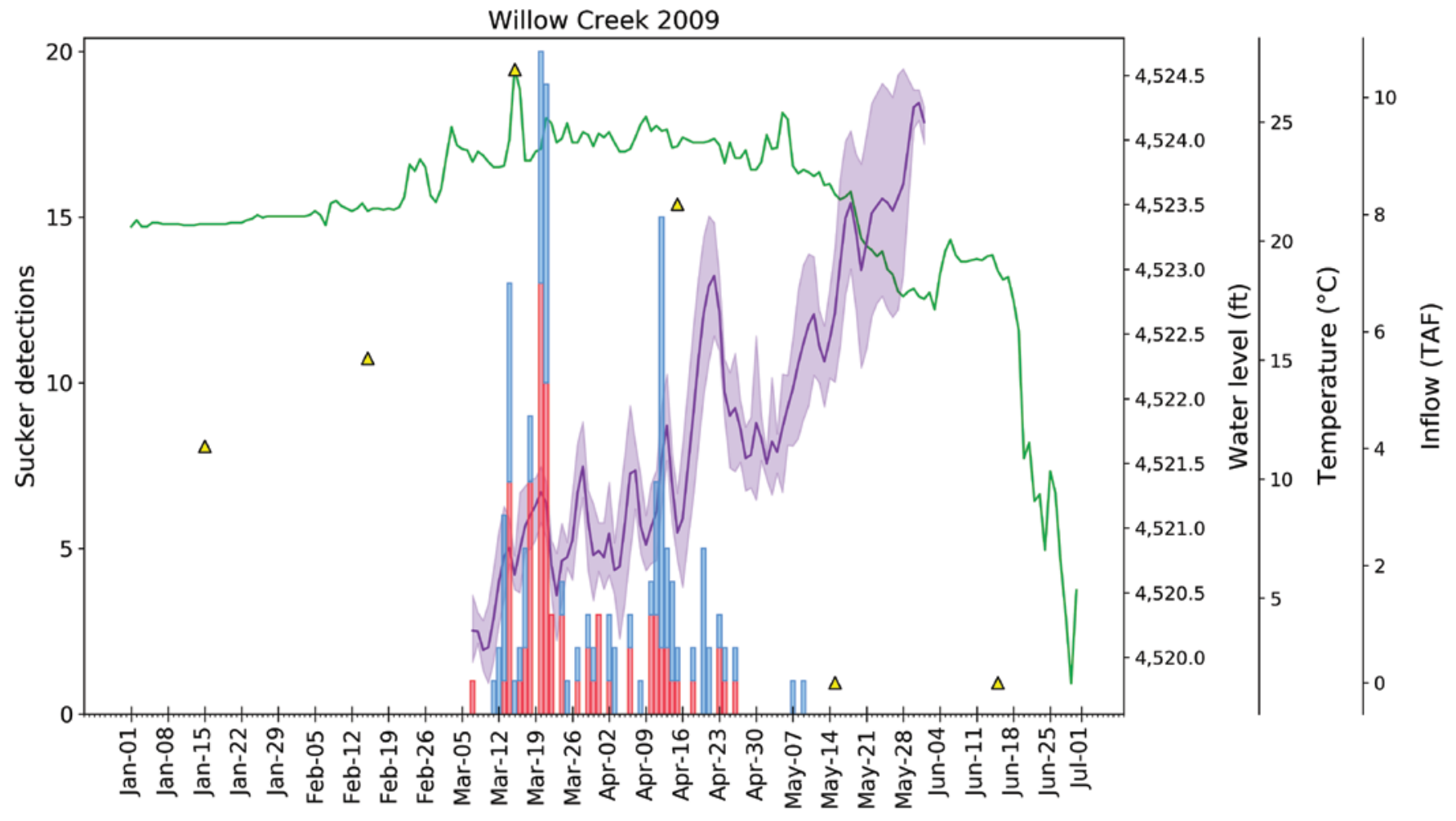

- Dam level - Temperature $\Delta$ Inflow $\square$ SNS-KLS LRS

Figure 2.4. Number of individual Lost River suckers (LRS) or shortnose sucker and Klamath largescale sucker combined (SNS-KLS) detected on passive integrated transponder antennas located in Willow Creek in 2009. Water level in Clear Lake Reservoir, California measured in feet ( $\mathrm{ft})$ above mean sea level at the Clear Lake Dam, daily mean and range in water temperatures in degrees Celsius $\left({ }^{\circ} \mathrm{C}\right)$, and calculated Willow Creek inflow in thousand acre-feet (AF) are shown for the 2009 sucker spawning season. 


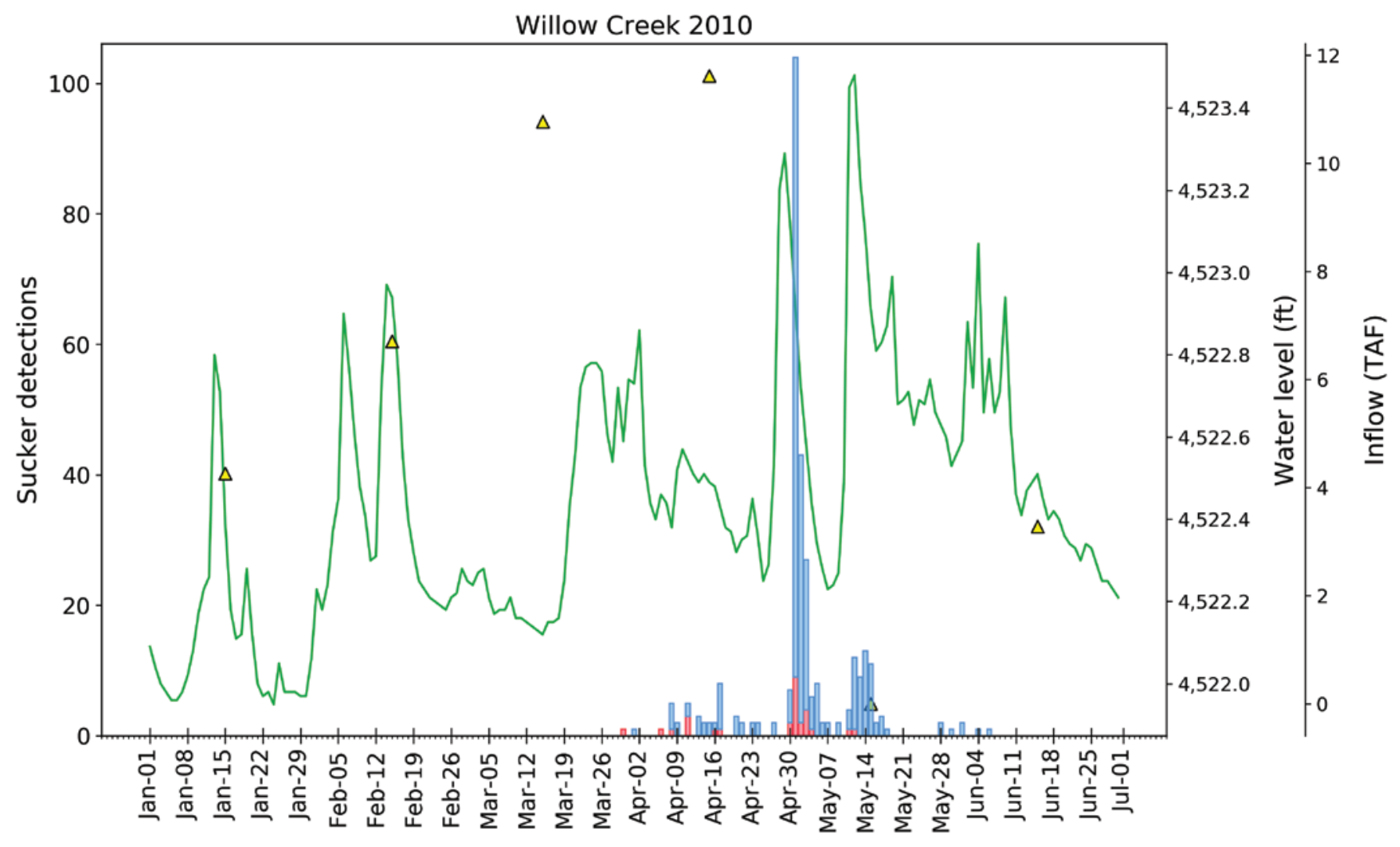

$$
\text { Dam level } \Delta \text { Inflow SNS-KLS LRS }
$$

Figure 2.5. Number of individual Lost River suckers (LRS) or shortnose sucker and Klamath largescale sucker combined (SNS-KLS) detected on passive integrated transponder antennas located in Willow Creek in 2010. Water level in Clear Lake Reservoir, California measured in feet (ft) above mean sea level at the Clear Lake Dam, and calculated Willow Creek inflow in thousand acre-feet (AF) are shown for the 2010 sucker spawning season. 


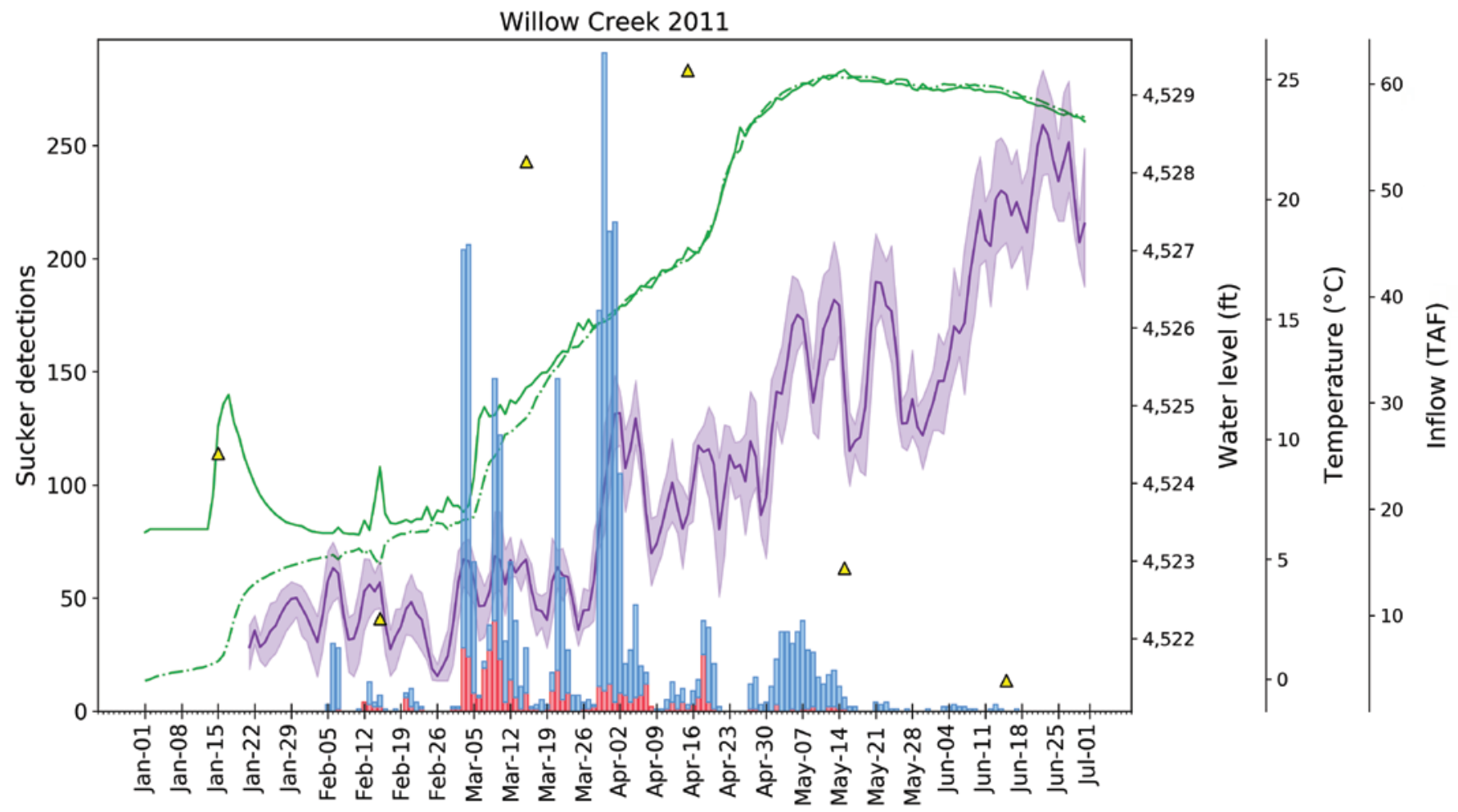

— Dam level --- WL level — Temperature $\Delta$ Inflow SNS-KLS LRS

Figure 2.6. Number of individual Lost River suckers (LRS) or shortnose sucker and Klamath largescale sucker combined (SNS-KLS) detected on passive integrated transponder antennas located in Willow Creek in 2011. Water level in Clear Lake Reservoir, California measured in feet (ft) above mean sea level at the Clear Lake Dam and in the west lobe of the lake, daily mean and range in water temperatures in degrees Celsius $\left({ }^{\circ} \mathrm{C}\right)$, and calculated Willow Creek inflow in thousand acre-feet (AF) are shown for the 2011 sucker spawning season. 


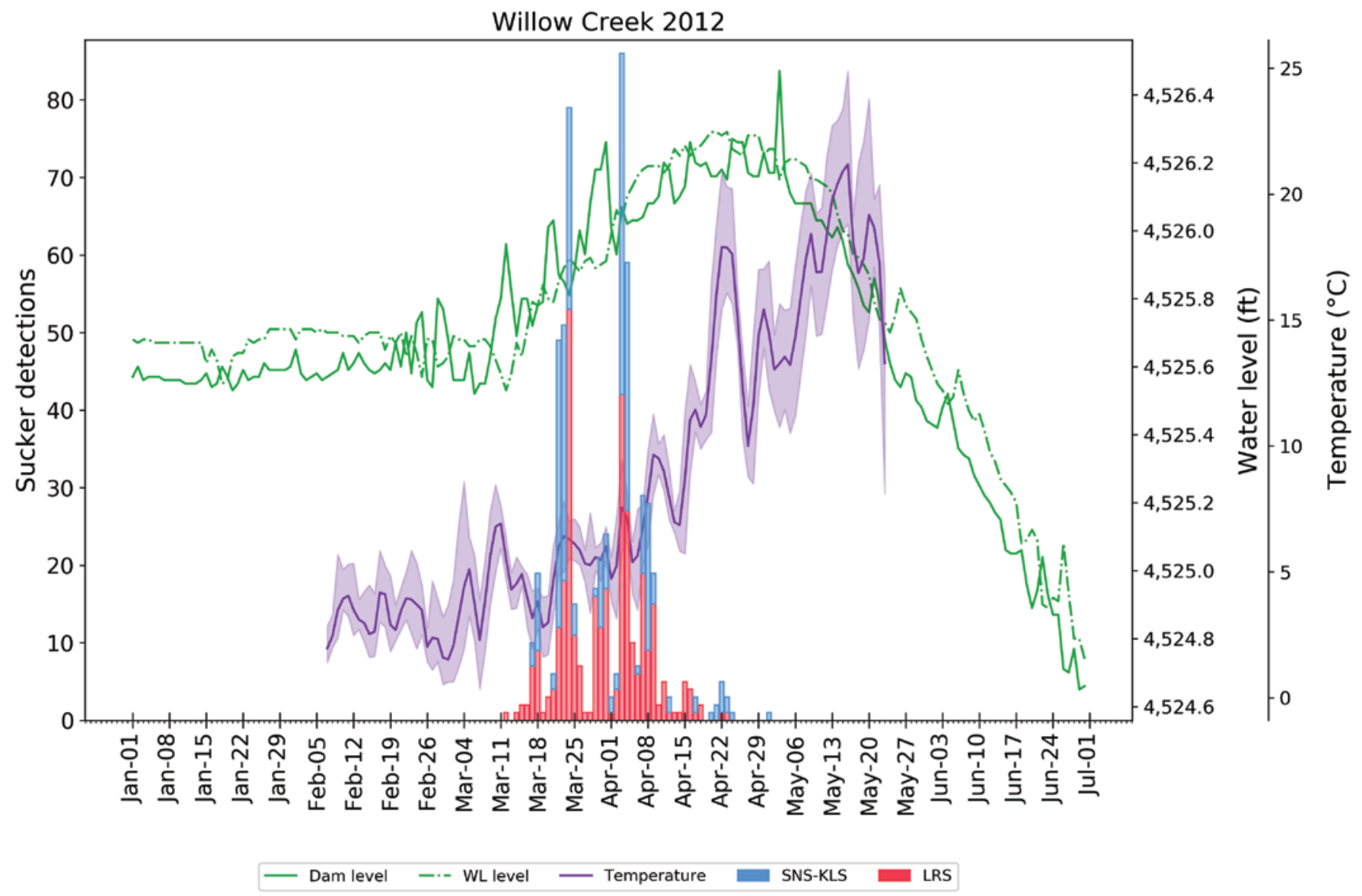

Figure 2.7. Number of individual Lost River suckers (LRS) or shortnose sucker and Klamath largescale sucker combined (SNS-KLS) detected on passive integrated transponder antennas located in Willow Creek in 2012. Water level in Clear Lake Reservoir, California measured in feet ( $\mathrm{ft}$ ) above mean sea level at the Clear Lake Dam and in the west lobe of the lake, and daily mean and range in water temperatures in degrees Celsius $\left({ }^{\circ} \mathrm{C}\right)$ are shown for the 2012 sucker spawning season. 


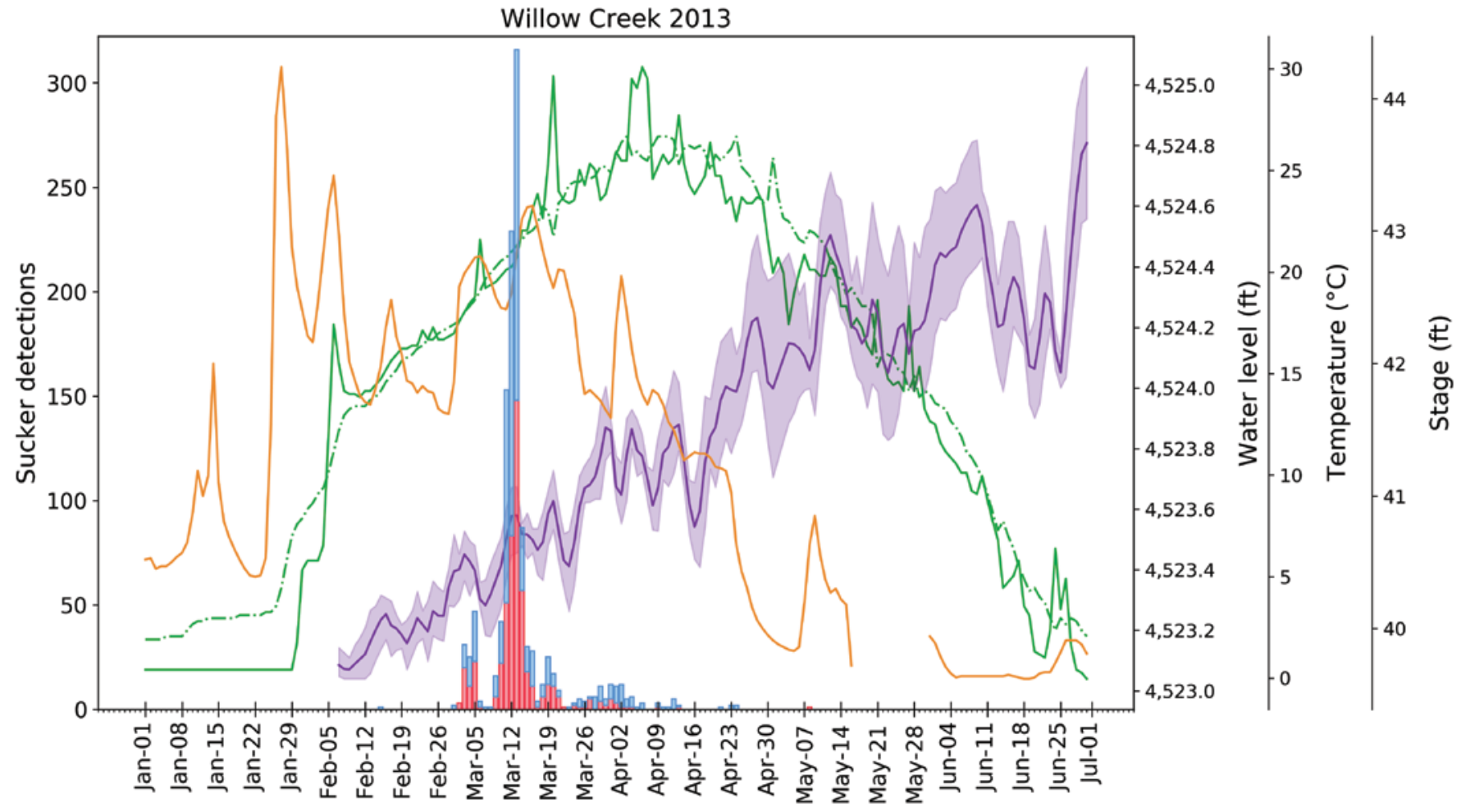

- Dam level --- WL level — Temperature - Stage

Figure 2.8. Number of individual Lost River suckers (LRS) or shortnose sucker and Klamath largescale sucker combined (SNS-KLS) detected on passive integrated transponder antennas located in Willow Creek in 2013. Water level in Clear Lake Reservoir, California measured in feet (ft) above mean sea level at the Clear Lake Dam and in the west lobe of the lake, daily mean and range in water temperatures in degrees Celsius $\left({ }^{\circ} \mathrm{C}\right)$, and stage in $\mathrm{ft}$ at the Willow Creek gage are shown for the 2013 sucker spawning season. 

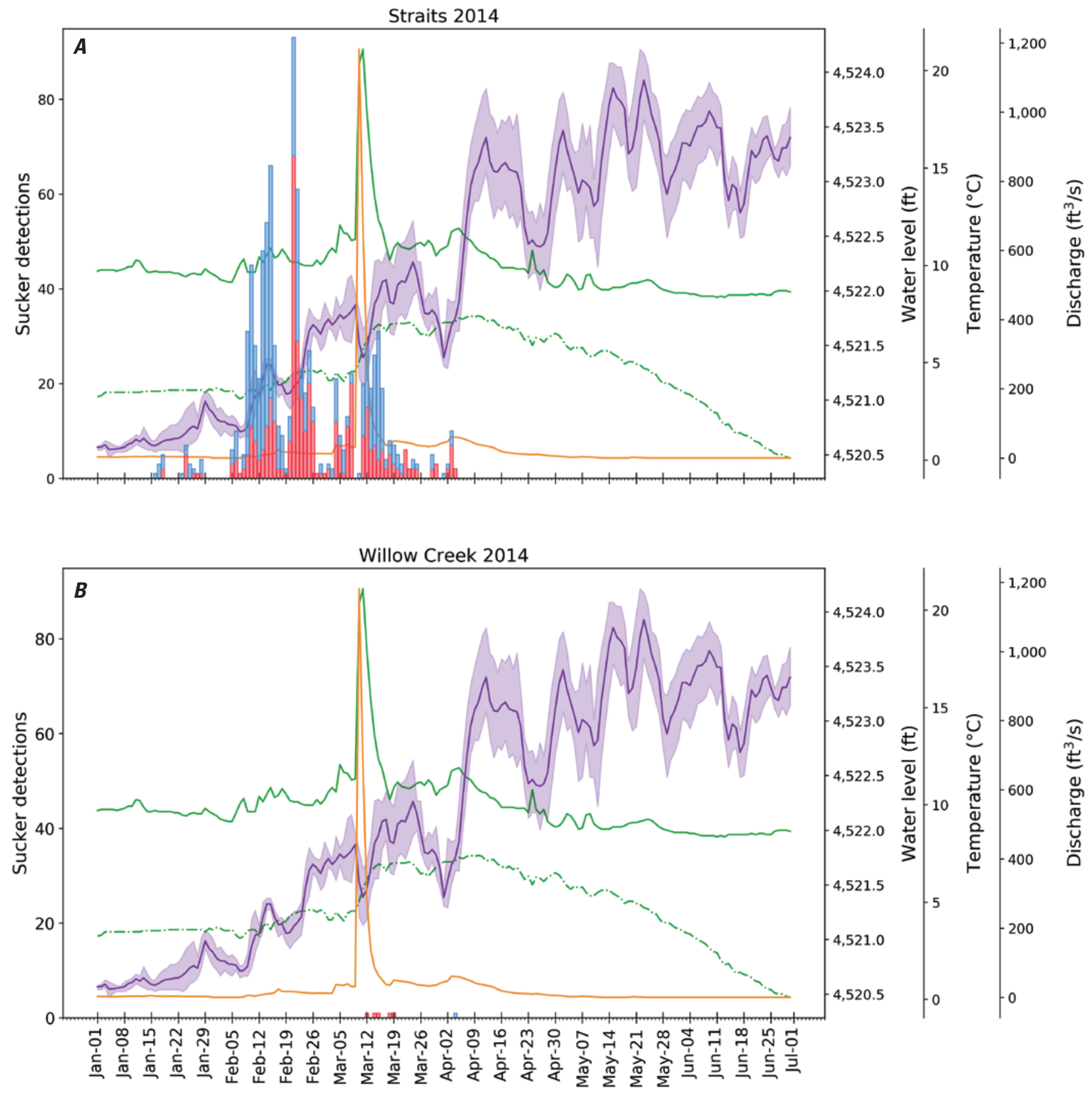

Figure 2.9. Number of individual Lost River suckers (LRS) or shortnose sucker and Klamath largescale sucker combined (SNS-KLS) detected on passive integrated transponder antennas located in the Clear Lake straits (A) and Willow Creek (B) in 2014. Water level in Clear Lake Reservoir, California measured in feet (ft) above mean sea level at the Clear Lake Dam and in the west lobe of the lake, daily mean and range in water temperatures in degrees Celsius $\left({ }^{\circ} \mathrm{C}\right)$, and discharge $\left(\mathrm{ft}^{3} / \mathrm{s}\right)$ at the Willow Creek gage are shown for the 2014 sucker spawning season. 

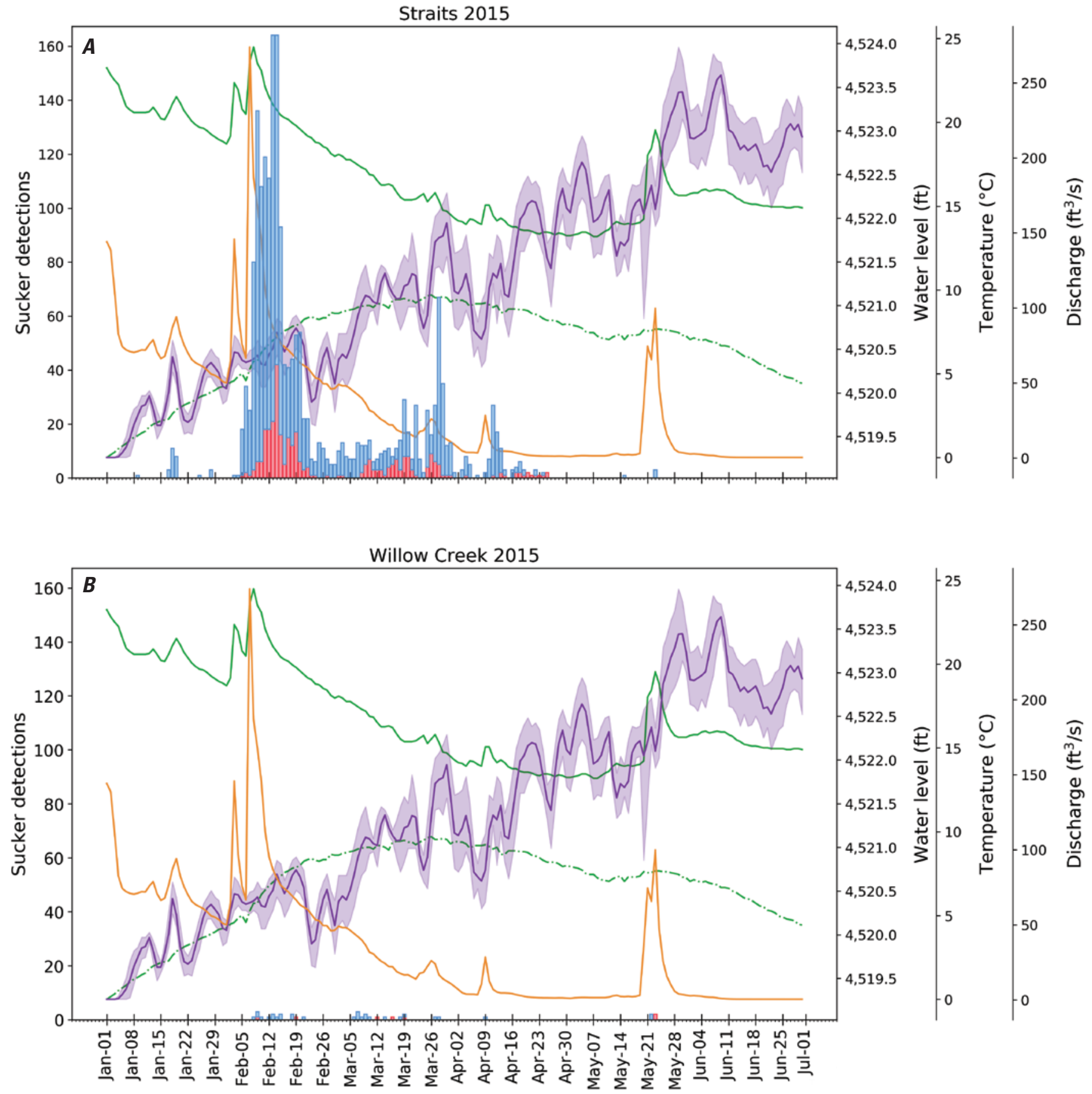

— Dam level --- WL level — Temperature - Discharge SNS-KLS LRS

Figure 2.10. Number of individual Lost River suckers (LRS) or shortnose sucker and Klamath largescale sucker combined (SNS-KLS) detected on passive integrated transponder antennas in the Clear Lake straits (A) and Willow Creek (B) in 2015. Water level in Clear Lake Reservoir, California measured in feet (ft) above mean sea level at the Clear Lake Dam and in the west lobe of the lake, daily mean and range in water temperatures in degrees Celsius $\left({ }^{\circ} \mathrm{C}\right)$, and discharge $\left(\mathrm{ft}^{3} / \mathrm{s}\right)$ at the Willow Creek gage are shown for the 2015 sucker spawning season. 

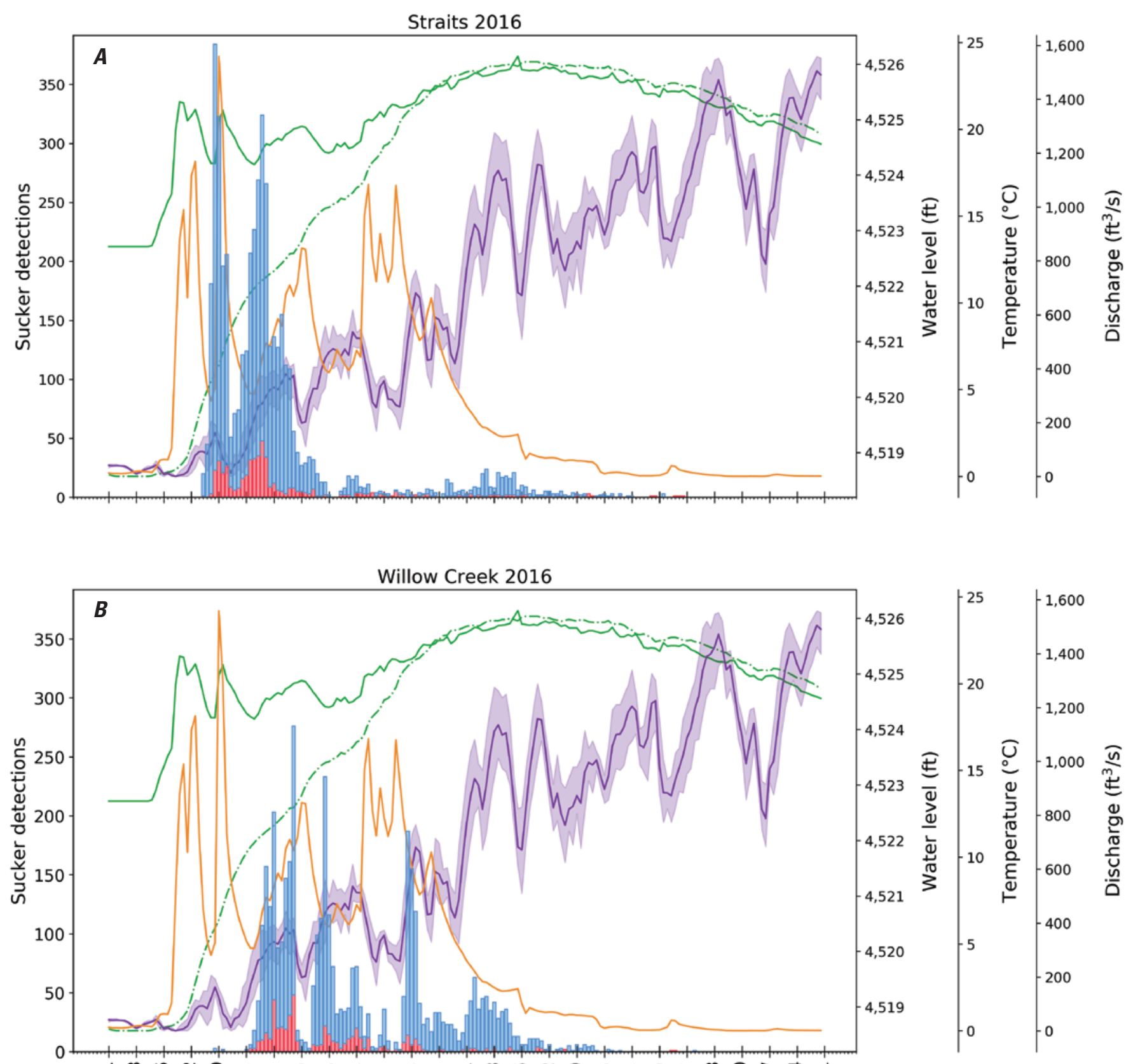

훙ำ

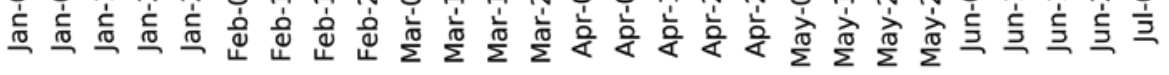

- Dam level --· WL level — Temperature - Discharge SNS-KLS LRS

Figure 2.11. Number of individual Lost River suckers (LRS) or shortnose sucker and Klamath largescale sucker combined (SNS-KLS) detected on passive integrated transponder antennas located in the Clear Lake straits (A) and Willow Creek (B) in 2016. Water level in Clear Lake Reservoir, California measured in feet (ft) above mean sea level at the Clear Lake Dam and in the west lobe of the lake, daily mean and range in water temperatures in degrees Celsius $\left({ }^{\circ} \mathrm{C}\right)$, and discharge $\left(\mathrm{ft}^{3} / \mathrm{s}\right)$ at the Willow Creek gage are shown for the 2016 sucker spawning season. 

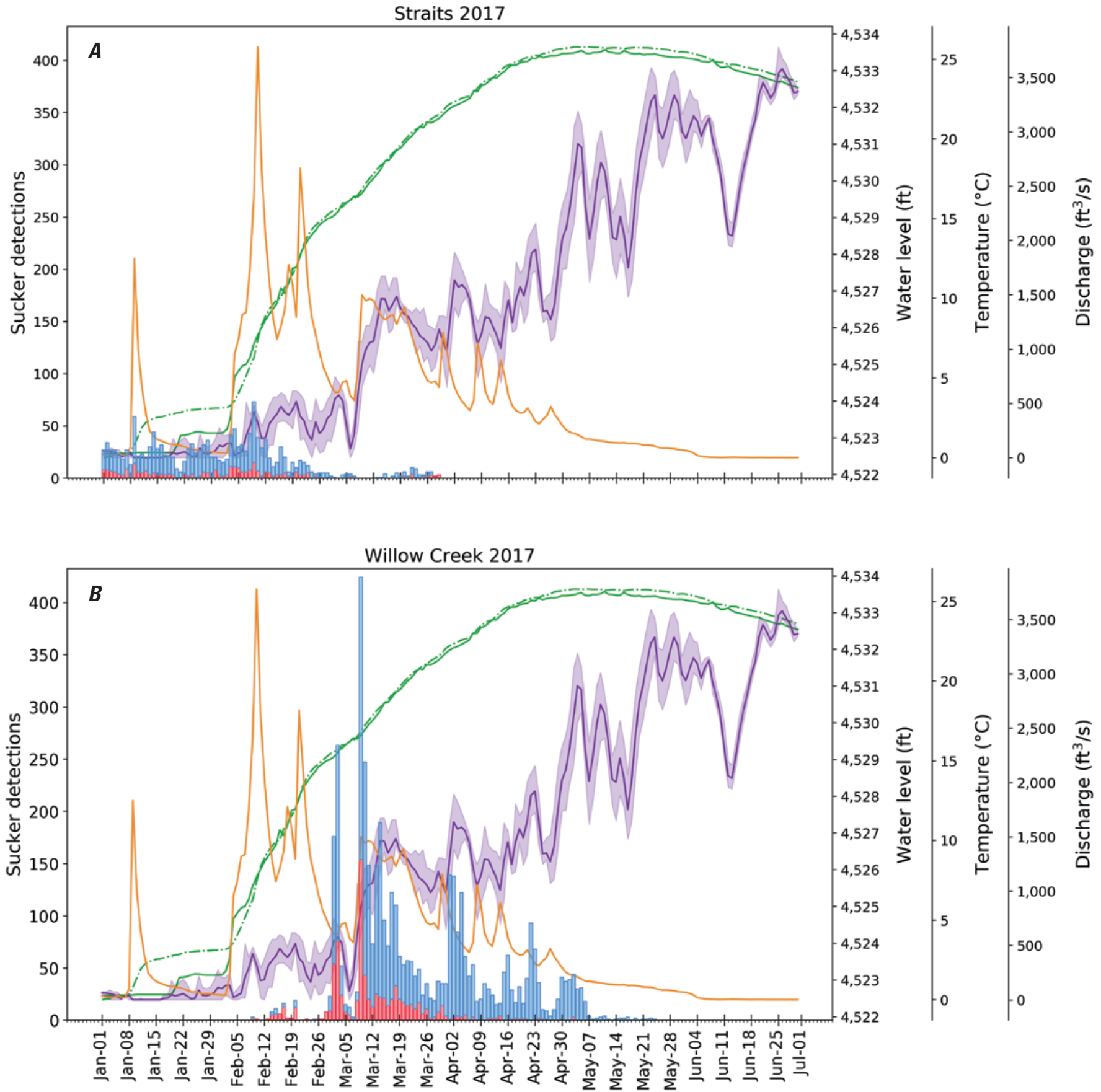

Figure 2.12. Number of individual Lost River suckers (LRS) or shortnose sucker and Klamath largescale sucker combined (SNS-KLS) detected on passive integrated transponder antennas in the Clear Lake straits (A) and Willow Creek (B) in 2017. Water level in Clear Lake Reservoir, California measured in feet (ft) above mean sea level at the Clear Lake Dam and in the west lobe of the lake, daily mean and range in water temperatures in degrees Celsius $\left({ }^{\circ} \mathrm{C}\right)$, and discharge $\left(\mathrm{ft}^{3} / \mathrm{s}\right)$ at the Willow Creek gage are shown for the 2017 sucker spawning season. 


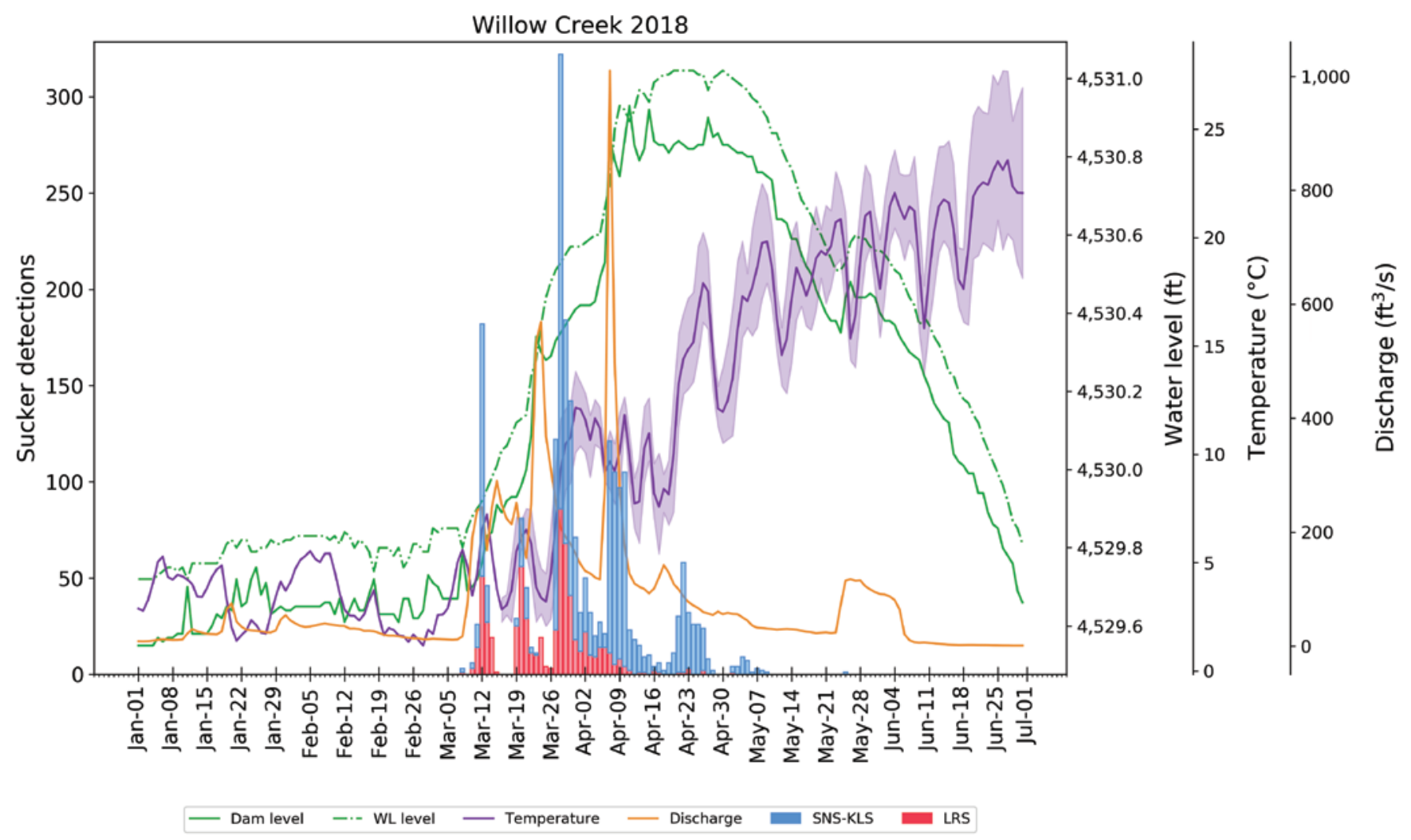

Figure 2.13. Number of individual Lost River suckers (LRS) or shortnose sucker and Klamath largescale sucker combined (SNS-KLS) detected on passive integrated transponder antennas in Willow Creek in 2018. Water level in Clear Lake Reservoir, California measured in feet (ft) above mean sea level at the Clear Lake Dam and in the west lobe of the lake, daily mean and range in water temperatures in degrees Celsius $\left({ }^{\circ} \mathrm{C}\right)$, and discharge $\left(\mathrm{ft}^{3} / \mathrm{s}\right)$ at the Willow Creek gage are shown for the 2018 sucker spawning season. 


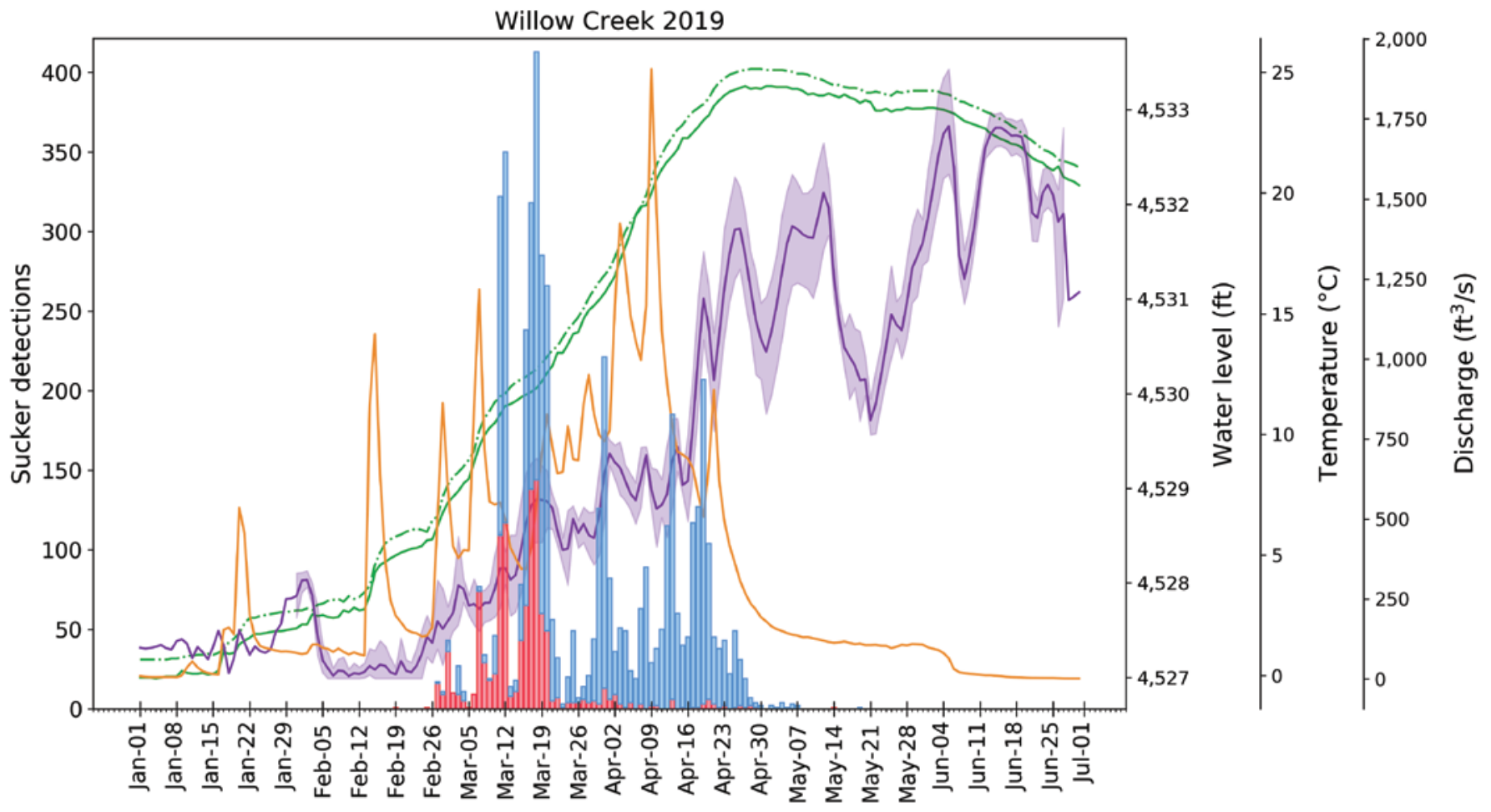

— Dam level --- WL level — Temperature - Discharge SNS-KLS L LRS

Figure 2.14. Number of individual Lost River suckers (LRS) or shortnose sucker and Klamath largescale sucker combined (SNS-KLS) detected on passive integrated transponder antennas in Willow Creek in 2019. Water level in Clear Lake Reservoir, California measured in feet (ft) above mean sea level at the Clear Lake Dam and in the west lobe of the lake, daily mean and range in water temperatures in degrees Celsius $\left({ }^{\circ} \mathrm{C}\right)$, and discharge $\left(\mathrm{ft}^{3} / \mathrm{s}\right)$ at the Willow Creek gage are shown for the 2019 sucker spawning season. 

Publishing support provided by the U.S. Geological Survey Science Publishing Network, Tacoma Publishing Service Center

For more information concerning the research in this report, contact the

Director, Western Fisheries Research Center

U.S. Geological Survey

6505 NE 65th Street

Seattle, Washington 98115-5016

https://www.usgs.gov/centers/wfrc 


\section{$\mathbb{E}$}

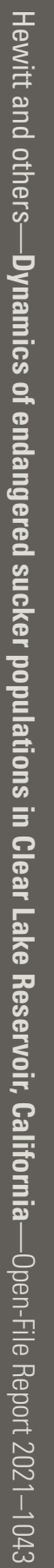

